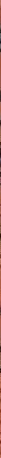

A JWW JWHORY

Or THE

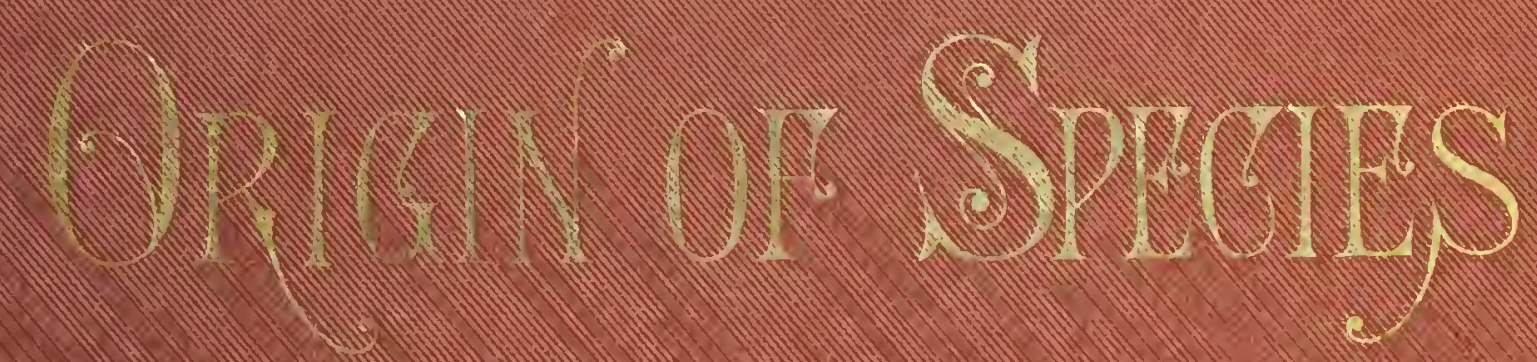

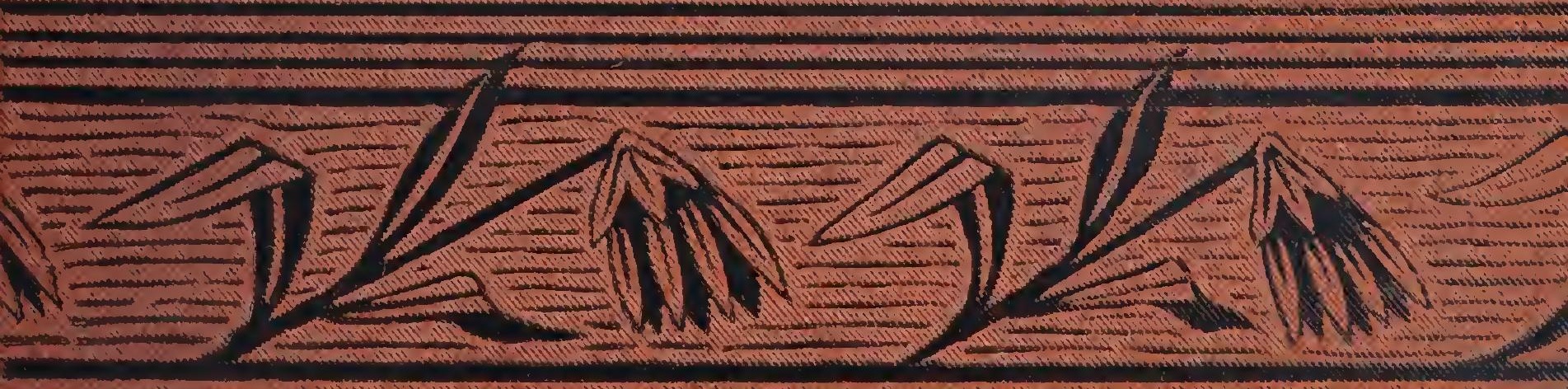




Inf. Golduni Sinith Irmen the Anther inite rejaces 
Digitized by the Internet Archive in 2020 with funding from University of Toronto 


\title{
A NEW THEORY
}

\author{
OF THE
}

\section{ORIGIN OF SPECIES}

B Y

BENJ. G。 FERRIS.

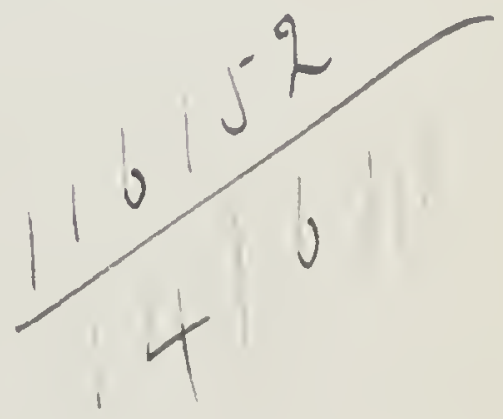

NEW YORK :

FOWLER \& WELILS, F3 BROADWAY. 
Copyright, $183_{3}$.

By Fowler \& Wells. 


\section{CONTENTS.}

Chapter I.-PReliminary-Classification of Animals and Plants-What are Species-Evolution of Same Kind the

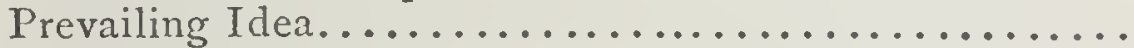

PAGE.

$$
?-16
$$

Chapter II.-Theories-Of Lamarck and Others-Darwinian Theory-Views of Owen, Huxley, Spencer, and

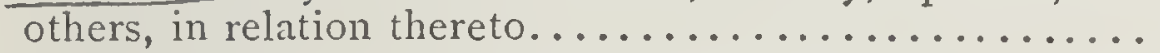

Chapter III. - Trieories-Darwinian (Continued)-Sexual Selection-Asthetic Taste in Animals-How Man Becanie Denuded of Hair......................

Chapter IV.-Theories-Darwinian (Continued)-Laws of Heredity-Secondary Sexual Distinctions-Origin of the Sexes, and their Distinctions-Rudimentary and Aborted Organs............................ 79-106

Chapter V.-What is Life?-Views of Buchner and others-Speculations and Definitions of Herbert Spencer -Author's Definition. ................... ro7-125

Chapter VI.-Difference Between ANimal and Human LIFE-Animal Life Fractional-Man's Life more than the sum of Animal-Difference between Mind and Instinct-Difference as to Language.............. I26-I47

Chapter ViI.-Difference between Men and Animals IN BRAIN CAPACITY-Difference as to the Marriage Relation.................................. 48 I66

Chapter VIII.-An'tiquity of MAN-The Old IdeaFirst Traces of Man in the Pliocene-The Pre-historic Ages-Ancient Literature-Brain and Mental Capacity of Primitive Man-Primitive Man Uncivilized, but not Inferior-General Conclusions................. I67-193

Chapter IX.-Is there an Inteligent First CauseGeneral View-Theories Examined-Pain and Suffering not Inconsistent with Design-Evidences of Design in Nature-Universality of Belief in a Personal Deity... I94-22I

Chapter X.-The Order of Creation-From Lowest

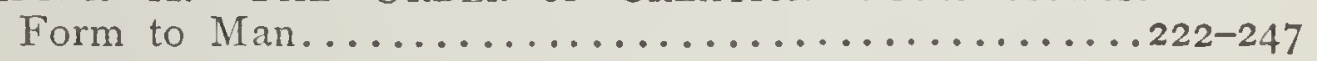

Cirapter XT:-The New Theory-A Matrix Necessary to Reproduction-Evidence of Embryology-Extraordinary Generation-Male and Female Elements in CreationMiraculous Conception-Psychological Preparation for Man-Multiple Creation of Organisms.............248-278 



\section{A NEW THEORY}

OF THE

\section{ORIGIN OF SPECIES.}

\section{CHAPTER I.}

\section{PRELIMINARY}

Classification of Animals and Plants-What are Species-Evolution of same kind, the prevailing idea.

The animal kingdom was classified by the late Prof. Louis Agassiz into five great branches or types, to wit: Protozon, Radiates, Moluuscs, Articulates and Vertebrates, according to a plan of structure peculiar to, and running through each.

Protozoa, is the name now given to a numerous family of nearly structureless forms of life, furnishing, as it were, the raw material from which the other great types have originated and diverged. The Moners constitute a large class of this type, of which Haeckel says-" They are not only the simplest organisms with which we are acquainted, but also the simplest living beings we can conceive of as capable of existing ; and though their entire body is but a single, formless, small lump of protoplasm, (each molecule of it being like the other), without any combination of parts, yet they 
perform all the functions which in their entirety constitute in the most highly organized animals and plants what is comprehended in the idea of life: namely; sensation and motion, nutrition and propagation." (1-VIII-67).

Radiates include all animals whose organs radiate from a common center, and branch out into three classes-Polyps, Acalephs and Echinoderms.

Molluscs are all soft bodied animals, without articulated members, though sometimes containing hard parts internally, and are sometimes covered with hard shells. This type divides into three classes-Acephals, Gasteropods and Cephalopods.

Articulates are those having bodies more or less divided into lobes, rings or joints, with a skin or crust, sufficiently hard to form an external skeleton. Of these there are three classesWorms, Crustaceans and Insects.

Vertebrates include those having two elongated cavities, one above and the other below a bony axis, called the back bone. The upper cavity contains the spinal cord which enlarges at one extremity into the brain; and the lower, the organs of respiration, digestion and reproduction. This type divides into five great, classes-Fishes, Batrachians, Reptiles, Birds and Mammals.

Haeckel, however, divides the animal kingdom into seven types or tribes, to wit: 1 , The Protozoa. 2, The Zoophytes (or plant animals). 3, The Vermes (orworms). 4, Molluscs (or soft bod 
ied animals). 5, The Echinoderms (or star animals. 6, The Arthropoda (or articulated animals). 7, The Vertebrata. (38-I-46).

The division of the classes in each type, runs into orders, families, genera and species. There are wide differences between the types; less wide between the classes; and these differences continue to diminish as we descend to families, genera and species.

The other forms of life are vegetable, commencing in microscopic Diatoms, which furnish food for the humble Moner, and diverging thence to the magnificent growths of the forest.

The vegetable kingdom divides itself into two great branches-Phænogams, or flowering plants and Cryptogams, or flowerless plants. The Phænogamous are of two classes-Exogens and Endogens-the former comprising all plants composed of pith in the centre, bark outside, and wood between the two; and growing by annual additions of concentric rings of wood; and the latter comprising all plants whose stems are not composed of concentric layers, but whose woody substance is distributed through the stems in threads and bundles.

The Cryptogamous comprise all the lowest forms of vegetation; and instead of flowers have some thing analagous thereto, and produce spores instead of seeds. Of these there are three classes -Thallophytes, comprising sea-weeds, lichens and fungi-Anophytes, comprising mosses and small plants with leafy stems and simple narrow 
leaves-and Acrogens including ferns and lychopods.

A genus is a group of animals comprising one or more species. Thus of the genus Equus, the Horse, Ass, Zebra and Quagga are considered as species. But what are species? Strange to say, this is a question which does not appear to be well settled; no definition yet given seems to have been universally satisfactory to naturalists. Darwin, who ought to be good authority, is by no means satisfied. He says: "Certainly no clear line of demarcation has as yet been drawn between species and sub-species-that is, the forms which in the opinion of some naturalists come very near to, but do not quite arrive at, the rank of species; or, again between sub-species and well marked varieties, or between lesser varieties and individual differences. These differences blend into each other by an insensible series; and a series impresses the mind with the idea of an actual passage." Again: "From these remarks it will be seen, that I look upon the term species as one arbitrarily given, for the sake of convenience, to a set of individuals closely resembling each other, and that it does not essentially differ from the term variety, which is given to less distinct and more fluctuating forms." (2-52-3). (New Ed. from 6th English, 41-2).

According to this a genus may be regarded as the original type, and species as the varieties which have branched therefrom, and this appears 
to be the construction given to Darwin's idea by Haeckel. (3-I-42-3).

According to Quartrefages: "Species are individuals resembling each other more or less, which may be regarded as having descended from a single primitive pair by an uninterrupted and natural succession of families."

Prof. Rice (26 N. Englander, 604) says: "A species has been defined as a group of individuals descended from a common pair. In order to avoid a disputed question this definition may be modified as follows: A group of individuals presenting individual differences compatible with possible community of descent."

There are between 60 and 70 elementary substances, which with their endless combinations make up the entire composition of the globe. These substances and their compounds we call matter, as distinguished from life or mind; and they constitute as well, the bodies of all living organisms.

Sixteen of these substances make up the bulk of the earth, and of its organic forms, to wit:Oxygen, hydrogen, nitrogen, fluorine, chlorine, carbon, sulphur, phosphorous, silicon, albruminum, potassium, sodium, calcium, magnesium, iron and manganese.

Advancing a step further within the limits of physical causation, we find that the earth, and all the elementary substances of which it is composed, owe their existence to the sun. Thus far we can go with scientific certainty, in reference to the 
composition of living forms, irrespective of their life. It is also well established that inorganic nature has been brought into existence and to its present forms, by gradual processes and from simpler elements. The hardest rocks, and the most rigid metals, equally with water and air are but the results in a regular chain of causes, from the action of prior incandescent gases, which contained the elements of all that followed.

We then come to the great question: What is the origin of the vast numbers of the species of plants and animals upon the earth, having a compound existence of life and material substances? How came they to be differentiated into species? This question involves that of the creation of the universe, physical and psychical-the universe of life and of the organic forms by which life is manifested. It involves the methods by which all things have been produced.

Assuming that the earth and its organic forms are the work of a personal Creator, there would then be, relatively, but two order of existences, the Creator and the created-the one uncreate, infinite, stabje and perfect-the other imperfect, limited and changeable. This relative imperfection would result as a necessity of creation, inasmuch as it is not a supposable idea that the Creator could or would duplicate himself. Nevertheless, created things have a degree of relative perfection. Thus oxygen, though ever changing in connection with other material substances-sometimes in good company and sometimes in bad- 
remains perfect oxygen. So the mind or soul of man, from its attribute of imperfectibility, changing from good to bad, and bad to good, and all their intermediates, remains mind and nothing else.

The logic of creation lies in its unity, uniformity and completeness. As a question of power, it requires the same degree of force to create an insect and a planet--no more, no less. It is a mit, because it culminates in man as the ultimate design of the Creator. Every step in the process has evidently had reference to that which was to follow-a cause to the effect to be produced. The creation of the gigantic ferns and other vegetable growths of the carboniferous era, were steps in the production of coal deposits, so necessary to modern civilization-the creation of the lowest monad was a step in the creation of man.

How creation has been effected is the vexed question of the day. The old belief asserts the formation of the first of every species in full maturity, without passing through a germinal or embryological state. The first man, male and female, had no infancy or childhood-the first of every species of plant, no seed or germination.* This

* The utter crudeness of the idea is well illustrated by the following extract from a sermon of Dupanloup, Bishop of Orleans : "God took a little earth in his divine hands, and it pleased himself to mould therefrom the body of a man, and this clay fashioned by such hands, soon received the most beautiful and robust form that had yet appeared in the world. Nevertheless that was but an admirable statue, and not the image and likeness of Gou. Then God breathed into its face the breath of life spiraculn? vitce, the 


\section{A Neze Theory of the Origin of Species.}

belief grew out of prior states of human simplicity and credulity, when opinions were formed upon appearances-when the sun was supposed to revolve around the earth, and the latter was believed to be an extended plane.

But the world is out.growing its infantile state and demands a theory consistent with scientific induction; and which may stand the test of enlightened discussion. Hence the origin and growth of the doctrine of evolution, founded on a series of facts inconsistent with the old faith. And it may be safely assumed that evolution of some kind has become the prevailing idea of men of science, and the aspect is that it will generally prevail.

Evolution, however, divides itself into that of the theist, and that of the strict materialist, and the real controversy is between the two. The one looks to a First Cause, and the evidences of design, while the other ignores both. Heretofore the controversy has been between Theology and Science; but since there is no dispute about the controlling facts, it must hereafter be carried on irrespective of religious creeds.

Among the problems to be solved in this contest are, whether matter is self-existent, and from its self constituted properties originated living forms; or whether it was created and made recipient of inflowing life from a personal and intelligent First Cause; whether species originated pure inspiration of eternal and divine life, and man became a living soul." (Littel's Living Age, April 2, 1870). 
from one or more primordial types, by branching out into multitudinous varieties as the result of a struggle for existence, co-ordinate with other natural influences; or whether they were created by the influx of the life of a new species into prior forms as each progressive period made new forms of life necessary.

No absolute certainty can be reached; and that theory must eventually be accepted which shall be found most consistent with the facts, and appear most probable to the average intelligent mind.

The thinking mind of the present day, both lay and clerjcal, is inclined to the belief, that living forms have been differentiated into species by some process of evolution. As early as 1794 such a process was partially outlined by Erasmus Darwin. This was followed, with more or less of detail, by Lamarck, Pouchet, and the author of "The Vestiges of the Natural History of Creation," all of whom encountered the bitter denunciations of theologians.

In 1859 Charles Darwin presented the theory in a definite and systematic form, and then and since has supported it by a vast array of facts. And it is the one, at present, the most extensively accepted. But in the judgment of many the "Darwinian Theory," so called, rests upon a mass of cumulative evidence, of which no single fact proves any thing material in its support; and by a loosely applied logic, it is received as true, 
16 A Neru Theory of the Origin of Species.

because no other has been presented which appears so well to harmonize with the facts.

In the theory now presented I have endearored to aroid this defect, with what success the read ing public must judge. 


\section{CHAPTER II.}

\section{THEORIES.}

Theories of Lamarck and others. The Damwinian Theory. Vicws in relation thereto, by Ozoen, IHuxley, Spencer, and others.

In 1809 Lamarck, a celebrated French naturalist, first promulgated the theory that one species was developed from another by certain physiological changes, made necessary by surrounding circumstances, and producing new organs by sheer force of will. Thus the snail as it draws itself along, is supposed to feel the want of organs to examine the bodies it comes in contact with; and in making the effort to touch them, forces the fluids towards the head, cansing two or more tentacula; and this is claimed to have happened to the whole gasteropod race.

So an herbivorous animal, pressed for forage, stretches its neck to reach the lower branches of trees, and becomes a giraffe. A shore bird desiring to swim in search of food spreads out its toes; and in time its feet become webbed. So too, in the language of Von Baer ; "a fish swimming towards the shore desires to take a walk, but finds its fins useless. They diminish in breadth for want of use, and at the same time elongate. This 
goes on with children and grand-children for a few millions of years, and at last who can be astonished that the fins become feet."

So the ape, most nearly related to man, made the first step to humanity, by ceasing to climb trees, and assuming an upright gait. This is supposed by him to have changed the spinal column-changed the fore limbs into arms and hands -the hind limbs to true legs-changed the food, and as a sequence, the jaws, teeth and contomr of the face-and more marvellous still, got rid of the tail. (1-S1).

All this is erinently fallacions; and in contra. vention of the fact that there are no materiai changes in the physical system of any given species, except such as lesult from adaptation to changed conditions; and such changes have never yet been known as effecting an undoubted change of species. So obrious was the inadequacy of this theoly to produce such momentous results, that the French philosopher gained few, if any, adherents. It nevertheless contains the germ of the now justly celebrated "Darwinian Theory.",

Another French natrualist, Pouchet, starts with a first germ produced by spontaneous generation, and from it supposes the organization of a form like the Protozoa. He says: "Let us return to this primordial anatomical elenent which we call individual element. It virtually, represents a vertebrate animal, just as the ovum detached from the ovary of the female represents a man, who is only waiting for favorable circumstances in order 
to develope himself. This individual element according to our hypothesis, is at first simply reproduced; then after some considerable time its descendants will, little by little, in their own sphere of activity, give birth to other elements in juxtaposition to themselves, in this manner perfecting it, and identifying more and more with the vertebrate type, which it offers for our consideration. After some considerable time, vertebrates of as simple an organism as myxine and lampreys will have thus appeared. Then again, after another considerable lapse of time-millions of centuries rather than thousands-these animals with elementary vertebra, will have successively produced, by transformation, all the vertebrata which stock the globe at the present day." (4-124.)

Between the time of Lamarck and that of the publication of the "Origin of Species," the most important work on the subject appeared anonymously in 1844, under the title of "Vestiges of the Natural History of Creation." It is a work of extraordinary ability, and the theory proposed, with all its defects, has the merit of recognizing the evidence of creative design.

What it was as originally published may be gathered from the following extracts :- "The first step in the creation of liie mpon the planet was $a$ chemico-electric operation, by which simple germinal vesicles were produced. This is so much, but what were the next steps? I suggest as an hypothesis countenanced by much that is ascertained, and likely to be further sanctioned by 
much that remains to be known, that the first step was an advance under peculiar conditions from the simplest forms of beings to the most complicated, and this through the medium of the ordinary process of generation." (1st edition p. 155).

Again - "The idea then is that the simplest and most primitive type under a law to which that of like production is subordinate gave birth to the type next above it, that this again produced the next higher, and so on to the very highest, the stage of advance being in all cases very smallnamely from one species to another?'" (p. 170). It will thus be seen that life is supposed to have originated in its lowest germ by "chemicoelectric" operation; and then the work of advancing and differentiating into species has been through "the medium of the ordinary process of generation." How fal the iclea that the origin of species is due to "the ordinary process of generation" will be noticed hereafter.

In the eleventh edition of the "Vestiges," published in 1S60, though the anthor, in a more extended elaboration of his theory, has varied his phraseology, he has not essentially changed his ground. He supposes the series of animated beings from the lowest to the highest are results under the providence of God: 1st, of "an impulse imparted to the forms of life, advancing them in definite times by generation." 2ud, of another nodifying impulse growing out of the environ- 
ment, answering to the "6daptation of the natural theologian." (13-138).

Under these and similar considerations, he restates as not "a very immoderate hypothesis that a chemico-electrie operation by which germinal vesicles were produced was the first phenomenon in organic creation; and that the second was an advance of these through a succession of higher grades, and a variety of modifications, in accordance with the laws of the same absolute nature as those by which the Almighty rules the physical department of nature." (13-139).

These impulses are regarded as possibilities of nature, as instanced in the manner in which bees so modify a larva as to produce the queen bee. (13 -144). So, speaking of the hermit crab, he says they are as truly the creatures of the great God. as if they had been made in the manner of "a human artist modeling a figure. But the means was inherent in natural forces in the constitation of the original tribe tending in generation to accomolate organic form to physical circumstances." (13-176.)

As a further illustration of what is meant by these impulses and inherent natural forces he says :

"It is the narrowest of all views of the Deity, and characteristic of an humble class of interests, to suppose lim constantly acting in particular ways for particular occasions." (p. 11\%.) Much more worthy of him it surely is to suppose that all things have been commissioned by him from 
the first, though neither is he absent from a particle of the current of natural affairs in one sense, seeing that the whole system is supported by his Providence." (13-138).

This is very little removed from the old idea that the Creator impressed mpon the creation certain laws, like the winding up of a clock, leaving natural things in a measure to take care of themselves. It is to be regretted that the accomplished author could not have perceived a continual flow of creative energy from the Divine Being, acting at all times and places, and just as directly and potentially in the minutest, as the most general operations. "Is it, conceivable" he says, "as a fitting mode of exercise for creative intelligence, that it should be constantly moving from one spicere to another, to form and plant the various species which may be required in each situation at particular times"- "yet such is the notion which we must form if we adhere to the doctrine of special exercise?" (13-109).

Well let us see. The heat and light of the sun is absolutely necessary for the growth of wheat; and the farmers over the whole earth, and it may be in Jupiter and Saturn as well, have prepared the ground and sown the seed in especial reference to the operation of these elements. Does the sun find it necessary to give its attention, first to one farm and then to another; or first to the earth, then to Jupiter and lastly to Saturn? Or does he pour forth his heat and light uniformly without reference to time or space? 
There is certainly some misconception as to what constitutes a special, and what a general exercise of creative power. To suppose the Creator to have made an elephant, as a sculptor fashions a piece of statuary is one thing; to suppose him to have created the elephant by infusing the proper life into an approximate living form without ordinary generation, is quite another thing; and yet both may be called special acts of creation. The first supposition is too incongruous to be entertained for a moment, while the other is consistent with a rational conception of ommipotent power.

$\mathrm{Mr}$. Herbert Spencer summarises the theory of "The Vestiges" thus: "The broad general contrasts between lower and higher forms of life, are regarded by him as due to an innate aptitude to give birth to forms of more perfect structures." And he says that Prof. Owen re-enumerates the same doctrine in asserting, "the axioms of the continuous operation of creative power, or of the ordained becoming of living things." He roundly characterises this as "unphilosophical" because "it is the ascription of organic evolution to some aptitude naturally possessed by organisms, or miraculously imposed on them as "an explanation which explains nothing" __"a shaping of ignorance into the semblance of knowledge" -as " unpresentable in thought," etc. (5-I--403-4).

All this is very Spencerian. Nevertheless, I think it will be found in the sequel, that both "Vestiges" and Prof. Owen enjoy an advantage 
in having, at least, a gimmering of the truth. At any rate, it provokes the query, whether the "innate aptitude" of the "Testiges," is any more miraculous or unpresentable in thought, than the "inherent power's," by which, according to Mr. Spencer' (as will be seen), organisms are formed.

Dr. Erasmus Darwin (grand father of Charles Darwin) in Zoonomia published in 1794, reasoned that species descended from one or a few primor. dial germs, ascribing their derelopment to a tendency given to such germ when created. In regard to warm blooded animals, he suggested that they have arisen from one living filament, which "THe Great Frist CaUse endued with animality, with the power of acquiring new parts, attended with new propensities, directed by imitations, sensations, volitions, and associations; and thus possessing the faculty of continuing to improve by its inherent activity."

He also anticipated the ilea of Lamarck, that animals are modified by force of their own desires, in respect to which he said: "From the first rudiments or primordiums, to the termination of their lives, all animals mondergo transformations, which are in part produced by their own exertions in consequence of their desires and aversions, of their pleasures and their pains, or of irritations, or of associations; and many of these acquired forms or properties are transmitted to their posterity."

Mr. Spencer, while admitting that desires, by leading to increased action of the motor organs, 
may induce further development of the organs, and that such modifications may be transmitted to posterity, nevertheless questions the theory because it "involves the assumption that desires and aversions, existing before experiences of the actions to which they are related, were the originaturs of the actions, and therefore of the structural modifications caused by them." (5-I-405). He asks, "How comes there a wish to perform an action not before performed?" And lays down this general doctrine: "Every desire consists primarily of a mental representation of that which is desired, and secondarily excites a mental representation of the actions by which it is attained; and any such mental representations of the end and means imply antecedent experience of the end, and antecedent use of the means."

If this be true, it follows that the moner experimented upon diatoms, to determine whether the absorption of it would be wholesome food; the wolf pursued and captured the deer to try the quality of renison; the primitive ox tasied various substances until grass was found to be the most nutritious article of diet, running the risk in the meantime of being poisoned by henbane $\mathrm{ol}^{\circ}$ digitalis. Why, too, an animal should go through a series of experiments in the selection of food, without an appetite, is a marvel, inasmuch as appetite is nothing more than a desire for food.

It is difficult to see how there can be any action of a living animal, without the exercise of some kind of will or desire; and Mr. Spencer's idea in- 
volves the necessity of spontaneous action before desire or aversion can be excited. It stands thoroughly in conflict with the, apparently, established fact, that every living animal below man, comes into existence with that degree of mind known, in common parlance, as instinct, which enables it, without tuition or experience, to select its food and do all other acts essential to its existence and propagation. And this would be the "mental representation of the end and the means," given to it at its creation.

In 1859, Dr. Charles Darwin published his first work on the subject, in which the origin of species is ascribed chiefly to "Natural Selection," or the survival of the fittest, in the struggle for life. He starts with from one to four or five original progenitors, from which all animals have descended, branching out under the operation of this law, into the almost innumerable species which now exist.*

He says: "Although much remains obscure, and will long remain obscure, I can entertain no doubt, after the most deliberate study and dispassionate judgment of which I am capable, that the view which most naturalists entertain, and which I formerly entertained-namely, that each species has been independently created-is erroneous. I am fully convinced that species are not immutable; but that those belonging to what is

* "Analogy would lead one step further, namely, to the belief that all animals and plants have descended from one prototype." $(2-420)$. 
called the same genera are lineal descendents of some other and generally extinct species, in the same manner as the acknowledged varieties of any one species are the descendants of that species. Furthermore, I am convinced that Natural Selection has been the main but not exclusive means of modification." (2-13).

Again, "by my theory, these allied species have descended from a common parent; and during the process of modification, each has become adapted to the condition of life of its own region, and has supplanted and exterminated its original parent and all the transitional varieties between its past and present states." (2-156).

As one of his numerous illustrations of the mode in which this law produces the survival of the fittest, he instances the case of the wolf, during a period of scarcity of the animals on which they prey, in which "the swiftest and slimmest wolves would have the best chance of surviving." (p. 2-s6).

It will thus be seen that a fundamental point in the theory is, that the change in the organs, and production of new organs must be of service to the animal in the struggle for life.

The other agencies which co-operate with Natural Selection, are the environment, the local circumstances of climate, geographical situation, etc. The combined operation of these causes is by "slight successive variations." Nature "can never take a leap but must advance by the shortest and slowest steps." (2-174). 
If (he says), it could be demonstrated that any complete organ existed which could not possibly have been formed by numerous successive slight modifications, my theory would absolutely break down." (2-169).

He does not tell us how his four or five primordial types were created. Whether they were fashioned from crude earth by the Creator as he is, in popular estimation, supposed to liave formed Adam; or whether, after earthy materials came into existence the atoms having chemical affinities rushed together, and formed protoplasmic bodies, productive or recipient of life, are mysteries which he leaves unsolved.

In "Iay Sermons," p. 279, 280, we find Prof. Huxley saying: "with respect to the origin of this primitive stock or stocks, the doctrine of the origin of species is obviously not necessarily concerned. The transmutation hypothesis for example, is perfectly consistent with the conception of a special creation of the primitive ger'm, or with , the supposition of its having arisen as a modification of inorganic matter by natural causes."

We are not quite prepared to admit that the transmutation hypothesis is consistent with the "special creation" of Darwin's four or five primitive germs; because it breaks the uniform plan mpon which we have a right to suppose creation proceeds. If there were special creations of five primitive stocks, why not five hundred or five thousand as well? Nay, why not of every distinct species? Nor is the alternative pleasant 
that we must believe these germs to have arisen as a modification of inorganic matter by "natural causes."

What the theory really is may be more fully understood by reference to the views of the most prominent of the scientific men who have, in whole or in part, adopted it; and it will be seen that they do not always harmonize with each other or with Darwin.

Prof. Owen made a distinction between "Derivation" and natural selection, and advocated the former. He said: "Derivation recognizes a purpose in the defined and pre-ordained course due to innate capacity or power of change by which created Protozoa, have risen to the higher forms of plants and animals." "Derivation holis that every species changes in time by virtue of inherent tendencies thereto. Natural selection holds that no such change can take place without the infinence of altered external circumstances educing or selecting such change." "So being unakle to accept the volitional hypothesis, or that of impulse from within, I deem an innate tendency to deviate from parental type, operating through periods of adequate duration, to be the most probable nature or way of operation of the secondary law, whereby species have been derived one from another." (6-51).

From this it would seem that one species was derived from another, in a rising scale of advancement under the pressure of an "innate capacity," or of "inherent tendencies ;" though it is diffi- 
cult to see much difference between this and the "impulse from within" of the "Vestiges."

Darwin, however, does not assent to this. He says: "Natural selection includes no necessary or universal law of advancement or development," but "only takes advantage of such varieties as arise and are beneficial to each creature under its complex relations of lile.' (2-119). In other' words, it is a mere struggle for existence coupled with changing conditions.

Prof. Kölliker, cited by Huxley, said : (7-310, 311).

"The fundamental conception of this hypothesis is, that under the influence of a general law of development the germs of organisms produce others different from themselves. This might happen (1) by the fecundated ova passing, in the course of their development, under particular circumstances, into higher forms; (2) by the primitive and later olganisms producing other organisms, without fecundation, out of germs or eggs (Parthenogenesis). " "It is obvious that my hypothesis is very similar to that of Darwin's, inasmuch as I consider that the various forms of. animals have proceeded directly from one another, My hypothesis of the creation of organisms by heterogeneous generation, however, is distinguished very essentially from Darwin's by the entire absence of the principle of useful variations, and their natural selection; and my fundamental conception is, that a great plan of development lies at the foundation of the origin 
of the organic world, impelling the simple forms to more and more complex developments. How this operates, what influences determine the development of the eggs and the germs, and impel them to assume constantly new forms, I cannot pretend to say; but I can at least adduce the great analogy of the alternation of generation. If a Bipennaria, a Brachiolaria, a Pluteus, is competent to produce the Echinoderm, which is so widely different from it; if a hydroid polyp can produce the higher Medusa if the vermiform trematode 'nurse' can develop within itself the very unlike Cercaria, it will not appear impossible that the egg, or ciliated embryo, of a sponge, for once, mnder special conditions, might become a hydruid polyp, or the embryo of a Medusa, an Echinoderm.'

Great plans are not of spontaneous generation, but must of necessity be formed by an intelligent power equal to their conception and fulfilment. If by the words, "A great plan," used in the above connection by Prof. Kölliker, he means that the Creator uses, or has used, simpler forms to create the more complex, he is much nearer the truth than he was himself aware. Otherwise, he does not in the least improve upon the "innate capacity," "inherent powers," "inscrutable mysteries," and other like phrases, used so frequently to express an utter inability to explain *

* Recently my attention has been for the first time directed to the History of Evolution by Prof. Alex. Winchell. In this he 
Then again as to the doctrine of transmutation, to wit; that life as well as form is transmuted, there is a dificulty of no little magnitude to be surmounted. Is there any thing in the vast array of facts collected and arranged by Darwin, that in the remotest degree accounts for the transmu. tation of the opposite principles of life into each other? Such as the sheep into the wolf or the reverse?

In support of his theory, the author has collected a great mass of facts, not only in lis original work, but in the subsequent one of "The Variation of Animals and Plants under Domestication." His wide range of research and illustration, combined with logical skill in arranging and applying his facts, made a deep impression upon the scientific word, and gained some distinguished converts.

classes me with Kölliker, as adopting the theory of Parthenogenesis, which, he says, "is in contempt of the universal law of life" (40-53). Parthenogenesis is expressive of the origin of the life of a new species by extraordinary generation, exclusive of reproduction in the ordinary manner. In my pamphlet (published in 18\%2) what is meant by extraordinary generation, as there used, is set forth substantially as in the present work; and in this, as the reader can see, the origin of a new species is ascribed to the direct inflow of life from the Creator, exclusive of ordinary generation. It is a misnomer, therefore, to class me with Kölliker, without giving the reader some idea of the modus operandi of "extraordinary generation," as explained by me. This, however, would be of little account, had not Prof. W. made a seeming attempt to adopt the same theury. He says: "It does not exclude divine agency from the work of organic advancement to assume that it has been effecte 1 through the reproductive and other pliysiological processes. The Creator no less made man if he caused him to be derived by descent from the orang outan" (40-15). 
So far he had not undertaken to account for the origin of man, without which his theory manifestly lacked logical coherence, and the mass of scientific men were slow to believe that the wide gulf between the instinct of the highest ape and the lowest human mind, could be bridged over in that way.

In a later work, "The Descent of Man," (1871), he makes the effort, with great logical ingenuity, to supply this lack, and now his theory, whether sound or unsound, presents an unbroken chain of development from the lowest organism up to and including man.

It will thus be seen that the theory claims to be true to the amazing extent of accounting for all the structural and physiological distinctions between animals in the long chain from the Moner to Man.

The working of the theory is by extinction and divergence. "Natural selection leads to divergences of character, and to much extinction of the less improved and intermediate forms of life." $(2-117)$.

Animals improve by domestication; and under changed conditions by adaptation; and in both cases varieties are produced. But no instance has ever yet been known where any thing like a radical change of species has occured either by domestication or natural selection: Nor can such change ever occur, under such influences alone, except by a complete absence of the principle of heredity. Take Darwin's favorite comparison of the growth 
of a tree (2-118)-the Linden we will suppose. It is true the green and branching twigs of the last year are replaced by the growth of the present, but the new growth is neither oak, chestnut, nor pine-it is Linden and nothing else; and so it will remain in all its divergences. Until a well marked case of a complete change in species is found, the theory remains, not only unproven, but improbable. In strictness it seems well nigh absurd, as may appear by the following test:-

Commence with Dar'win's five or six primordial types, and suppose the Rhizopod to be one, and that the fittest of its progeny survived, the rest perishing. This going on for a long period of time finally produces an organism radically different from the original type. The process supposes a continual advance, and a continual dropping out and disappearance of the intermediate links in the chain as living animals: And if there be any substantial force in it, there ought now to be only six species of animals in existence. Granting, however, this to be an over-strict construction, yet the advocates of the theory have greatly overrated the efficiency of the causes of change which are supposed to exist.

Mr. Spencer says :- "He, Darwin, has worked up an enormous mass of evidence into an elaborate demonstration, that this preservation of favored races, in the struggle for life-is an everacting cause of divergence among organic forms." (5-I-446). Granting the amount of evidence presented by Darwin to be immense, it, is nevertheless 
claimed that it fails to make out his case-that it falls far short of the demonstration claimed. It is fully conceded that in the struggle for life of any given generation - of wolves for instance- the strongest and swiftest, live the longest, as a general rule. But there is an important error in supposing the offspring of these strong and swift wolves to be, on the average, stronger or swifter than their progeuitors; and the theory must fail unless a gradual advance of the average can be shown. It must fail unless it can be shown that in every succeeding litter of wolves, there is one or more stronger or swifter, or both, than the progenitor ; and unless too, these survivors have, in addition to their strength and swiftness, diverged in some degree from the original type in other respects.

But the fact is familiar to common observation, that in every generation of animals in a natural state, there is a sliding scale between the relative strong and weak-an average of strength or swiftness, or both-which remains permanent. There is no known fact proving, nor any well founded reason for supposing, that the wolves of the Russian Steppes were of any less strength or swiftness one thoasand years ago than at the present day. Otherwise we might witness something like the following absurdity: the wolves growing swifter in the pursuit of deer, the deer growing swifter in eluding pursuit, - the result would be a race between pursuer and prursued, like two locomotives going at the rate of sixty miles an hour! It fol- 
lows that the relative distance between the carnivora and their prey must ever remain the same; and that a departure from this law would effect the destruction of the one, or the other, or both. If the wolf increased in fleetness, while the deer remained stationary, the latter would be destroyed, and the former would perish for want of food. The converse would save the deer, but destroy the wolf from inability to secure his prey.

Mr. Spencer, himself, recognizes this iden of average, in what he says in a limit to growth:

"Nevertheless it is demonstrable that the excess of absorbed over expended nutriment, must, other things being equal, become less as the animal becomes greater. In similarly shaped bodies the masses vary as the cubes of the dimensions, whereas strengths vary as the squares of the dimensions." On this he reasons, that when the animal has increased to a weight of eight times, it has overcome eight times its strength, and the creature begins to be overworked. $(5-1-121)$.

It is true that under domestication some animals may be forced above the common average, and some varieties are, at least, temporarily, produced; but there is a limit to these changes, and the highest advance, or greatest variety yet reached in this way, when abandoned to the influence of natural causes, invariably revert to the original standard.

So, too, a change in the environment will pro- 
duce a variation, more or less marked, which also disappears in restoration to original conditions; and this rule is alleged by $\mathrm{Mr}$. Spencer to be invariable.

J. D. Cator, during a sojourn in the Sandwich Islands, says, that nearly all the animals that have been introduced in the islands, as well as those which were held in domestication, have reverted to the wild state--among these are the ox, horse, goat, sheep, hog, dog, cat, turkey, peacock and barn yard fowls (1-Xx-716).

Darwin, however, evidently regards this idea of reversion as vitally adverse to his theory. "Having alluded to the subject of reversion, I may here refer to a statement often made by naturalists, namely, that our domestic varieties when run wild gradually, but certainly, revert in character to their original stocks. Hence it has been argued that no deductions can be drawn from domestic races to species in a state of nature. I have in vain endeavored to discover on what decisive facts the above statement has so often and so boldly been made. There would be great difficulty in proving its truth; we may safely conclude that very many of the most strongly marked domestic varieties could not possibly live in a wild state." (2-20).

His conclusion that very many of the domestic varieties could not possibly live in a wild state substantially concedes that varieties are not permanent, and so far is an admission that domesti- 
cation furnishes no reliable evidence in support of his theory.

In his work on Domestication he returns to the subject, and after remarking, "It is curious on what little evidence this matter rests.' - -says"Nevertheless, I do not doubt that the simple fact of animals and plants becoming feral does cause some tendency to reversion to the primitive state, though this tendency has been much exaggerated by some authors." In professing to run through the recorded cases on the subject, he says : "Thus the horses which run wild in South America are generally brownish gray, and in the East dun colored; and this may be due to reversion." Again, "Feral cats, both in Europe and La Plata are regularly striped, and in some cases they have grown to an unusual size, but do not differ from the domestic animal in any other character. When variously colored tame rabbits are turned out in Europe, they generally reacquire the coloring of the wild animal." Again, "The best known case of reversion, and that on which the widely spread belief in its universality apparently rests, is that of pigs. These animals have iun wild in the West Indies, South America, and the Faikland Islands, and have every where acquired the dark color, the thick bristles, and great tusks of the wild boar.' (33-II-46-67.)

The question then, so far as Darwin is concerned, is reduced to this: 'There is some evidence that domesticated animals when restored to 
original conditions do revert, and none that they do not.

So far as probabilities are concerned, irrespective of evidence, they are in favor of reversion. The variations are artificial departures from natural conditions, and when the canses which produced them are removed, the inevitable conclusion would seem to be, a gradual reversion to the wild state.

According to Haeckel, the efficiency of domestication, as an aid to natural selection, was shown by the Spartans, who raised a community of athletes by murdering all the weak and sickly children, and all affected by any bodily infirmity. "By this means (he says), the Spartans were not only preserved in excellent strength and vigor, but the perfection of their bodies increased with every generation." But the illustration is not a happy one. Spartan history, in the Regatta of $\mathrm{Na}$ tions, amounted to little more than a spurt, so to speak. No permanent results were produced; nor is there any evicence that Spartan perfection in strength or vigor, exceeded the maximum found in all improving nations.

Equally wide of the mark is the same author's allegation that the Indians of North America, by the same barbarous custom, produced a greatly strengthened race; and this he assures us cannot be doubted. (3-I-170). It is quite safe to say that no one, living or dead, has ever seen a North American Indian who ever came up to the maxi- 
mum strength of the white races who took possession of the country.

Before any thing substantial can be claimed either by the agency of domestication, or changes in the environment, it must be made to appear that these causes have produced something more than mere varieties.

Dogs, pigeons, and horses, furnish notable and familiar examples; the dogs having been domesticated during the entire historic period, and the pigeons for a very long time. Yet it is certainly true that no instances have ever come to light of the production of a new species, or of the slightest approach to it in either case. The pigeons have remained pigeons, and the dogs, dogs, though the pouter differs much from the rock, and the terrier from the bull dog. But the space which separates the pigeon from the hawk, and that of the dog trom the sheep has not been diminished to the extent of a single indubitable species.

The domestication of the horse through a pexiod commensurate with that of the dog; has been with a similar result, except that it has produced fewer varieties.

It is now claimed, however, by Professor Huxley and others, that by recent discoveries of certain equine fossil remains, the evolution of the horse has been traced through a regular and unbroken chain of descent from the Eohippus found in the lowest Eocene, and that demonstrative proof of the truth of Darwin's theory has thus been furnisher. (1-X-286). 
This claim is based upon the distinctions between the anatomical structure of the horse and that of the fossilized animals forming the several links in the chain.

In the anatomy of the horse, as described by Professor Huxley, the knee of the fore leg corresponds to the wrist in the human arm; the bone from the knee down to the human fingers; and the hoof to one of the finger nails. There are also two splints, or rudimental bones, commencing at the knee on each side and terminating at points a little above the hoof, which correspond to the metacarpal bones of the second and fourth human fingers. In the hind limbs there are two rudimental bones (as in the fore) answering to the human metatarsal bones.

The first link in this chain of evidence is the Pliohippus of the Pliocene, a one-toed animal, which differed very slightly from the present horse in the conformation of its limbs, and in having a shorter crown in its grinding teeth.

The next is the Protohippus, corresponding to the European Hipparion of the Pliocene. This animal had only one usable toe; but the splint 'or rudimental bones in the horse and Pliohippus were extended, terminating in the third and fourth hoofs which were not usable, and the same peculiarity was in the hind limbs.

Next is the Miohippus, which corresponds pretty nearly with the Anchitherium, and is found in the Miocene. This animal had three usable toes, one large median and two lateral 
ones; and a small rudimental bone answering to the human little finger. There were three usable toes in the liind limbs.

In the older Miocene is found the next linkMesohippus-which had three usable toes in front, and a large splint-like rudiment representing the little fingers; and three usable toes behind.

Next comes the Orohippus, of the lower Eocene, with four usable toes on the front, and three on the hind limbs.

The last is the Eohippus, found by Professor Marsh in the lowest Focene. It had four well developed toes in front and the rudiment of a fifth, and three toes behind.

Besides the anatomical distinctions above mentioned, there were a few other mnimportant ones, such as the teeth being, at first, quite simple and becoming more complex as the descent progressed. The size, too, of the Fohippus was about that of a fox, and this gradually increased in each successive link down to historic time.

The whole series presents a beautiful illustration of the power of adaptation, in living organisms, to changes in the environment. But the point is, whether these changes have resulted in new species, or only in varieties of the same. Each organic link in this remarkable chain is conceded to be a horse and nothing else; and admitting the modern one to be descended from the Fohippus, as claimed, what evidence does it furnish that the species has been changed? In other words, is the horse of to-day any thing more than a 
variety of the same species which in Eocene times was called Eohippus?

The only material changes have been in the number of toes, four of which have ceased to be developed; in the teeth becoming more complicated; and in the size: and these changes have undoubtedly been produced by changed conditions.

The Eothippus had four usable toes with the rudiment of a fifth, the Orotuippus had four without the rudiment, and the Mesothippus had three. Did these three animals represent three different species? As well class a man with six fingers for toes as a new species; and the same reasoning will apply to each link in this equine chain.

As to size, the modern horse varies too much to make that a matter of any significance.

Reverse the process, and suppose the condition of the earth to be retrograded gradually to that of the Pliocene-would not the mollern horse become a Pliohippus? Retrograde still further to the Miocene-would he not become a Miohippus? and so all the way through to the lowest Eocene.

Organs not used become aborted to a mdimental state and disappear; but this does nct necessarily change the nature of the animal. The word species, in this connection, as used by some is misleading. We must look at the substance of the matter, bearing in mind that systems of classification have not always been correct.

In deciding the question of a new species, psychological distinctions must be taken in to the ac- 
count. If the modern horse was carnivorous, and in its fossilized descent its hoofs (or toes) had gladually been converted into claws, there would be some plausibility in claiming the evidence as demonstrative of the theory in question. But as the case stands it furnishes strong proof that species ale permanent.

Mr. Spencer, who goes deeper into the science of Darwinisun than Darwin himself, supposes the case of an animal living on wild food, taken from the woods and brought up under domestication. In such case it "is subject to new outer" actions, to which its inner actions must be adjusted." "The old equilibrimm is destroyed and a new equilibrium is established.' (5-T-261). And he says-"TVhen the animal has its constitution thoroughly disturbed, it will go on varying indefinitely.' 'This, he claims, is due to function, a functional perturbation ending in a re-adjusted balance of function; and from this his inference is that, "altelation of function is the only known intelnal cause to which the commencement of the variation can be ascribed.' (5-r-263).

If we are to understand by this, that a change of function initiates a tendency to vary which runs into a change of species, the hypothesis is not supported by any well authenticated fact. The dog "Argos" that welcomed Ulysses on his return from the Trojan war, more than 3,000 years ago, was a domestic animal, and from Homer's description did not essentially differ from those of the present day. It is true the race has 
run in to much variety ; but its carnivorous nature has not been changed, though rendered less sav. age hy restraint. If, therefore, the dog first domesticated, was taken wild from the woods, the change of function has not been to the extent, nor productive of the effect claimed.

Mr. E. D. Cope regards the agency of "Natural Selection" as of little account, and attributes the evolution of speries to other causes. In an elaborate essay on "Evolution and its Consequences," published in Penn Monthly in 1872, he says: "Great obscurity has arisen from the supposition that natural selection originates any thing, and the obscurity has not been lessened by the assertion often made, that these variations are due to inheritance." Again: "Another reason why natural selection fails to account for the structures of many organic beings is the fact that in expressing 'the survival of the fittest,' it requires that the structures preserved should be especially useful to their possessors. Now, perhay,s half of the peculiarities of the parts of animals (and propably of plants) are of no use to their possessors, or not more useful to them than other existing structures would have been."

Again: "Plainly enough then, nothing ever originated by natural selection; and as the pres. ent essay relates to the origin of types, little space can be given to its discussion, for natural selection, important though it be, is but half the question, and indeed the lesser half."

In place of "Natural Selection" and "Sur- 
vival of the fittest," he substitutes two forces, "Acceleration and Retardation," the former of which, by some mysterious agency (aside from the ordinary course of reproduction) advances the organism, or some part of it, beyond its parerrt, while the latter, by a defect of force prevents some part of the organism from reaching the parental standard. By these two forces, or more correctly, by this force and absence of force, acting, of course, specially and not continuous, a new species is introduced.

The most important part of this essay, and that which best illustrates what $\mathrm{Mr}$. Cope means by these positive and negative forces, is the process of the supposed evolution of man from the monkey. For this purpose he selects a half grown specimen of the Cebus apella, a Brazilian monkey, in which he finds "a head and brain as large relatively to the body as in man; a facial angle quite as large as in many men; with jaws not more prominent than in some races; the arm not longer than in long-armed races of men, that is a little beyond half way along the femur."

That is to say, "Acceleration" increased the size of the head and facial angle, while "Retardation" diminished the jaws and shortened the arms. The conclusion arrived at is, that man originated "by retardation in the growth of the body and fore limbs as compared with the head; retardation of the jaws as compared with the brain case; and retardation in the intrusion of the canine teeth." 
Retardation, then, would seem to represent a want of developement in accommodation to the environment, and acceleration, a fuller developement from the same cause.

Whether there are any other accelerating or retarding forces than here indicated, known to science, may well be doubted: Certainly the Cebus apella examined by Professor Cope furnishes no proof to that effect. That specimen, as he says was but half grown; and it is a well known trait of the ape race, especially of the Anthropoids, that "the young animal in every respect resembles man more than the adult; and that the relapse to the resemblance of the brute consists essentially in the fact that the cranium remains stationary as regards cerebral capacity, whilst the jaws and face are greatly developed and project in the form of a muzzle."

If the supposed acceleration in this half-grown Cebus had continued to adult age, there might be some show for this improvement on Darwin's theory. But as it now stands, there is no evidence whatever that this particular specimen differed essentially from the young of the same species for the last ten thousand years. It would seem, too, as if these accelerating and retarding agencies must have acted with singular caprice in selecting a low species of ape, instead of those nearest to man in structure and appearance; and that while enlarging the cranium and shortening the arms, they should have omitted to eracicate the tail. 
He does not attempt to show why these positive and negative forces should have taken the particular directions indicated-why any other parts of the animal should not have been accelerated, or retarded as well.

The Darwinians, pure and simple, would doubtless urge that these forces proceeded upon the principle of use to the animal; but $\mathrm{Mr}$. Cope has satisfied himself of the almost entire worthlesness of that rule.

His theory presupposes a Cebus apella of the usual and normal size, which by force of accelera. tion gives birth to another with a much larger head, brain, etc.,--such an agency, in fact, as neutralizes the force of heredity.

Common observation proves that there are two forces always in operation in the succession of animal organisms, to-wit: Heredity and Variation - acting and re-acting upon each other, with the added effect of changes in the environment. We have seen this exemplified in the case of the horse from the lowest Eocene down to the present time.

There are no two individuals of the same species exactly alike-there never has been nor ever will he. But heredity is a prevailing force, which keeps the organism within certain limits, and species are thus kept substantially permanent.

Elsewhere in the same essay Mr. Cope treats of "Growth Furce," which appears to stand in the relation of a motive power to acceleration. Grow th Force would seem to be that vital principle of a living organism through which effect is given to 
nutrition, producing increase of growth. Its ordinary operation is (1) to increase the organism to its full size; (2) to keep it up to that point; (3) but disturbances often occur by which nutrition is obstructed in one part, and from that cause is directed to another.

Every fruit-culturist knows that pruning out redundant growth in a tree increases the growth force in the remaining limbs. So too, freeing a grape vine from the suckers which start from its root prevents a diversion of the sap from the main body. But who ever heard or dreamed that this process, however long continued, would change the cherry in to an apple, or the frost grape into an Isabella?

Assuming for the nonce, the absence of an intelligent resign in creation; that teleology is a myth; and that Darwin's theory, as explained and modified by his followers, is the orthodox theory of the production of species-there are nevertheless certain peculiarities for which, upon such assumption, it seems utterly impossible to account. How, for instance, is the poison faculty developed in some serpents, and why should it not be found in all as well? Why is the bite of some insects poisonous and of others not? Why is the organ of poison found in the tail in bees, wasps and scorpions, and in the head of spiders, bugs and centipedes?

There are white, black, reddish and olive complexioned men. Which was the primitive color, and how did the varieties of it occur? If white 
was the original color, how did natural selection turn some black, some red and others olive?

These instances might be extended much farther, but I will only mention the case of the Ruminants. The peculiarities of this class is confined to certain mammals, and so far as researches now go, it appeared first in the Pliocene.

In brief, certain herbivorous mammals are provided with two stomachs-an anomalous one as a reservoir for the reception of the food in a crude state, and the other a true stomach to receive the food after it has been forced back to the mouth and fully masticated. How this peculiarity was produced, and why it is not found in the horse and others of the herbivora, is not explained by the theory in question.

In his "Descent of Man" Darwin, if he does not manifest a waning confidence in his own theory, has, to say the least, materially damaged it in the estimation of others, by the admission of serious mistakes; and the discovery of other and more important agents of change. On page 146 of vol. I, he admits that after reading Nageli on plants, he had in the earlier editions of the Origin of Species "probably attributed too much to the action of natural selection, or the survival of the fittest." "I had," he says, "not formerly sufficiently considered the existence of many structures, which appear to be, as far as we can judge, neither beneficial nor injurious; and this I believe to be one of the greatest oversights as yet detected in my works." 
Again on page 148: "An unexplained residuum of change, perhaps a large one, must be left to the assumed uniform action of those unlsnown agencies, which occasionally induced strongly marked and abrupt deviations of structure in our domestic productions."

Here there are admissions of "strongly marked and abrupt deviations of structure" -and "structures which are neither beneficial or injurious," which according to his own statement in the Origin of Species absolutely breats down his theory. Nor is this all; there is it seems "a large res. iduum of change" brought about by "uninown agencies," and the statement that "In the greater number of cases," referring to occasional modifications and monstrosities, "we can only say that the cause of each slight variation and of each monstrosity lies much more in the nature and condition of the organism than in the nature of the surrounding conditions."

Akin to these "unkown agencies, etc.," is the statement in a note to page 215 in regard to the sterility of hybrids in which he speaks of them as "the incidental results of certain unknown differences in the constitution of the reproductive system of the species which are crossed."

What may be the force and extent of these "unknown agencies," "constitution of the organism," and "unknown differences," he does not attempt to define. They stand as unknown quantities, which for aught that appears may be sufincient to produce all the results heretofore 
ascribed to natural selection. They appear to perform the convenient office of a residuary clause in a will, which not unfrequently gathers in a much larger amount of the estate of the decedent, than is before enumerated in the form of bequests and legacies. 


\section{CHAPTER III.}

THEORIES.

Darninian Theory (continued). Sexual Selection. Esthetic Taste in Animals. How Man Became Denuded of Hair.

In the original work of Darwin, "Natural $\mathrm{Se}^{-}$ lection," is made the chief agent in producing" a division into species. "Sexual Selection" is briefly referred to as a struggle between the males of polygamous animals for the possession of the females, whereby the progeny of the victors were increased, and that of the vanquished diminished; and in this way he undertakes to account for the developement of certain organs of offense, such as the horns of the stag, and the spurs of the cock. By parity of reasoning lie also undertakes to account for the gay plumage of the males of certain species of birds, by supposing the females to have selected the best looking for their mates, leaving the unselected withont offspring: and the whole subject is disposed of in less than three pages. (2-83, etc).

In the "Descent of Man," however, the subject occupies directly or indirectly three-fourths of the whole work. "Sexual Selection (he says) depends on the advantages which certain individuals have over other individuals of the same 
sex and species in exclusive relation to reproduction." (9-I-24S).

In elaborating.the subject, he necessarily supposes a period when the male and female of any given species. were substantially the counterparts of each other, except as to the primary sexual differences-the same in form, size and color.

The foundation of the theory, so far as it $\mathrm{l}^{2} \mathrm{e}$ lates to the choice of mates, rests wholly upon the idea, that the females among animals have been and are endowed with the asthetic taste, or sense of beauty, heretofore supposed to belong to man alone. On this point he is sufficiently explicit. IIe says: "In the same manner as man can give beauty, according to his standard of taste to his male poultry-so it appears that in a state of nature female birds, by having long selected the more attractive males, have added to their beauty.' (9-I-250).

Again: "Sense of Beauty-This sense has been declared to be peculiar to man. But when we behold male birds elaborately displaying their plumes and splendid colors before the females, while other birds not thus decorated makes no such displays, it is impossible to doubt that the females admire the beanty of their male partners. As women everywhere deck themselves with these plumes, the beauty of such ornaments cannot be disputed. The Bower birds, by tastefully ornamentiug their playing passages with gayly colored objects, as do curtain humming birds their nests, offer additional evidence that 
they possess a sense of beauty. So with the song of birds, the sweet strains poured forth by the males during the season of love are certainly admired by the females, of which fact evidence will hereafter he given. If female birds had been incapable of appreciating the beantiful colors, the ornaments and the voices of their male partners, all the labor and anxiety exhibited by them in displaying their charms hefore the females, would have been thrown away; and this it is impossible to admit." (9-I-61).

In reference to color the reader is presented with an interesting detail of the almost endless variety of feathered beauty. Conspicuous in this respect are the Bird of Paradise-the Rubicola crocea-the Golden Pheasant and the Peacock.

"The case of the Argus Pheasant is eminently interesting, because it affords good evidence that the most refined beauty may serve as a charm for the female and for no other purpose." (9-II$88)$.

He deems it marvellous that the female should possess this almost human taste but sugrests that-" perliaps she admires the general effect rather than each separate detail." (ic. so). Iet he tells us that-_"as any fleeting fashion in dress comes to be admired by man, so with birds, a change of almost any lind in the structure or coloring of the feathers in the male, appears to have been admired by the female." (id. 70).

These changes, we are assured, are produced 
apon the same principle as under domestication. "The sole difference between the cases is, that in the one the result is dne to man's selection, while in the other, as with humming birds, Birds of Paradise, etc., it is due to sexual selectionthat is, the selection by the females of the most beantiful males.' (id. 75).

Jut man selects with a knowledge of the effect which he desires to produce. Does he mean that the cases are parallel to this extent?

It seems, however, that any one doubting the full appreciation of "such refined beauty" by the female Argus Pheasant will be "compelled to admit that the extraordinary attitudes as. sumed by the male during the act of courtship, by which the wonderful beanty of his plumage is fully displayed, are purposeless : and this is a conclusion which for one, I will never admit." $(9-I I-S 9)$.

It may well be questioned whether the doabter can be reduced to this dilemma. The real question is not between the turuth of the hypothesis and the purposelessness of the display, but whether he has hit upon the proper solution.

If it be true that dull colored birds make no such displays, it, is equally true that all the gayly colored do not. It is not, therefore, a rule sufficiently prevalent to draw the general conclusion that the admiration of the bird is to be classed with a woman's taste in dress. The point is whether the admiration is for the color itself, or because it is the color of her mate-whether it 
is not sexual instead of artistic-whether the admiration of the female raven is not fully as keen for her sable mate, not because black is to her taste, but because it is the color of the raven family.

Some cases are mentioned in which certain male birds, not much ornamented, go through with these antics; and the common Linnet is referred to, which-"distends his rosy breast, slightly expands his brown wings and tail so as to make the best of them by exhibiting their white edging." (9-II-90).

But in the next sentence we are cautioned against_-"conclnding that the wings are spread out solely for display, as some birds act thus whose wings are not beautiful. This is the ease with the common cock, but it is always the wing on the side opposite the female which is expanded, and at the same time scraped on the ground."

The wings of the Linnet and the cock in these displays are of as much importance in the consideration of the hypothesis in question, as those of the Argas Pheasant and the Bird of Paradise. They can furnish no more evidence of the existence of xsthetic taste in the one case than in the other. Otherwise the phenomena of nature are prodaced in a hap-hazard way, with no consistant or uniform plan, and this "I for one will never admit."

In adverting to the question whether these fe. male preferences produce variety in the male bird, 
Darwin makes a statement in reference to the origin of these displays, which does not well harmonize with his theory. He says: "As all the males of the same srecies display themselves in exactly the same way, it appears that actions at first perhaps intentional have become instinctive." (9-II 92). That is to say, these birds at a certain period of their descent acted with a distinct intent to please the females, but subsequently performed the same acts without any intent. That they all display themselves in the same manner is evidence that the method of display has never been changed; and the inference is that they were originally instinctive and have ever remained so. The inference too would follow, with equal force, that if the action of the male has been uniformly instinctive, that of the female has been equally so in the choice of her mate, without being in the slightest degree influenced by a taste for beauty in color.

We can to some extent bring this question to a practical test, by going back to a period when the male and female were alike, except as to the primary differences; and weigh the probabilities in the light of commonly observed facts. Take the case of the Golden Pheasant-the initial point of departure from the normal color must have been extremely small, because nature takes no sudden leaps. A male is hatched having a plumage slightly colored above the average, which excites the tasteful admiration of the females to the extent of selecting him for a mate, 
in preference to all others. Following this is the leading idea that the normally colored males, to a certain extent, remain unselected and without posterity, and gradually give place to the more highly colored ; and the brighter ones have contimued to grow brighter and brighter until the present results have been reached. Suppose the newly hatched male to belong to a family of one hundred pairs in a given area. It is not likely that more than one or two would at the same time appear with any marked shades of difference.

Given then, two males out of that number with brighter colors, and suppose them quickly mated -are the males having only the normal colors, or any considerable portion of them, to remain unselected? Are the females, which have become crazed after the new shade in color, to remain unmated, or driven to a polygamous union with the gayly colored males?

Birds, with few exceptions, are not polygamous; and there are no known facts which justify the notion that such caprices exist; certainly not to an extent sufficient to produce any appreciable change. As male birds of the same species are now colored substantially alike, whatever they may have been previonsly, it would be well belore accepting the hypothesis in question, to find some instance in which a choice had been made, because one feather, or tip of a feather, had appeared a shade brighter in one male than in ano'her.

Taste in color, it seems, is not confined to the 
feathered race, but prevails in almost the entire animal kingdom. Commencing with mammals, Darwin says: "After having studied to the best of my ability the sexual differences of animals belonging to all classes, I cannot avoid the conclusion that the curiously arranged colors of many antelopes, though common to both sexes, are the result of sexual selection primarily applied to the males." (9-rI-287).

Under the same potent influence, the Banting Bull (Bos Sancliacus) is almost black, "with white legs and buttocks; the cow is of a bright dun, as are the young males, until abont the age of three, when they rapidly change color." (9-II$275)$.

In this connection there is also alleged to be a mammalian taste in other ornaments, such as beards on the male orang (Pithecus Satyrus) and goats; dewlaps and curled hair on the bull, and other peculiarities of a kindred character; and the probable conclusion is drawn, "that the strongly marked colors and other ornamental characters of male quadrupeds are beneficial to them in their rivalry with other males, and have consequently been acquired through sexual selection." (9-II-281).

Does he mean that these strongly marked colors and other ornamental characters are the result of taste, or of the issue of battle? The question is left in doubt, and the reader may well be excused for deeming the one just about as efficient as the other. 
Descending a step lower, we learn that the male Chameleon Owenii "bears on his snout and forehead three curious horns, of which the female has not a trace ;" from which, as they are of no use for fighting, the inference is that they serve as ornaments to please the females." (9-II-33-34).

After mentioning one or two more similar cases we have the following: "On the whole, we may conclude with tolerable safety, that the beatifoll colors of many lizards, as well as various appendages and other strange modifications of struoture, have been gained by the males through sexual selection for the sake of ornament, and have been transmitted either to the male offspring alone or to both sexes. Sexual selection, indeed, seems to have played almost as important a part with reptiles as with birds." (9-II-35).

Why the transmission should exhibit the freak of favoringin some cases the male alone, and in other cases the male and female offspring alike, no explanation is attempted.

Among the crustacea it appears that, "In the female of a Brazilian species of Gelasimus, the whole body is of nearly a uniform greyish brown," while "in the male the posterior part of the cephalo-thorax is pure white, with the anterior part of a rich green, shading into dark brown."

From these peculiarities he says: "It seems highly probable that the male of these species has become gayly ornamented in order to attract or excite the female." (9-I-326-7). 
The Coleoptera cerealis among beetles are beautifully striped with various color's, "which are often arranged in stripes, spots, crosses, and other elegant patterns;" and these splendid colors, "can hardly be beneficial as a protection except in the case of some flower-feeding species; and we cannot believe that they are purposeless. Hence the suspicion arises that they serve as a sexual attraction." (IC. 35.5-6).

Of butterllies and moths he says: "TWe have seen that their colors and elegant patterns are arranged and exhibited as if for display. Hence I am led to suppose that the females generally prefer, or are most excited hy the more brilliant males; for on any other supposition they wonld be ornamented, as far as we can see, for no purpose." And after stating that ants recognize their associates after separation, he continues: "Hence there is no abstract improbability in the Lepidoptera, which probably stand nearly or quite as high in the scale as these insects, having sufficient mental capacity to admire bright colors." $(9-\mathrm{I}-3 \mathrm{S6})$.

Esthetic taste among ants! The same taste which delights the human eye in the beauty and harmony of colors found in an anthill! It seems very much, to use a common mode of speech, as if this was running the whole thinginto the ground.

Animal music also receives extended consideration in the theory of sexual selection. The only mammal for which any pretence is made in this respect, is the Hylobates agites, which has a loud 
musical roice, and, according to Prof. Owen, this Gibbon "may be said to sing."

The only animals, however, which really sing are birds, belonging mostly to the order of Insessores, which have vocal organs much more complete than other birds.

All other birds, however, have calls or cries, such as the caro of the crow, used chiefly in the breeding season; and the singing being usually in that season, it is fancied by Darwin, that bird songs are love songs, and have been developed from the original cry by the selective taste of the female. We are to suppose, then, that there was an original bird just evolved from some lizard-like form by natural selection; and that it had a call or cry peculiar to itself. What was that call? IVas it the caro of the crow, or is that an evolution from it? And have the calls and cries of non-singing birds been produced from it by the exercise of taste in the females?

Some of the Insessores, such as the raven and parrot, do not sing, though they have, it is said, the necessary complex organs. Are we to suppose a want of taste in the females, in not bringing their organs into exercise? And why, not being used, have they not ceased to be developed, or suffered retardation? The subject, as pre. sented, is full of intricacies, nor do either of the selections appear to fumish any means of extrication.

Darwin says: "Birds can be taught various tunes, and even the unmelodious sparrow has 
learned to sing like a linnet," (9-I-52). But this furnishes no satisfactory evidence of the existence of taste, in as much as the order of birds in question possess, to a certain extent, the power of imitation. This is well illustrated in the parrot, which can pronounce words corsectly, withont the slightest ilea of their meaning. The mocking bird is a noted instance of how far this can be carried into song. There is just as much reason to believe that this is done withont any appreciation of music, in the human sense, as that the parrot can repeat words without understanding them. Nor is there any more significance in the rival singing of two canaries beyond that of two hostile roosters in crowing at each other.

In some instances there are bright tinted birds which have the gift of song; and in these cases, he says: "It would appear that the female birds, as a general rule, have solected their mates either for their sweet voices or gay colors, but not for both combined." If for the sweet singing, how did the colors become gay? If for the colors, how did the sweet voice originate? He claims, indeed, that natural selection helps, when sexual selection is not efficient, a mode of solving the difficulty not very satisfactory to the reader.

Again he says: "That the habit of singing is sometimes quite independent of love is quite clear, for a sterite hybrid canary bird has been described as singing while viewing itself in a mirror, and then dashing at its own image" (9II -5()$)$. 
So do the female canary, robin, lark and bullfinch, "pour forth melodious strains in a state of widowhood." Some males also sing out of the breeding season, and of this the author naively remarks that "nothing is more common for animals to take pleasure in practicing whatever instinct they follow at other times for some real good" (id. 51).

If they do it for pleasure out of the breeding season, why not in it as well? They certainly must feel as joyons then as at other times. As to female sterile birds, and those in a state of widowhood, and ont of the breeding season, they sing for precisely the same reason that the males do; and the fertile females do not sing in the breeding reason, simply becauso the same force is spent in the functions required for breeding-they have something else to do.

It will thus be seen that the entire theory of the origin of song in birds, rests upon the idea, that certain species of birds had a taste for "the concord of sweet sounds," and selected their mates according to their proficiency. I concede to the fullest extent that the female of every kind of singing bird is pleased with the song of its mate. But I claim that it pleases them for the same reason that the harsh cry of the male king-fisher, hopee and macaw please their female mates-that it is wholly instinctive, without motive, purpose or discrimination, and has always been so-that the bird of each species has its own peculiar song, or cry, whether melodious or harsh to the human 
ear, and that its offspring sings the same song, or utters the same cry withont any tuition or training.

The song of each bird, in correspondence with its life, is a mere fraction in music, and has little or no variety bey ond some instances of the power of imitation, and it is only a single item in the sum of music as a whole. But in man the elements of music exist in their complex, not as an instinct, but as a part of his life. In him it develops slowly, but is capable of improvement almost without limit, until it becomes the most joyous and exalted expression of the affections and emotions of the mind. And as the mind of man is the summing up of all prior organic life, I cannot help believing that nature, throngh the songs of its birds, has been prophetic of the diviner music of the human sonl.

Descending from birds to insects, it appears that the Cicada pruinosa, of the Homoptera has the gift of song, and we are assured that "as there is so much rivalry between the males, it is probable that the females not only discover them by the sounds emitted, but that like female birds they are excited or allured by the male with the most attractive voice"' (9-I-341).

But more wonderful still the origin of the instrumental music appears to be due to another insect. It seems that "in the Locustida the two wing covers gradnally become differentiated and perfected, on the principle of the division of labor, the one to act exclusively as the bow, and the 
other as the fiddle," - "a grating thus occasionally and accidentally made by the males, if it served them ever so little as a love-call to the females, might readily have been intensified through sexual selection by fitting rariations in the roughness of the nervures having been continually preserved." (9-I-345). This is certainly provocative of the quare, as to how the males and females of this order managed to get together, prior to the invention of the Locustidie fiddle.

Many other instances of the supposed existence of taste in animals for the beantiful in colors and music are detailed in this interesting work, but enough has been said to definitely exhibit the stand-point from which the subject is viewed by the anthor. It only remains to give some general reasons, in addition to the suggestions already made, showing that his theory has no real foundation.

Esthetic taste is that quality of the mind by which we judge of the sublime, the bean tiful and the proper ; and distinguish them from the ridiculons, the ugly and the unsuitable. It is a quality which in its exercise ranges through the entire domain of nature and art; and is capable of a high degree of cultiration. We admire the starry heavens, a landscape, painting, statuary, literary performances, music, oratory, and so on to the end of a very long chapter, if, indeed, it have an end. The human infant is simply attracted by bright colors, and so far it is evidence of incipient taste; and such is very much the case with uncivilized man. 
It requires culture to bring it to the standard of Homer, Raphael, or Powers. So great is its range that in the highest states of civilization the differences of appreciation are endless, giving rise to the well-known saying: "De guśtibus non disputandum."

But it is not so with animals. With them it has no range or versatility whatever beyond a limited power of imitation. Each beast, bird and insect admires the color, form and peculiarities of its mate; nor is there any difference of opinion amongst them on the subject-the female crow, peacock, stag, lizard, butterfly and locust being in perfect harmony with the male about the family color; and you can cheat them only by disguising the wrong animal with the orthodox color, as in the case of a female zebra mating with an ass, after the latter had been painted to resemble a zebra. (9-II-281.)

It is not safe to find evidences of taste in the gay coloring of birds because it is pleasing to the eye of man. We admire the peacock, - so does the pea hen,- - we, because he is decorated according to our sense of beauty; she, because he wears the plumage of her mate. Toads admire their mates by reason of the same instincts which control the pea hen; but to us, resthetically, the toad is an ugly object. Both of these animals are confined within the limits of their kind. We have no reason to suppose the pea hen is ever entranced by the gay plumage of the golden pheasant; or that a frog ever went into ecstacies over the tame hues of the 
bull head, though the mate of the latter may think them very fine.

Darwin is puzzled that certain low organisms, such as corals, sea-anemones, some jelly-fishes, star fishes, \&c. (including some where the sexes are separated), should exhibit brilliant colors, inasmuch as it cannot be supposed they are a sexual attraction by reason of their low mental powers, nor do they serve as a protection, and being out of sight, they are not intended to please the eye of man (9-I-313-314).

It is indeed a puzzling question in view of the fact that nature is harmonious in her action; and if under her laws the male of the golden pheasant owes his gay plumage to sexual selection, these low organisms which have been separated into sexes, must be beautified in the same way. Surely, if the female locust has mind enough to choose her mate by reason of his proficiency in instru. mental music, and the female butterfly enough to adorn her mate with gaudy colors, it will require no great stretch of imagination or thought to suppose the females of these low organisms sufficiently intellectual to make a similar choice. He endeavors, however, to escape from the dilemma by concluding that the colors must arise from chemical agency, independent of any useful end. But this proves too much, because all colors, on the basis of chemical action, may be accounted for in the same way. There is, in truth, but one conclasion to be drawn from the fact that the mass of hese low organisms, not separated into sexes, are 
highly colored, and that is entirely adverse to the hypothesis in question.

It is useless to indulge in abstract speculation as to why one animal should be bright, and another dull colored. We may as well marvel why there should be a variety of colors in flowerswhy the rose shonld be red, the violet blue, and the marigold yellow; or why there should be different colors in the rainbow. To say that it can be accounted for by natural or sexual selection, would be sufficiently absurd; and naturalists must find some other cause, or admit their ignorance on the subject.

Wallace, in a review of Darwin, published in "The Academy" for March, 1871, says: "that the kind of sexual selection which depends on the female preferring certain colors or ornaments in the male has not been proved to exist" - that colors of insects are due to causes unknown. But upon what rational ground can the canse of the origin be different in insects from that of birds? 'The only logical conclusion is that if it be unknown in the one case, it is in that of the other.

It seems to me the differences between the male and females of the same species, such as color, size, horns, spurs, \&c., may be more rationally accounted for by the fundamental differences of sex. The male and female elements are essentially different, though well adapted to each other. The female element is recipient, more passive and therefore less aggressive. Unless there are such 
mental distinctions, why does the castration of the male produce a reversion in color to the female and a degree of general effeminency? (9-II-283314). Thy, too, the fact that the male embryo, at one oi its stages, resembles the female, and thence becomes more distinctively male?

So far as to asthetic taste in animals: But when and how under the reign of natural selection this quality was transferred from thence to the human mind is worthy of some consideration.

To be at all consistent, the development of taste in man, upon Darwin's hypothesis, should be through the ape. But it appears the highest and most varied display of the beautiful in animals, is found in insects and birds.

These, however, being on collateral lines of descent, there can be no pretence that man became endowed with this quality from either. The ape race in this respect has less variety, and much. less that accords with onr present sense of the beautiful. The female Rhesus monkey has a large surface of naked skin around a tail of a brilliant carmine red; with the Mandrills, the female Cynoceptuatus Mormon, is of a fine blue, with the ridge and tip of the nose of the most brilliant red; the Mandrill of Africa has a deeply furrowed and gaudily colored face-not to mention other cases. Man could not have descended from either of these, because each race, whether white, black or olive, is of a uniform color. Some savages, it is true, paint their faces, but this is imitation only, and simply shows a low standard of 
taste. Man, then, reasoning upon the same hy. pothesis, of whatever race, must have descended from an ape of a uniform color; but, singular as it may seem, the only evidence of incipient human taste treated of in "The Descent of Man" is the assumed dislike of primitive man to a hairy body.

Assuming, for the nonce, that Darwin has to a reasonable extent proved his theory, so far as relates to the animal kingdom (below man), yet it must be regarded as unproven, unless it can be shown that primitive man was born with a hairy body. Man is a pare of the animal kingdom. To suppose, therefore, that all the species of animals were produced by natural selection and man not, would be an insurmountable inconsistency. Whether primitive man was born hairy or naked. becomes, then, a test question.

In the "Descent of Man" sexual selection is for the first time made prominent; and a moment's reflection will show what its office is assumed to be. Natural selection, or the survival of the fittest in the struggle for life, is made the efficient frotor by which one species is proluced from another. Sexual selection is made to play its part, not in producing a new species, but in improving the appearance of the male or female of a species already in existence. Natural selection is the creator-sexual is the beautifier. The former has created the Argus pheasant, male and female, whereas the latter has covered the male with gaudy plumage. 
If man was evolved from some ape-like form under the law of natural selection, the first of the race must have been covered with hair, and on this point Darwin is sufficiently explicit: "The early progenitors of man were, no doubt, covered with hair, both sexes having beards; their ear's were pointed and capable of movement, and their bodies were provided with a tail having the proper muscles." The males, too, had great canine teeth which served them as formidable weapons. (9-I198).

As evidence of this primitive hairy condition, he refers to the woolly hair or lanugo found on the human fœtus, and of the rudimentary hairs scattered over the body during maturity; and he infers that the animal from whom man descended was not only born hairy, but remained so during life. (9-II-359.)

But human beings are now born naked, with the exception of a slight covering of hair upon the head, and have been so born during the entire historic period; and the question for the disciples of the prevailing theory of evolution is, how this almost entire nakedness has been effected. On this subject Darwin has been compelled to malie assumptions and draw conclusions which conflict with the fundamental principles of his theory.

As woman of all races now has a less hairy body than man in being destitute of a beard, he assumes that our female semi-human progenitors were first denuded of hair, and that this occurred at the remote period when the several races had not 
emerged from a common stock, and 'as our female progenitors gradually acquired this new character of nudity, they must have transmitted it in an almost equal degree to their young offspring of both sexes, so that its transmission, as in the case of many ornaments with mammals and birds, has not been limited either by age or sex." (9 II, 360.) From this the assumption is that the prevailing nudity has been brought about by the asthetic taste of our primitive mothers, who became disgusted with so much hair. But why did they not relieve their husbands and their male offspring of their bearts? 'That they became disgusted with that a pe ornament is just as reasenable to be inferred from the fact that they became beardless themselves.

It seems that in coming to this conclusion Darwin's mind has been in a state of great uncertainty, for in the first volume of his Descent of Man (143) he states the fact that elephants living in elevated and cool districts are more hairy than those in the lowlands, and in reference to this says: "May we then infer that man became divested of hair from having aboriginally inhabited some tropical land? The fact of the hair being chiefly retained in the male on the chest and face, and in both sexes at the junction of all four limbs with the trunk, favors this inference, assuming that the hair was lost before man became erect, for the parts which now retain most hair would then have been most protected from the heat of the sun." But flom 
this position he falls back upon sexual selection, because other members of the order of Primates are found covered with hair in the same regions. And in this, it seems, both parties participated, the man choosing his wile for her attractions, and the woman hel husband for his good looks and his ability to take care of and defend her. (9-I143.)

But all human infants are now, and for long ages have been, born withont beards-the females remaining witliont during life-the males sporting them at puberty. As stated abore, if primitive man and woman were of exclusively ape parentage, the infants of both sexes must have been covered with hair all over their bodies, including the face; and sexual selection, participated in by both sexes, as Darwin assumes, must in the first instance have removed the beard from the male, as well as the female. Why then does the beard appear upon the face of the male at puberty, and not upon that of the female? Did the resthetic sense of beanty of the woman undergo such a change in reference to the beard as to restore it by selection? And if restored in that way, why is not the infant male now born with a beard the same as when his progenitor first emerged from apehood?

If the mudity of man was produced by sexual selection, why did mankind subsequently cover their boclies, first with the skins of animals, and afterwards by clothing manufactured for the pur- 
pose? Was there a change of taste, and did the parties become dissatisfied with nakedness?

There is another point more to the purpose, still to be considered in connection with this branch of the subject; and it is, that the change produced by natmral selection must be for the benefit of the animal, and that it never originates a change which is injurious. Darwin, in his work on the Origin of Species, after stating that variations useful to man have undoubtedly occurred, and that other variations useful in some way to each being in the great battle of life do probably sometimes occur, says: "On the other hand, we may feel sure that any variation in the least degree injurious would be rigidly destroyed. This preservation of favorable variations and the rejection of injurious variations, I call natural selection. Variations neither useful nor injurious would not be affected by natural selection, and would be left a fluctuating element, as perhaps we see in the species called polymorphic," (2-78).

He admits that "the loss of hair is an inconve. nience and probably an injury to man even in hot climates; for he is thus exposed to sudden chills, especially in wet weather." (9-II-359.) But so fixed is he in the idea that primitive man was born hairy, that he is willing to overrule the most dominant law of his celebrated theory in favor of sexual selection. He says : "The absence of hair on the body is, to a certain extent a secondary sexual character; for, in all parts of the 
world, women are less hairy than men. Therefore, we may reasonably suspect that this is a character which has been gained through sexual selection." (Id. 359-60.) "Suspect," indeed; so it would appear, the interference of sexual selection is a matter of guess-work!

Inasmuch as the inconvenience of nakedness has stimulated the inventive genius of man in protecting himself against the cold, by clothing, the construction of dwellings, and numerous other appliances, whereby he is able to inhabit the most rigorous regions, it is far more rational to conclude that he was originally created in his present naked condition.

It is quite safe to say that animals never take a dislike to their external covering of hair, or feathers, or a thick pachydermic skin, as the case may be. Suppose a chicken hatched without feathers, or an ape born withont hair, or a child with a hare-lip, or an albino, the fair inference would be that such cases would be looked upon with dislike as deformities. If men had been hairy, like the ape, that would have been regarded as their normal condition, and any considerable deviation therefrom a deformity. How could our primitive mother have fallen in love with nudity without having seen the specimen of a naked man? Darwin's logic is surely lame in the inference that any race of beings could, as matter of taste, have ever preferred to be divested of their natural clothing.

As some evidence that aboriginal man was covered with hair, Darwin refers to instances of men 
hairy all over the face, as cases of reversion to the ape. If so, why did they not, in other respects, resemble the ape? It appears that those born with hairy faces are subject to defective teeth, and we may therefore fairly infer that owing to some abnormal condition of the mother, the hair has been retained upon the face at the expense of the further development of the teeth. It does not necessarily follow that every case of monstrosity is a reversion; if so, what is to be said of the Siamese twins? Evolutionists of all shades may as well accept the fact, that there are cases of lusus naturce from time to time occurring, the causes of which are not obvious, and which have no necessary connection with any theory of descent.

That the ape has much to do with the descent of man, I admit; but there is a wide diference between the evolution of man by natural selection, and his creation through prior organic forms which approach nearest to him; a method which is so far special as it differs from the process of re-production. 


\section{CHAPTER IV.}

\section{DARIVINISM CONTINUED.}

Lans of Hercdity-Sccondary Sexual Distinctions-Origin of the Sexes, and their distinctions-Rudimentary and Aborted Organs.

The laws which govern heredity are of such manilest influence in connection with the theory of the evolution of the species that Darwin has given the subject extended consideration. If the offspring invariably inherited the form and characteristics of the parent, there would be no possibility of a change of species by natural selection, combined with all the aids derived from changes in the environment, acceleration, retardation, \&c.

Darwin, as already mentioned, starts with the idea that the male and female type of any given species were alike except as to the primary distinctions of sex. If this be granted it would follow that heredity would substantially keep them alike. To surmount this difficulty he has been compelled to make rules of descent to meet particular cases, in apparently the most capricions manner.

In reference to the species of birds which have secondary sexual differences, he holds that the male, having acquired bright plumage by selec- 
tion, has transmitted it by heredity to the male offspring alone, the female remaining of the normal color for the sake of protection-in other words, that protection in such case prevails over heredity. The substance of this would seem to be that the female offspring inherited only from the mother, and the male only from the father, an idea which it is difficult to accept.

In that class of birds in which the young of both sexes resemble the adult female, (which by the way is the general rule), his conclusion is: "that successive variations in brightness, or in other ornamental characters occurring in the males at a rather late period in life, have alone been preserved, and that most or all of the variations, owing to the late period of life at which they appeared, have been from the first transmitted only to the adult male offspring. (9-II-191.) This is stated as "the most probable view," but why the force of heredity is stronger in the male Tate than early in life, it is difficult to see. Are the male offspring hatched at a late period in the life of the parent more bright than those of an earlier period? If there be any truth in the idea some such phenomenon would have been exhibited. Nevertheless he repeats it in various forms, and in a way which is perplexing to the reader, unless he chances to have some knowledge of the psychological distinctions of sex. Thus he says: "These relations are fairly well explained on the principle that one sex-this being in the majority of cases the male-first acquired through 
variation and sexual selection bright colors or other ornaments, and transmitted them in various ways, in accordance with the recognized laws of inheritance." (9-II-212.) And this perplexity is increased when we are assured as a law of inheritance, that secondary sexual characters "are transmitted through both sexes, though developed in one alone." If transmilted through both, why not developed in both?

Again, "In one small and curious class of cases the characters and habits of the two sexes have been completely transposed, for the females are larger, stronger, more vociferous, and brightly colored than the males. (9-II-226.) Did they start alike dull colored, and the female become brighter by the selection of the male? And is there a law of heredity for one species different from that which prevails in another?

Other cases are mentioned which seem to throw "the recognized laws of inheritance" into utter confusion. Thus, in regard to fishes of which both sexes are brightly colored, he says: "On the whole, the most probable view in regard to the fishes of which both sexes are brilliantly colored, is that their colors have been acquired by the males as a sexual ornament, and have been transferred in an equal or nearly equal degree to the other sex." (9-II-17). So of certain monkeys (Semnopithecus rubicundus) he says: "It is scarcely conceivable that these crests of hair and strongly contrasted colors of the fur and skin can be the result of mere variability with- 
out the aid of selection; and it is inconceivable that they can be of any use to these animals. If so, they have probably been gained through sexual selection, thongh transmitted equally to boith sexes.' (9-II-292). Why should a different rule of heredity prevail with fishes and monkeys than with birds?

The law of battle is founded on the principle of the right of the strongest, as distingnished from selection by choice-it is a display of strength and not of charms.

In this way the horns of the stag and other mammals, the tusks of the boar and walrus, the canine teeth of the carnivora, the spurs of the cock, etc., together with the greater strength of the male are claimed to have originated and been developed.

Yet, here, too, there is the same perplexity and confusion in regard to the force of heredity. Why the strength gained by the male in battle is not transmitted by inheritance to the female as well, is here also among the unexplained mysteries. In many cases the female is without horns, and then we are asked to conclude that they are transmitted to the male offspring alone - "according to the recognized laws of inheritance." In other cases the female is supplied with horns, and then we are to "conclnde that horns of all kinds, even when equally developed in both sexes, were primarily acquired by the males in order to conquer other males, and have been transmitted more or less completely to 
the former in relation to the force of the equal form of inheritance." (9-1I-236.)

Here are at least two kinds of inheritance-one the "recognized" and the other the "equal form," operating to produce different results. And it is a curious fact to note that the "equal form" was intended to check the tendency of man to become unduly superior to woman, for we are assured that "It is, indeed, fortunate that the law of the equal transmission of characters to both sexes has commonly prevailed throughout the whole class of mammals; otherwise it is probable that man would have become as superior to woman as the peacock is in ornamental plumage to the pea-hen." (9-II-313.)

Yet if the woman could remain as unconscious of her inferiority as the pea-hen, there would be no great harm done after all-it would be a clear case of the bliss of ignorance.

From Darwin's stand-point, the most rational conclusion would seem to be, that heredity does not operate according to any system or law which can be understood; and that some such idea has floated throngh his own mind is fairly to be inferred from such utterances as the following:

"The laws governing inheritance are quite unknown; no one can say why the same peculiarity in different individuals of the same species, and in individuals of different species, is sometimes inherited and sometimes not so." (2-19.)

"Inheritance is governed by so many unknown 
laws or conditions, that they seem to be most capricious in their action." (9-I-396.)

"Looking back to the several orders, we have seen that the two sexes often differ in various character's, the meaning of which is not understood." (Id., 404.)

"Why various characters should sometimes have been in one way, and sometimes in another, is in most cases not known; but the period of variability seems often to have been the determining cause." (9-II-224.)

"That the degree of limitation should differ in different species of the same group will not surprise any one who has studied the laws of inheritance, for tiney are so complex that they appear to us in our ignorance to be capricious in their action." (9-II-169.)

Darwin endeavors to explain some of the apparent contradictions and eccentricities of heredity by Pangenesis, in relation to which his theory is 1 , "That each of the myriad cells in every living body is to a great extent an independent organism ; 2, That before it is developed, and in all stages of its development, it throws 'gemmules' into the circulation which live there and breed, each truly to its kind, by the process of self division, and that consequently they swarm in the blood in large numbers of each variety, and circulate freely with it; 3 , That the sexual elements consist of organized groups of these gemmules; 4, That the development of certain of the gemmules in the offspring depends on 
their consecutive union, through their natural affinities, each attaching itself to its predecessor in a regular order of growth; 5, That gemmules of innumerable varieties may be transmitted for an enormons number of generations without being developed into cells, but always ready to become so, as shown by the most insuperable tendency to feral reversion in domesticated animals."

The foregoing is from a condensed statement of Darwin's hypothesis made by Mr. Francis Galton, F. R. S., and to thoroughly test its value he has made a large number of experiments in breeding rabbits. (10-372).

The process was to infuse into the veins of one variety blood drawn from other varieties. If there be any foundation for the hypothesis, some of the offspring, at least, should have been mixed or mongrel. Yet in eighty-three experiments with the silver gray rabbit the offspring was all silver gray, with the exceptions, that one had a white foot to above the knee, and one was a Sandy Himalaya; but this was from a breed of silver gray which sometimes cast the Himalaya. In thirty-eight experiments on the common rabbit transfused with the blood of the silver gray, all of the offspring were like the father and mother. The only conclusion is, that there is no value whatever in this hypothesis in explanation of heredity.

In a communication publishod in "Nature" (Vol. 24-p. 25), Darwin speaks of the case of a 
gentleman whose hair began to turn gray at the age of twenty, and became perfectly white in four or five years after. Of his four danghters, the hair of two became white at from twenty to thirty years of age. In anotler case a gentleman, in his boyhood had both his thumbs deformed in consequence of skin lisease aggravated by exposure to cold. Of his four children one had both thumbs, and another one thumb similarly deformed. Two of his grandchildren were marked in like manner, and with them the deformity disappeared. 'These cases, in connection with some experiments made by Dr. Brown-Sequard, showing that Guinea pigs of the next generation were effected by operations on certain nerves of the parent, satisfied Darwin that the effects of a mutilation are really inherited beyond mere accidental coincidences-implying that they are sufficiently permanent to produce distinct varieties.

The instances of the early blanching of the hair, and of the deformed thrmbs, are to be classed with the abnormal cases of children born with six fingers, \&c., which generally disappear in two or three generations.

It is generally molerstood that chronic diseases in the parent which eflect, more or less, the whole system, give a tendency in the offspring to the same diseases. But whatever may be found to be true of the inherited effects of mutilation with Guinea pigs, it is certainly not true of the human races. There have been thousands of cases in which men have had children, after the amputa- 
tion of an arm or a leg-yet no instance has been recorded of children born to a parent, so mutilated, having hut one leg or arm. Does the history of China record a single instance of an infant, male or female, born with clubbed feet? Yet for, probably, a thousand years the female children of that country have been tortured by appliances to produce deformed feet.

That there are laws of inheritance which have a mode of action nearly, or quite as uniform and consistent, as those which govern attraction and repulsion in physics may be understood, when we understand the differences between the male and female life of animals. The difficnlty of this great author is in not having grasped these vital differ. ences. Hence he has assumed that the male and female ty pe of any given species" commenced without any secondary sexnal differences.

There is a theory in much better harmony with the facts, to wit: that the male and female principles, though perfectly adapted to each other, are fundamentally distinct-that they co-existed in the moner (a mere undeveloped cell) - that as a necessity of creation they became, at a very early period of the introduction of life, separated into distinct organisms with secondary sexual differences-and this theory, if true, is fatal to that of selection, both natural and sexual.

There is an animal psychology which has not been sufficiently considered in connection with sexuality and heredity. I hold that every animal 
life, and human as well, puts on a body of natural substances, which corresponds to, and is the ontward expression of such life; and that heredity follows, or is controlled by the life.

The psychology of sex differs as much as the bodily organism which gires it an outward expression. The male and female of any given species differ in life, mind or soul, because there are different functions to be performed by each; and they differ in a primary and secondary mannerby reason of this, and not because of the supposed operations of any kind of selection.

In a certain sense each mated pair constitutes a unit, because a union is necessary for the continuance of therace, and for mutual benefit and protection; and earh member of the pair supplements what seems not fully developed in the other. In other words, male and female in sexmality is both corporeal and mental-acting in union. Infants of both sexes, human and animal, are very much alike, because the secondary sexual differences, especially in the male, are not psychologically developed-a fact which Darwin admits (9-II-30?). The ovum of the female is only the receptacle into which life flows, proximately from the male; and from the period of impregnation a body is gradually put on from the female. By reason of this fact the maternal predominates in the body of the infant, let the sex be what it may. But as development of the life and structure after birth proceeds in unison, the father's likeness, if the sex be male, will gradually appear, with the ordinary 
variations of which mention has been made; and if it be female, the same likeness will appear, though shaded and softened by the radical sexual differences, giving to brothers and sisters the wellknown family resemblances.

This rule is illustrated by crosses between allied species. The offspring of the ass and mare is the mule, which as it matures resembles most the ass ; while that of the stallion and the female ass is the hinny, which resembles most the horse: and this invariably happens in all crosses between the horse and the ass. The same thing is observed in the crosses between different races of men. Thus the offspring of the white man and the negro woman is the mulatto, resembling most the father; while that of the negro man and the white woman is a negro. So in the white races, where there is not a family resemblance between a man and his wife, the children when grown, as a general rule, have a stronger resemblance to the father than the mother.

It would seem to follow that in embryology the female element is first in point of time; and this explains why the vesicutce prostatice, and rudiments of the uterus with the adjacent passage, and also rudiments of mamma are found in the male mammal. The existence of these rudiments is used in support of the idea, that there was a period when there was no primary distinctions of sex in separate organisms. Darwin, alter" speaking of these rudiments, asks: "are we then to suppose that some extremely ancient mammal 
possessed organs proper to both sexes, that is, continued androgynous after it had the chief distinctions of its proper class, and therefore after it had diverged from the Iower classes of the vertebrate kingdoms" (9-I-199). This he thinks improbable, and claims "that when the five vertebrate classes diverged from their common progenitor the sexes had alleady become separated"' (9-I-200).

ihis only removes it a little further off, and supposes a period not very remote from the common progenitor when the animal was androgynous. But when and how did the seres on this assumption become separated? The following passage indicates his supposition that it arose from the necessity of a division of labor!

"No naturalist doubts the advantage of what has been called the 'physiologrical' division of labor; hence we may beliere that it would be advantageous to a plant to produce stamens alone in one flower, or on one whole plant, and pistils alone in another flower, or on another plant. In plants under culture, and placed under new conditions of life, sometimes the male organs, and sometimes the female organs become more impotent. Now if we suppose this to occur in ever so slight a degree under mature, then as pollen is already carried from flower to flower, and as a more complete separation of the sexes of one plant would be advantageous on the principle of the division of labor individuals with this tendency more and more 
increased, would be continually favored or selected, until at last a complete separation of the sexes would be effected" (2-8S).

The idea appears to be, that a plant now having stamens and pistils in different individuals is the product by natural selection of a progenitor plant of the same species in which the stamens and prstils were in the same individual, and that the motive principle of the change has been to pro. duce a division of labor. Iet if this has been any active power in plant life the effect should be universal ; whereas a large number of plants have reproductive organs united in the same individual.

How or in what way the process applies to animals except upon the hypothesis of an "innate tendency" to a sexual divergence (which Darwin discards), or upon Von Baer's idea of an exercise of will, it is difficult to see. Man like all other animals is developed from a cell; and from this other cells were propagated until the organism became complete. But on account of the necessity of a division of labor, one set of cells performed the office of propagntion, another accomplished nutrition, another protection, another locomotion, \&c (1-154).

Admitting the facts, all this may be clear enough in a strictly materialistic view. But the qucere naturally arises as to how the riecessity of a division of labor could have been suggested. How could the cells differing from the parent one in respect to the offices to be performed by them,- be propagated, except by a conrse of reasoning by 
which propagation, nutrition, \&c., were found to be desirable? There must have been an exercise of mind somewhere.

Life is now manifested as male and female, and its reproduction in animal forms requires a cooperation in the union of sperm cells and germ cells. How it came to exist in sexual division, and why such co-operation is necessary for reproduction, are questions which Darwin attempts to solve as above stated.

Spencer, in an inferential way, thinks the result has been produced by natural selection. Upon the hypothesis that "natural selection appears capable of producing and maintaining the right proportion of the sexes in each species" (a matter by $n 0$ means shown by Darwin or any one else); he adds, "it requires but to contemplate the bearings of the argument to see that the formation of different sexes may itself have been determined in the same way." (5-I-449.)

This is a very slender support upon which to rest so important a conclusion. The argument referred to relates to the different kinds of genesis in certain low organisms, involving questions which the author admits biological science not yet sufficiently advanced to answer. (5-I-233.)

In support of his position he instances the propagation of the Palmellce and certain conferve among the plants, in the former of which there is a complete fusion of the individual and in the latter a union of the contained granules of two adjacent cells. "There is (he says) reason to 
think that in the lowest Protozoa a fusion of two individuals is the process from which results the germ of a new series of individuals. But in animals formed by the aggregation of units that are homologous with Protozoc the sperm cells and germ cells are differentiated." $(\tilde{5}-\mathrm{I}-219$.

He marvels why these sperm and germ cells should be invested with these properties beyond other cells, and why those not brought into contact are incapable of further development and disappear; but he takes refuge in the use of the phrases "inherent powers" and "intrinsic aptitudes," which appear to be kept habitually on deposit for similar emergencies. (5-I-219.) That these peculiar cells which fail of contact and dis. appear is proof of the development of this kind of cell for specific purposes, to-wit, that they may furnisil a medium for influent life; and the marvel if not so much why they are developed, as how natural selection or the division of labor, can possibly have any agency in their production.

The causes of the distinctions of sex lie far deeper than either Darwin or his followers have imagined. Such distinctions were primarily in the life of the lowest organisms, and there would be quite as much reason to ascribe the separation of heat and light in the sun to natural selection, as that of the primary sexual divisions.

Prof. E. Van Beneden, of Liege, has discovered that of the two membranes of which the hydroid nolyps are composed, the outer (ectoderm) gives 
rise to the testes and spermatozoa, and the inner to the ovaries, so that the outer layer is male and the inner female. He consiclers that fecundation takes place in the union of an egg with a certain number of spermatoids, which brings together chemical elements of opposite polarity, these after uniting in the egg separate again, and that the new being is formed at the moment when the union between the elements of opposite polarity is effected as absolutely as the molecule of water is formed by the union of atoms of hyarogen and oxygen. (11.)

The ordinary process of reproduction, as now known, requires the contact of the ovum with zöosperms secreted by the testes. We learn from a scientific work by Prof. Burt G. Wilder, that the ovum is an internal bud-in other words that the bud is an effort to differentiation into ova and zöosperms. He says, "But even in the highest stage, there is only a modification of the simple division which occurs in the lowest; for ovum and zöoseperms are merely internal offshoots, minute though they often are, from a parent stock, and it may be shown how gradual is the transition between the extremes of animal life from the moner to man; for the differences relate to the proportion between the stock and the bud." (19-20.)

The male and female principles thus appear separated in the lowest organisms. The facts justify the conclusion, that such a thing as an hermaphrodite never existed, except as a monstrosity ; or 
in certain low forms which propagate by budding or segmentation. Darwin himself says: "Modern research has much diminished the number of supposed hermaphrodites, and of real hermaphrodites, a large number pair; that is, two individuals regularly unite for re-production." (2-90.)

Modern research will probably continue to diminish these anomalons beings until they disappear.

Again, the male characteristics thronghout almost the entire animal kingdom, are so uniform. ly alike, and so uniformly distinguished from the traits peculiar to the female, as to make it next to certain that the differences are from causes far deeper, than the accidents and probabilities of selection. The male is larger, stronger, more courageous and more aggressive. This is universally true of the mammalia. Among the noted instances mentioned by Darwin is that of the Rhesus monkey, which are "bolder and fiercer than the females "." and "lead the troop, and when there is danger "ome to the front." -II-305.) The same is true of the bull, buffalo, ram and wild stallion.

Man, whether civilized or savage, is larger and stronger than woman, (1-XIV-202). There are some exceptions to the rule, as to size, among fishes and some insects, on account of the production by the female of large numbers of ova.

The mental differences are quite as marked, and hey can be stated in no more appropriate lan- 
guage than that used by Darwin himself: "No one will dispute that the bull differs in disposition from that of the cow, the wild boar from the sow, the stallion from the mare, and, as is well known to keepers of menageries, the males of the larger apes from the females. Woman seems to differ from man in mental disposition chiefly in her greater tenderness and less selfishness; and this rolds good even with savages, as shown by a well-known passage in Mungo Park's Travels, and by statements made by other travelers. Woman, owing to her natural instincts, displays those qualities towards her infants in an eminent degree, and, therefore, it is likely that she should often extend them towards her fellow-creatures. Man is the rival of other men; he delights in competition, and this leads to ambition, which passes too easily into selfishness. These latter qualities seem to be his natural and unfortunate birth-right. It is generally admitted that with woman the powers of intuition, of rapid perception, and perhaps imitation, are more strongly marked than in man; but some, at least, of these faculties are characteristic of the lower races, and, therefore, of a past and lower state of civilization." $-\mathrm{II}-310-11$.)

This is all very well, thongh there are points in it open to criticism-such as the idea that female kindness is due to the habit derived from the maternal instinct, rather than to a genuine sympathetic pity for distress; nor is it easy to see why 
certain female characteristics are any less genuine because they have been exhibited in low states of civilization.

Superiority of bodily strength, or of the reasoning faculties, does not necessarily imply general superiority. Man is inferior to woman in those mental qualifications in which she differs from him. They are mutually dependent on each other. It is a great mistake to predicate a question of superiority between them, because being dependents upon, and supplements to each other, there can be no necessary rivalry-as well institute a comparison respecting the relative importance of the heart and lungs in the human body, or between that of the heat and light of the sun in the solar system.

Another significant fact tending to prove that the secondary sexual difierences are fundamental and not due to selection is, that when the male is emasculated, these differences are either not developed or disappear. Says Darwin: "As with animals, so with man, the distinctive characters of the male sex are not fully developed until he is nearly mature; and if emasculated, they never appear.', (9-II-302.) Speaking of antelopes, "young males cannot be distinguished from young females until about twelve months old; and if the male is emasculated before this period he never changes color." "The emasculated bull reverts to the color of the female." (id. $2 \% 4-5$ ).

In regard to colors of certain male mammals: "We should bear in mind that these colors do 
not appear in the male at birth, as in the case of most ordinary variations, but only at or near maturity; and that unlike ordinary variations, if the male is esmasculated they never appear or subsequently disappear." (9-II-281.) In regard to man : "His vocal chords are about one-third larger" than in woman or than in boys; and emasculation produces the same effect on him as in lower animals, for it arrests that prominent growth of the thyroid, etc., which accompanies the elongation of the cords." (id. 314.)

From these facts two things follow: (1) that the secondary differences are from sex and not from selection, or of any supposed necessity for a division of labor, and $(2)$ that the female principle is developed first.

Herbert Spencer, in an article on the psychology of the sexes, denies, or, at least, doubts, the permanence of the mental differences between men and women. (1-Iv-35.) After pointing out with great clearness the actual differences now found to exist, and after admitting the a priori inference "that fitness for their respective parental functions implies mental differences between the sexes as it implies bodily differences, is justified"; and also the kindred inference "that secondary differences are necessitated by their relations to one another," he says: "That they are fixed in degree by no means follows-indeed, the contrary follows. Determined as we see some of them are by adaptation of primitive woman's natures to the natures of primitive men, it is infera- 
ble, that as civilization readjusts men's natures to higher social requirements, there goes on a corresponding readjustment between the natures of men and women, tending in sundry respects to diminish their differences. Especially we may anticipate that those mental peculiarities developed in woman as aids to defence against men in barbarous times will diminish. It is probable, too, that though all kinds of power will continue to be attractive to them, the attractiveness of physical strength, and the mental attributes that commonly go along with it will decline, while the attributes which conduce to social influence will become more attractive. Further, it is to be anticipated that the higher culture of women, carried on within such limits as shall not unduly tax the physique (and here, by higher culture, I do not mean mere language learning, and an extension of the detestable cramming system at present in use), will in other ways reduce the contrast, slowly leading to the result everywhere seen throughout the organic world, of a self-preserving power inversely proportionate to the race-preserving power, it will entail a less early arrest of individual evolution, and a diminution of those mental differences between men and women which the early arrest produces."

If it be true, as Mr. Spencer has before alleged in the same article, that in primitive times, "the wives of merciless savages must, other things being equal, have prospered in proportion to their power's of disguising their feeliugs." And 
if it be true that "women who betray the state of antagonism produced in them by ill-treatment wonld be less likely to survive and leave offspring than those who concealed their antagonism; and hence, by inheritance and selection, a growth of this trait proportionate to the requirement." "And that the arts of persuasion enabled women to protect themselves, and by implication their offspring, where in the absence of such arts they would have disappeared early, or would have reared fewer children." In other words, if it be true that the female traits of concealing antagonism on necessary occasions, and of the arts of persuasion, are due to natural selection and inheritance from primitive times, then it might follow that the sexual difierences in question are not fixed in degree, and are likely to be obliterated. It might also follow that if these differences are so liable to change, the time will come when the girl may mature no sooner than the boy, and the woman may become so much like the man as that they will stand in each other's way and become rivals instead of companions.

Mr. Spencer's conclusion is in conflict with his admissions, "that fitness for the respective functions implies mental differences," and "that secondary differences are necessitated by their relations to one another." These relative functional positions are permanent, and will effectually prevent the ultimate state of rivalry contem plated. It is obvious, too, that such rivalry would lead to the disorganization of the family, and the family, 
it must be borne in mind, is the basis of all stable governments.

In coming to this conclusion he makes some singular assumptions.

In the first place he assumes a want of adaptation between the natures of primitive man and woman. If the assumption be true, it certainly furnishes a remarkable exception to the uniform adaptation of male to female, and the converse in the rest of the animal kingdom. Is there any want of adaptation between male and female dogs, cats, horses, hogs, sheep and cattle? These are domestic animals, and the fitness of the sexes to each other is open to familiar observation ; and so far as the rest of the animal kingdom is known, it is safe to say no want of adaptation in these re. spects has yet been detected. There is, therefore, a want of analogy to sustain the position.

In the second place, he assumes that primitive men were not merely uncivilized, but so utterly savage as to neutralize or destroy the domestic affections, and make the practice and development of the arts of dissimulation and persuasion a sine qua non to save the race from extinction. The announcement of such an idea in the hearing of the men of the Stone Age, or of that preceding. it, would, I fancy, have created some astonishment. Certainly there is no evidence from the researches of travellers amongst the lowest tribes of savages now existing which warrants any such conclusion. The only show of evidence in that direction is found in the treatment of women 
among savage tribes of the present time, which if practiced in civilized lands would be regarded as oppressive. Instance the North American Indians, among whom the squaws are burdened with all the drudgery, while their lords are engaged in hunting, or war, or lounging in lazy idleness. Yet they perform these services willingly, without the slightest idea of being the subjects of tyranny.

On the Darwinian standpoint even, it seems incongruous that man just out of apehood should lack the sexual adaptability which belonged to the ape in common with other animals. The subject is well illustrated in the following, from an essay on "Biology and Woman's Rights," published in the Quarterly Journal of Science (1-Xrv-203): "Persons are not, however, wanting who, while admitting the general inferiority of women in physical strength, contend that this weakness is the result of continual and systematic repression. Woman, they say, has been forcibly debarred from invigorating pursuits, and comparative feebleness is the result. We would ask whether this systematic repression has been also carried out among the lower mammals, and if nct, what is the origin of the wealsness of the female sex in their case, which is at least as well marked as among mankind? Has the subjugation of woman had its parallel in the "subjugation" of the cow, the mare, the lioness?"

My own conclusion, from all the facts known, is that the average primitive man was no less 
affectionate to his wife, nor any less in the love of offspring, than the average modern man: That in the slums of cities and on the outslirits of civilization, there are found cases of oppression and crime affecting the domestic relations, of parallel ontrage to any known among savages: That civilization, so far from changing the adaptative principle, has only changed its mode of action: That whereas primitive woman worshipped in man strength of arm and success in battle, the modern woman, for precisely the same reason, worshipsstrength of mind and successful statesmanship, oratory, authorship, etc. That, in fine, human nature and sexual adaptation have remained substantially the same from the first appearance of man to the present time.

The Darwinian theory of descent depends very much upon the question, whether adaptation to changing conditions in organic forms is sufficient: to overcome heredity. If not, such forms would physically and psychologically be held near the original types, though in many cases ia a dwarfed and deteriorated condition, in others in a more advanced condition; and others still would die out when such capacity for adaptation had reached its limits. For example, the fern which started as far back as the Devonian age, became a tree 30 to 40 feet high, but has gradually dwarfed to a plant of scant two feet. The Trilobite first appeared in the lower Silurian, reached its maximum in the upper, and disappeared in 
the Carboniferous. The horse appeared in the lower Eocene with four toes, and about the size of a fox, and has become the large, one-toed animal of the present time, the superfluous toes disappearing and the size increasing, by force of adaptation to changes in the environment.

Haeckel, however, in his "History of Creation," is positive that the existence of rudimentary and aborted organs clears up whatever mystery there may have been on the subject. His idea seems lo be that adaptation and rudimentary organs mutually explain each other; and both prove beyond a doubt Darwin's theory of descent. He says: "The widely-spread and mysterious phenomena of rudimentary organs, in regard to which all other attempts at explanation fail, is perfectly explained, and, indeed, in the plainest way by. Darwin's theory of Inheritance and Adaptation." (3-I-16).

Again: "I must here repeat that even if we know absolutely nothing of the other phenomena of development, we should be obliged to believe in the truth of the theory of Descent, solely on the ground of the existence of rudimentary organs. Not one of its opponents has been able to throw even the glimmer of an acceptable explanation upon these remarkable and important phenomena" (id. 291).

Surely this is a very convenient arrangement by which "Inheritance and Adaptation" on the one hand, and "Rudimentary Organs" on the other, are made a mutual aid society, and quite suffi- 
cient for the purposes claimed without any collateral support. Not content, however, with these pretentious and positive assertions, the distinguished Professor is impelled to carry the war into the enemy's camp in this wise: "If its opponents, the dualists and teleologists, understood the immense significance of rudimentary organs, it would put them into a state of despair," (3-I-294). Such a specimen of partisanship naturally leads to the suspicion that the anthor knows much less of the significance of rudimentary organs than he pretends.

'That Darwin's theory of descent is to some extent true may be safely conceded; that is, it may be conceded that subsequent to the primeval creations through protoplasmic matrices, no animal has ever appeared upon the earth in any other way than by birth from another animal. But this is the extent of the concession. In the case of a radically new species, the birth is indeed from an animal, but the conception, or influent life is from the Creator, the same as in the case of the lowest form of life from earthy matter.

Upon this theory (which is more fully presented in another place), it is not difficult to understand the significance of an important class of rudimentary organs. Instance the rudiment of a tail in man, - the embryo, in passing through the prior stages, exhibits the ape's tail; and this in further development to the human, is reduced to a rudiment. 
As to another class, such as the mam mary glands, in the male they belong to, and grow ont of the peculiar and fundamental relations and distinctions of the sexes to and with each other ; and these, the learned German professor is not alone in ignoring. Another class still, such as the aborted organs of sight in the cave fishes, have no significance whatever, so far as relate to the production of a new species. The organs are reduced to a rudimentary condition by simple non-use, in consequence of being deprived of light; and undoubtedly would be gradually restored, on a restoration to primal conditions.

It is well known that extra use increases an olgan to a certain extent, and that disuse will diminish it. A blacksmith, by use, increases the size and strength of his right arm to a certain maximum. These modifications from use and disuse are supposed by Darwin to be inheritable (2-122; but it may well be doubted whether they are so to any permanent degree.

A child, whose ancestors for ten generations have been blachismiths, may have a tendency to develop brawny muscles; but if he abandon the hereditary business and is of sedentary habits, his right arm will not come up to the parental standard. On the contrary, the son of a long line of effeminate ancestors, if reduced in early life to the necessity of labor, will become strong and muscular. 


\title{
CHAPTER V.
}

\author{
WHA T IS L I F ?
}

Views of Buchner and others-Speculations and Definitions of Herbert Spencer-Author's Defination.

Before proceeding further, it is important to consider the question, What is Life?

From the numberless exhibitions of it that we see around us, this question may seem a very simple one; but in the treatment of it by men of science, it is found to be sufficiently complex. Some understanding of what it is, and of its relation to matter, is quite essential to any rational theory of the origin of species.

It is quite certain that there was once a period when there was no living plant or animal-a period when the earth was a nebulous mass of heated vapor. This mass became gradually cooled and condensed; and having passed through varions changes and transformations, it finally reached a condition in which life could be sustained. Then it appeared in its lowest manifestations in protoplasmic organism, so shapeless as to be almost in. organic.

What it then was-how it came to be manifested-what it now is in the various forms of plants 
and animals, from the simplest to the most complex-whether it is ono of the qualities of matter, or something which may be distinguished from it - are among the standing problems of scientific and philosophic thought. The various speculations on the subject by distinguished men of science must necessarily be referred to and contrasted, to grive an intelligent idea of the present state of the question.

Prof. Büchner, without undertaking to formulate what he means by life, gives us some curious theorizing as to the origin of spirit or thought-terms which he evidently uses as the synonyms of Life. He says: "The brain is the sole cause of the spirit or thought; but not of the organ that secretes it." (12-13.) The inference is that spirit or thought is secreted by some gland-a mucous membrance, perhaps-stimulated by the brain. This provokes the quare whether the brain thinks what it is doing in the manufacture of spirit or thought, through the agency of some other organs; and whether, too, the brain or other parts are built into a structure, before spirit or thonght is secreted.

Again: "Thought "is the effect of the conjoint action of many materials endowed with forces or qualities" (id.-135-6). These materials, of course, reside in the brain, (that being "the sole cause of thought"') and in the secretions which it prompts. This again provokes the question, why not ana1yze the brain and these thinking secretions, collect and combine the constituent elements and produce thought? A thought mixture strong 
enough to 'resolve all the knotty questions of all coming time would not only be a profitable investment, but a great relief to the philosophic mind.

This learned Professor further assures us that"There is no such thing as metaphysical or transcendental knowledge" (id.-176). Metaphysics relate to questions concerning mind, soul, existence, perception, feeling, thought and other kindred subjects. 'Transcendental, in philosophy, is usually understood to be that which goes beyond, or: transcends the circle of experience, or what is not perceptible to the senses. All knowledge, therefore, under this assurance, is confined to the evidence of the senses: We must feel, see, hear, smell or taste the thing, or it does not exist. All philosophy-all reasoning-is thus confined in a straight jacket of nervous sensation; and we are left to marvel how metaphysical and transcendental ideas ever obtained a lodgment in the mind.

Prof. Graham (cited approvingly by Mr. Spencer), states that colloid, or jelly-like substances, are one of the forms of aggregations under which solid substances exist-the former being the dynamical, and the latter the statical condition of matter. He further states that a colloid substance possesses inergia (inherent power), and may be looked upon as the primary of the forces appearing in the phenomena of mattel (5-x-15, 16).

The author of the "Vestiges" adopts what may be called the chemical theory of the origin of life; crediting, however, to the Creator the gift of chemical qualities to matter (13.112). He cites, ap- 
provingly, the idea of Dr. Carpenter that "no reasonable ground has yet been adduced for supposing that if he, the chemist, had the power of bringing together the elements of any organic compound in their lequisite states and propor. tions, the result would be otherwise than that which is found in the living body."

He maintains that there is no distinction between vital and chemical affinities; that living structures result from a multitude of natural forces in combination; and that life and organization are essentially physical phenomena.

Mr. John Fiske adopts the idea of archæbiosis, or spontaneons generation, for the origin of life. Thus we are told: "However the question may eventually be decided as to the possibility of archæbiosis occurring at the present day amid the artificial circumstances of the laboratory, it cannot be denied that archæbiosis, or the origination of living matter in accordance with natural laws must have occurred at some epoch in the past" (14-I-430).

After detailing the process by which chemical combinations forming the crust of the earth were produced from the original gaseous form, he says: "In accordance with the modern dynamic theory of life, we are bound to admit that the higher and less stable aggregation of molecules which constitute protoplasm, were built in just the same way in which the lower and more stable aggregation of molecules, which constitute a double or single salt, were built up" (14-I-433). In this way it 
thus appears living protoplasm was the result of "carbon, nitrogen, hydrogen, and oxygen, when brought into juxtaposition," and "united by viltue of their inherent properties" (id. 433-4).

Having thus accounted for the origin of life by a kind of spontaneous generation growing out of the combination of certain substances, he yet admits-"that the ultimate mystery-the association of vital properties with the enormously complex compound known as protoplasm-remains mnsolved." (id. 434). I apprehend it will remain unsolved with a certain class of materialists until they learn to distinguish between life and form--until they learn that there is no inherent vitality in matter.

Haeckel does not appear to be troubled with any doubts on the subject whatever. True he does not imagine "cells to have arisen by spontaneous generation, but only monera, those primeval creatures of the simplest kind conceivable," and he considers the question. "Is the whole organic world of a common origin, or does it owe its existence to several acts of spontaneous generation?" of no manner of "importance." (3-II-41-2).

Again he says: "The simplest animals, and the simplest plants, which stand at the lowest point of the scale of organization, have originated and still originate by spontaneous generation."

" Every organism, every living individual, owes its existence to either an act of parental, or spontaneous generation, or to an act of Parental generation or Propagation." (3-II-183). 
This if true would convict nature of incongruity of action. If spontaneous in one or several instances, why not in all? If spontaneous in the production of the Protozua, why not in the forms which proceed from the Protozoa? If living forms have their sole origin in the forces of nature, we have the right to look for uniformity in their proluction.

To aroid the force of this objection, he says: "The mind or Psyché of man developed together" with, and as a function of the medullary tube, and just as even now the brain and spinal marrow develop in each human being from the simple medullary tube, so the 'human mind,' or the mental capacity of the whole human race, has developed gradually step by step from the mind of the lower vertebrates." (id. 451).

According to this the mind is simply a function of the medullary tube, instead of the latter being an organ by which the mind acts. This brings up the question mooted by $\mathrm{Mr}$. Spencer, whether life precedes structure, or the reverse. Iraeckel contends that those who oppose his views on the subject must suppose a period when the mind entered the brain.

Prof. Geo. W. Barker, in a paper read before the American Association, Sept. 4th, 1880, says: "Life is now mniversally regarded as a phenomenon of matter, and hence of course as having no separate existence." (41-I-113). If life has no separate existence aside from the material body, then the one dies with the other; and to say this 
is universally accepted is very wide of the truth. If he had said that life is only manifested to us through its material covering, he would have more closely expressed the general belief on the subject.

In addition to the various speculations as to the origin of Life, attempts have been made to distinctly define it.

Schelling said: "Life is the tendency to individuation." According to Richerard : "Lile is a collection of phenomena which succeed each other during a limited time in an organized body." According to DeBlainville: "Life is the two-fold internal movement of composition and decomposition, at once general and continuous." As G. H. Lewes defines it: "Life is a series of definite and successive changes, both of structure and composition, which take place in an individual without destroying its identity." *

Herbert Spencer questions the correctness of these several definitions, and refers to an article in the Westminster Rev. for April, 1852, in which he formulates Life as "the co-ordination of ac. tions." And says: "I still incline towards this definition as one answering to the facts with

* The following in italics from Haeckel (3-I-335) will probably amuse, quite as much as instruct, the reader: "The peculiur "chomico-physical properties, and especially the simi-fuid state of ag"gregation, and the early decomposibility of the excedingly com"posite albuminous combinations of carbon, are the mechanical causes "of those peculiar phenomena of motion which distinguishorganisms "from anorgana, and which in a namow sense are called life." 
tolerable precision." He further says in its favor: "It includes all organic changes alike in the viscera and the brain. It excludes the great mass of organic changes, which display little or' no co-ordination. By making co-ordination the specific characteristic of vitality, it involves the truths, that the arrest of co-ordination is death, and that imperfect co-ordination is disease."

Yet he admits that like the other definitions, it includes too much; for it may be said of the solar system, with its regularly recurring movements, and its self-balancing perturbations, that it also exhibits co-ordination of actions." (5-I-60).

$\mathrm{He}$ then considers the definition of $\mathrm{G}$. H. Lewes: That part of it which states the persistence of a living oryanism as a whole, notwithstanding these changes, he regards as important. Yet he thinlss it faulty in not excluding--" the more visible movements with which our ideas of life are most associated"-and, too-" in describing vital changes as a series it scarcely includes the fact that many of them, as Nutrition, Respiration and Secretion, in their sub-divisions, go on simultaneously" (id. 61).

Alleging that no one of these definitions is more than approximately true; and admitting that it may be impossible to find a formula which will bear every test, he nevertheless claims that a more adequate formula may still be found. In pursuit of this Mr. Spencer starts with assimilation as an example of bodily life, in connection with reasoning, as an example of that form of life 
known as intelligence. He considers the vital and non-vital changes arising from nutrition, connected with its transformation into tissue. "VVithout change food cannot be taken into the blood, nor transformed into tissue; without change there can be no getting from premises to conclusions." These changes are successive and simultaneous, and the first formula from a consideration of these examples runs thus: "Life consists of simultaneous and successive changes" (id. 65).

He next finds "That vital changes, both visceral and cerebral, differ from other changes in their heterogeniety," and from this stand-point the formula is: "Life is made up of heterogeneous changes both simultaneous and successive" (5-I-66.)

But looking at "some point of agreement be. tween the assimilative and logical processes," and distinguishing them from inorganic processes, he discovered that they are distinguished by the "combination subsisting among their constituent changes," and then the formula is, "Life is a combination of heterogeneous changes both simultaneous and successive" (5-I-68).

Then occurs the idea of definiteness as peculiar to the phenomena of life; and this is illustrated by the example of a glacier in which the changes go on in an indefinite manner. So, too, decomposition, which, though exhibiting both simultaneous and successive changes, "which are to a certain extent heterogeneous, and in a certain 
sense combined in a definite manner ;" and the formula with this addition reads thus: "Iife is the definite combination of heterogeneous changes both simultaneous and successive" (id. 69).

It seems however that the end is not reached yet--that the is to be preferred to a because the definition is defective both in allowing that there may be other definite combinations of heterogeneous changes, and in directing attention to the heterogeneous changes, rather than to the definiteness of their combination. Thus finally manipulated, " Life is the definite combination of heterogeneous changes, both simultaneous and successive" (id. 69, 70$)$.

Yet this, after all, proves, in the mind of the author an incomplete conception. Hesays: "The ultimate formula" (which is to a considerable extent identical with the one above given) "is, the co-ordination of actions, seeing that 'definite combination' is synonymous with 'co-ordination," and changes both 'simultaneous and successive' are comprehended under the term 'actions,' but which differs from it in specifying the fact that the actions or changes are heterogeneous, this ultimate formula I say is, after all, but proximately colrect" (id. "76).

I'rue, he continues, it does not fail "by including the growth of crystal," nor "the action of a galranic battery," nor "the motions of the solar system," nor "those of a watch and a steam engine, \&c., but "it fails from omitting the most distinct peculiarity of which it is the most 
distinctive expression," "such as the readiness with which in common life we distinguish between living and dead objects." Yet, alter all this elaboration, he says the formula fails to convey a complete idea of the thing contemplated; and to remedy this he takes into the account the effect of the environment upon the living organism, producing an adjustment of internal to external relations. Thus supplemented, "Life becomes the definite combination of heterogeneous changes, both simultaneons and successive, in combination with external co-existences and sequences" (5-I-74). And simmering the matter down still further, he finally gives, as the broadest and most, complete definition of life, "The continuous adjustment of internal relations to external relations" (id. so.)

This, then, is the best which the most acute reasoner of the age can do for us on this all important question. One may well be pardoned in regarding the "Parturient montes nascitur ridiculus mus" of ancient satire, as giving quite as substantial an idea of life, as shown by the parturient labors of modern materialistic philosopophy. The mouse was one form of the manifestation of life in connection with matter, and what more has Mr. Spencer given us in all these changing definitions, The question at issue is-what is Life? and in answer he gives us a formula which shows that life, as manifested in a living body, can only continue such manifestation while there is an adjustment of internal to external relations. 
In other words, it can only be manifested through matter under certain conditions. He does not give us an idea of what life $i s$, but only the conditions of its manifestation.

If life is only one of the qualities of the aggregations of physical matter found in a living organism, it would stand on the same plane with the other qualities of color, density, attraction, repulsion, \&c., and the formula would be approximately correct. But if it be an entity distinguishable from its physical clothing, then the formula amounts to nothing; and this is the very point now to be considered.

A living animal manifests life by an organism composed of materials of which we are able to discover the constituent elements. We can analyze flesh, blood, bones and hair. The animal dies, but the body remains for a time an organic structure, as before, the life only-that which moved and controlled it-being gone. The question is, what is that which has disappeared, as distinguished from the lifeless body?

After the life leaves the body the latter decays, and is found to consist of certain elementary substances-oxygen, hydrogen, nitrogen, phosphorus, \&c. These substances disintegrate from each other' and instead of being destroyed enter into new combinations. The body was built up from these substances by the life, and falls to pieces, so to speak, when the life leaves it. This life has never been obvious to the senses in the same way in which these elementary substances are ob- 
served ; but we witness its phenomena in connection with the body, and we are conscious ourselves that we live.' Hence, the inference that life is a something-a force-a power-superior to its elemental clothing; and that it has a conscious existence which the body has not.

The materialist, pure and simple, can never extract life from, nor discover its elements in, dead matter, whether colloid or crystalloid, any easier than a hen can hatch a chicken from a porcelain egg. The chicken is developed from a cell or egg, which already contains its appropriate life, and that is the case with every organic structure.

As before stated, we can describe the phenomena of matter containing life, and we can analyze matter devoid of life ; but the question returns, What is life by itself? What, in fine, is the difference between mind and matter?

The fact is well established that the egg or cell which is the initial point of one life, is apparently exactly similar to that of every other. Take two cells starting with vitality at the same time, and watch their development. One very soon grows into a butterfly. The other has a longer jonrney before it and travels more slowly; and passing through various embryological transformations, puts on the form of an elephant. The one flutters through its existence in a month-the other lives a century. Take two other cells, simultaneously starting with vitality. One soon produced the humble, though beautiful lily, which matured and perished in a fortnight - the other through a series 
of year's developed into the sequoia gigantea, which still lives, though it commenced thousands of years ago. It is quite certain that life was the starting point, without which neither structure could have been originated or developed. To say that these germinations and transformations are owing to some inherent force in matter fails to satisfy the mind. We immediately seek to know how it came to be invested with such force-how it can so nicely discriminate as to produce one form from one set of atoms, and another and different form from an exactly similar set.

Mr. Spencer propounds the question, "Does life produce organization, or does organization produce life?" and sums up the matter thus: "It may be argued that on the hypothesis of evolution, life necessarily comes before organization. On this hypothesis organic matter in a state of heterogeneous aggregation must precede organic matter in a state of heterogeneous agrregation. But since the passing from a structureless state to a structured state is itself a vital process, it follows that vital activity must have existed while there was yet no structurestructure could not else arise. That function takes precedence of structure seems also implied in the definition of hfe. 'If hfe consists of inner' actions so adjusted as to balance outer actionsif the actions are the substance of life, while the adjustment of them constitutes its form, then may we not say that the actions to be formed must come before that which forms them- 
that the continuous change, which is the basis of function, must come before the structure which brings function into shape." (5-II-167).

This is sufficiently clear and satisfactory. But then arises the question: How did life originate; where did it come from?

On this point the mind of Spencer is very much at sea, as appears by such utterances as these: "We must admit that a plant or animal of any species is made up of special units, in all of which there dwells the intrinsic aptitude to ag. gregate into the form of that species, just as in the atoms of a salt there dwells the intrinsic aptitude to crystalize in a particular way." "It is difficult to conceive that this is so, but we must see that it is so." (Id. 181). Again: "Conclnsive proof obliged us to admit that the component units of organisms have inherent powers of arranging themselves into the forms of the organisms to which they belong." (ICl.220).

Evidently all this is equivalent to saying that life is a quality of certain portions of matter which prompts them to combine into an organism, upon the same principle that certain substances, liaving chemical affinities, unite and form a new compound; and is not one whit in advance of Büchner's idea that spirit or thought is secreted by some one or more organs of the body. If this be true, how can there be nervous sensation in an animal organism, any more than in a quartz crystal, or in a quantity of common salt, or in any other aggregation of matter? 
It is quite evident that no animal form was ever yet initiated and developed without life; and the point to be considered is, how life came to be connected with an incipient organism. The question is evidently narrowed down to this point: Either life precedes structure, and stands to it in the relation of a cause to its effect; or it is merely one of the properties of matter correlative with density, gravity, \&c. Regarding the question as settled, that life precedes organization, repudiating utterly the idea that it is merely one of the qualities of certain portions of aggregated matter; and assuming that there is a personal Creator, I venture to give the following formula :

Life is the immaterial and active principle of individual, or differentiated being, which flows in from the Creator, having the function to put on and control a material organism corresponding to its identity.

'Take the case of the Protamoba, a mere globule of transparent jelly, scarcely visible to the naked eye and aptly termed "an organism without or gans." It has neither mouth nor stomach, but nevertheless expands itself in various directions, putting out a kind of false feet, keeping up a continued movement of protrusion and retraction, and incloses and assimilates the diatoms with which it comes into contact. In this way it increases in size and forms a ball, which finally breaks up and forms a certain number of independent moners.

This is a case, and it may be the very first, of the inflow of life from the Creator into a matrix 
of dead matter, resulting in the creation of an animal. And to the same process, though varying vastly in degree and receptacle for influent life, is due the existence of all vegetable and animal forms. It is, so to speak, the psychological part of organic existence. It is potentially differentiated at its inception, as instance the initial germ of a horse, though differing in appearance in no respect from that of a mouse, developes into a horse and nothing else. Being precedent to form, it puts it on, and life and structure are developed together. Every life is initiated by the Creator with a definite purpose, and puts on a form corresponding to its lind, and the uses it is intended to perform in the checks and balances of an animated existence. As the life matures the body grows, the one standing to the other in the relation of a cause to its effect.

The body is constructed on a system of repair and waste, and during growth the repair exceeds the waste. After full growth the repair and waste are equal until decay sets in, and then the waste exceeds the repair; and this goes on until the death of the body. If a perfect equilibriu in conld be kept up between the two, life in a physical structure might be indefinitely prolonged.

Mr. Spencer, on the assumption that life is "The adjustment of internal relations to external relations," holds that, "Were there no change in the environment, but such as the organism had adapted changes to meet, and it were never to fail with the efficiency with which it met 
them then, there would be eternal existence and universal knowledge" (5-I-80-SS).

The fact that such a case has never yet occurred is pretty good evidence that it never will; and the added fact that the earth does not contain standing room enough for one-eighth part of the human beings that have lived and died upon it, proves that the creation of human life is under a litw which precludes its perpetual existence in a physical body.

Why particles or atoms of matter should come together in the construction of organic forms, involves some points which Mr. Spencer finds it difficult to explain. But if life precedes organization, as he has been forced to admit (5-I-153-167), then the latter could never be constructed without the former; and the convenient suggestion that the process is initiated and perfected by the "intrinsic aptitude," or the "inherent powers" of certain portions of matter, would be the final end of materialistic reasoning upon the subject.

That life, vegetable or animal, puts on its corresponding form, shows a causation for such form beyond the reach of external sensation. And we must either assume that the atoms which originate and perfect the physical structure are selfexistent, and have sufficient intelligence to build up any given organism, or we must infer the existence of a distinct and personal creative power adequate to produce all the results which fall under our observation. To measure the dis 
tance between such a power and the human intellect, we must imagine a human brain capable, not only of producing the materials, but of forming and controlling a physical universe. 


\section{CHAPTER VI.}

DIFFERENCE BETWEEN ANIMLAL AND HUMAN LIFE. Animal Life Fractional-Man's Life more than the sum of Animal-

Difference between Mind and Instinct-Difference as to Language.

Having defined what we mean by Life, the next question relates to the difference between animal and human life; and this it will be found has much to do in testing the correctness of the Darwinian theory.

When we look at animals divided into species. as we find them, we are struck with the manifest difference of one life from another-a difference in many cases completely antipodal. The carnivorous animals, though much alike in their mode of subsistence, have nevertheless distinct traits of difference. 'The tiger, hyena, wolf, fox, \&c., all differ from each other by lines which are never crossed. The same may be said of the individual members of the great classes-the sheep, ox, deer, elephant, horse, ape, crocodile, anaconda, bee, ant, hornet, and so on through the entire and almost interminable zoological catalogue. The life of each is distinct from that of each other, and each 
puts on the corresponding organic form manifested to us.

When we regard the life of man, we find the curious fact that it is complex, and comprehends within itself the qualities of all the lower animals -the ferocity of the tiger, the quiet inoffensiveness of the sheep, the thrifty saving habits of the bee, the cunning of the serpent, \&c. In this, human life differs from that of all below. Animals exlibit a single characteristic. No one looks for mercy or mildness in the tiger, or ferocity in the hare-the one is carnivorous and the other herb. ivorous, without adnixture with other qualifications, and so they remain. A man, however, may be vindictive and cruel to-day, but at a future day forgiving and benevolent. History is full of examples-such as Howard, Nero, Washington and Tamerlane. The mental qualifications of man therefore are elastic and expansive, and capable of change from the lighest point of excellence and power, to the lowest descent of degradation and imbecility.

Animal life, as above stated, is not a whole life - it is only a fraction, each radically differing: from that of the other. The moner is but a small fraction-the amphioxus is larger, the elephant larger still, and the gibbon larger than the elephant. From the moner up to (but exchnding) man, is an ascending scale of fractional life, each one of which appears to be psychologically incapable of improvement beyond certain limits; but when we come to man we find a whole number composed of 
the summing up of all the animal fractions, with the superinduced human element, and forming a life capable of improvement. Imagine the earth just before the birth of man, and look at it nowlook at all that was performed by united animal life to and including the highest ape, and contrast it with all that has since been done by man, and escape the conclusion if you can, that animal life is but the basement story, and man's life the entire vital structure!

If man's life consisted only of the aggregate of the animal fractions, he would still be an animal ; but would have the combined qualities of all other animals - a combination of antagonisms and contradictions. As well suppose an animal combining the deer and the wolf in full activity at the same time-a thing wholly unthinkable. But the superadded human element is a controlling power, which reigns supreme over every animal instinct; and subordinates all for the time to some one. prominent desire or purpose. This ruling desire may be good, or it may be evil-that is, a man may be a Nero or a Washington-the woman a Lucretia Borgia or a Florence Nightingale. "Hence the almost infinite mental differences between the extremes of grood and bad, strong and weak. An evil disposed man is as much more to be dreaded than the most ferocious beast, as the size of the brain of the one exceeds that of the other; be. cause to the pitiless ferocity of the tiger is added the porver of combining and using the elements of destruction. 
- The dominant part of man's life, without the complex basis of the animal, would lack completeness; and thus isolated would compare with an edifice without a foundation, -it would lack the necessary connection to give it a physical abiding place. The instincts in each animal are like the isolated parts of a machine-the lever, wheel, shaft and piston; while in man these parts are placed in proper juxtaposition, and the machinery becomes complete.

This microcosmic nature of man is thus noticed by Oken: "Man is the summit, the crown of nature's development, and must comprehend every thing that has preceded him, even as the fruit includes within itself all the entire developed parts of the plant. In a word, man must represent the whole world in miniature." (15-2).

A general difference between men and animals is thus expressed by Quatrefages: "The latter have only physical wants, which they satisfy as compietely as possible. But this end thus attained, they go no further. The animal when left to itself does not know, or has scarcely any suspicions of the superfluous. His wants are therefore always the same. Man on the contrary, whether mind or body is in question, is always seeking the superfinous, often at the expense of ntility, sometimes to the detriment of the necessary." (The Human Species, 457).

It is a fundamental doctrine of Darwin that species are mutable, and that forms and life as well are transmutable. In view of the broad dif- 
ferences presented to us of life as well as form, it is difficult to see how such transmutation could be effected-how an inoffensive animal like the deer can be transmuted into the savage nature of the wolf, or the reverse. Nor does there seem to be anything in the vast array of facts gathered by him which in the remotest degree accounts for a change so radical.

Man as to his body is an animal of the class Mammalia. He has similar organs; is composed in the same way of flesh, blood and bones; the elements forming these-carbon, oxygen, hydrogen, nitrogen, \&c., are the same; and at death his body falls into dissolution precisely as in the case of the ox or the horse. So, too, as to the external or lower region of his mind, he has the same appetites; he eats, drinks and sleeps, and to this extent he is psychologically to all intents and purposes an animal. That this is so is illustrated by the case of a person insane from such derangement of the brain as hinders or destroys the working of the intellectual faculties; and such ii is well mnderstood are held irresponsible for their acts before the law. So too in the case of microcephalous idiots, in which the cerebrum is so defectively organized that the mind either does not exist, or cannot act. In these re practically have animals with human bodies. Darwin calls these idiots cases of reversion to the ape; but they seem to me cases of nori-development. If they were reversions they would at least have the instinct of the ape. 
But there are some other distinctions between human and animal, which it is quite essential to consider.

The author of the "Vestiges" says: "The difference between mind in the lower animals and in man is a difference in degree only, it is not a specific difference" (282), meaning by lower animals all below man. According to Darwin: "The difference in mind between man and the higher animals, great as it is, is certainly one of degree and not of kind " (9-I-101).

This makes the mind of man to be nothing more than a developed instinct; and both these distinguished authors (especially the latter') refer to a multitude of instances in support of the idea in which sundry animals have manifested memory, attachments, dislikes, vengeful feelings, and in a few cases some glimmerings of judgment or reason; all of which, by the way, may be accounted for by the fact that man in the lower region of his mind is an animal.

The idea that the mental differences of men and animals are of degree only leads to some curious results. The mind of the fox, for instance, is the same as that of a man, except. the former has a thimble full, and his highest achievement is to depredate upon the farmer's hen roost, whereas the latter has a pailful, under the force of which he is able to measure the solar system and accomplish numberless other kindred results. The quality is the same, but the quantily makes all the difference imaginạble; 
That there are traits in the human which differ in kind from any found in the animal mind, is as self-evident as that a given quantity of water differs from a like quantity of alcohol, or that a single color differs from the combined colors of the rainbow. It may be safely assumed, that the mind of every living organism is measured by the organs by which it is to be carried into effect. The dog is destitute of the organs by which to paint a picture, or construct a house ; and the fair inference is that he has no mental conception of either. Man has the organs which enable him to paint and construct, and he does both by ultimating his previous mental conceptions.

There are certain broad facts bearing upon this subject, which makes it very difficult for us to regaid these differences in mind, as we look rupon that between homoopathic and allopathic doses of medicine Looking at animal and human life at their initial points, we find some peculiarities that do not appear to have been sufficiently regarded by these learned authors. The question involved is the distinction between what we call instinct in animals and mind in man.

First, as to instinct, it may be stated as a rule without exception, that all animals below man are brought into being with all the linowledge or science necessary for their existence and propagation.

Under this rule each type of a distinct species of animals is cieated or produced in the most advanced state, mentally, of which it is capable. It 
reaches its limit, so to speak, at one bound, and can learn nothing more which enables it to pass the line between instinct and mind. The beaver without the slightest tuition or training knows how to build its dam; and as it built it in the time of Cheops, it builds it to day. The bee and the ant among the articulates furnish noted examples. Both have been known from the commencement of historic time, with no essential increase of their wonderful instinctive linowledge, beyond that now exhibited by them.

The following extract from a paper read before "The British Association" by Mr. D. A. Spalding, showing the results of actual observation and experiment, in relation to the instinct of fowls, will further illustrate the subject (1-II-56]):

"Chickens kept in a state of blindness by various devices from one to three days, when placed in the light under a set of carefnlly prepared conditions, gave conclusive evidence against the theory that perception of distance and direction by the eye are the result of associations formed in the experiences of each individual life. Often at the end of two minutes they followed with their eyes the movements of crawling insects, turning their heads with all the precision of an old fowl. In from ten to fifteen minutes they picked at some object, showing not merely an instinctive perception of distance, but an original ability to measure distance with something like infallible accuracy." 
"A chicken at the end of six minutes, after having its eyes unveiled, followed with its head the movements of a fly twelve inches distant, at ten minutes the fly coming within reach of his neck was seized and swallowed at the first stroke."

"A duckling one day old, on being placed in the open air for the first time, almost immediately snapped at and caught a fly upon the wing."

It may be added that it has been a common practice to hatch the eggs of turkeys and geese under hens. The turkeys and goslings so hatched will follow and brood under the hen for a timeyet no instance has ever been known in which any of such broods have adopted a single habit peculiar to the hen.

Instinct includes a memory which acts within the limits necessary for prescrvation and propagation. A cow will remember and resort to her feeding and watering places. So a horse, left to itself, will diverge on a level road from a direct one rising a hill. It is true, by means of memory, some animals are capable, to a certain extent, of learning to do things which are not useful to them. The tricks taught to dogs, and the feats of horses and other animals in a circus are familiar instances; and it is doubtless true that these performances become so far hereditary that the offspring are more easily taught in the same direction. But there is no evidence that any of these acquired traits becomeso fixed as to be permanently transmitted by heredity-the evidence is the other way. 
The animal mind or instinct has also sufficient range to adapt itself, in some degree, to circumstances. Pouchet, misled by this adaptibility, undertakes to prove that it is sufficiently elastic to improve indefinitely. He instances the European beaver, in that it burrows long galleries under ground, whereas its American confrere builds a dam, and this though the difference in organization is slight(1-Irr-151). But does not the latter burrow in addition to its darm-building? And would not the former build dams if it had the same facilities? The instinct of both is to burrow; and it is followed out by both with the differences arising îrom adaptation. Again, upon the hypothesis that there have been independent creations of fauna and flora in widely separated regions, the instinct of animals of kindred species might well have shades of differences suited to the environment.

Pouchet instances, also, that certain hymenopterous insects lay their eggs in little chambers formed of rose-leaves (1-IIr-157), but use other leaves when the rose is not to be found. This is very illustrative of adaptability. The instinct is to use some kind of leaf, and the rose-leaf being the best for the purpose is used when rose-leaves abound, just as a curculio will prefer a smooth coated plum or apricol to a rough-coated peach, but will resort to the latter in case of necessity. But with all the aids of memory, the boundary line of instinct is never crossed. 
Instinct in young animals is attempted to be accounted for by some, on the supposition that the male progenitor desired to do the act, and acquired the power by gradual effort; and this by repetition became fixed and was transmitted by heredity. But, then arises the question-how did this progenitor form the original idea-how did the remote turkey learn that the fly was its appropriate food, and that it could be caught in the way described? If such a capacity to try experiments existed, why has it not been improved and expanded, instead of becoming a fixed instinct?

Second, as to the human mind. If man comes from the ape by natural selection the human infant ought to be born with all the knowledge of the infant Gibbon or chimpanzee, to say the least; but the very reverse is the fact. The infant man presents almost a blank as to mind and an ntter helplessness as to body.*

Prof. W. Pryor has recently made it a study to trace the development of the human infant, and for that purpose he has closely observed a child from birth, almost daily, for about two years. The results of his observations appear in an article entitled "Psychogenesis in the Human Infant" (XVII-625). The following is a brief summary of his observations:

At first it was utterly helpless, and without any manifestations of mind. The first apparent exercise of will was at the end of fourteen weeks, when it began to lift up its head; and it was not until four months that it could keep its head well balanced. The power to sit up was acquired about the tenth month; and the ability to stand at the end of the first year. The imitative faculty did not begin until the second half year. For months it did not know that its arms and legs and feet belonged to it; and in the fifth quarter year it bit its own arm and cried from the pain. It was not until the end of the fourth 
About the only instinct he manifests is that of suction, and that is acquired by previous habit as a fótus. There is a brain containing an incipient mind, to be thereafter slowly developed. Animals are emotional, because they have no understanding; or in some exceptional cases, beyond the circumscribed knowledge which we call instinct, a mere trace of one. The infant man, on the contrary, has an understanding, which from a mere point as it were, gradually grows and matures; but before it becomes strong enough to exercise a controlling influence, he acts from emotion and impulse like an animal. In familiar phrase, man may be called a two-storied animal, all other animals in the complex forming but one story; and this lower animal story is the kase or mud sill, on which the upper--and properly human storyrests. The result is, the animal stops about where it begins; the man starts from next to nothing, and keeps on growing; and this is substantially admitted by Darwin when he says: "He (man) has to learn his work by practice; a beaver on the other hand, can make its dam or canal as well or

month that it raised its arm, with the appearance of longing for its parents.

It was born without language of any kind, and subsequently acquired it by the exercise of imitation. At first only rowel sounds were uttered. For the first six months, its prattling could not be represented on paper. Imperfect imitations of sound were noticed at the end of the first six months; great progress was made in it after the third half year; and the power of articulation became well developed at the beginning of the fourth half year. 
nearly as well, the first time it tries, as when old and experienced" (9-I-83).

Another marked distinction between men and animals, is that the former has speech; whereas the latter, being destitute of an understanding, with the exception before noticed, has emotional cries and calls only. These constitute their language; and they luave it in perfection without tuition. The hen has a call for food, which her chickens at once understand; and they recognize too, her cry of alarm as completely when first hatched as ever atter.

It may, I think, be assumed as a general rule, that every living organism can express by signs, or vocally, all its emotions and thonghts. And it is because man has emotions and thoughts infinitely beyond that of the highest mammal below him, that he possesses the necessary vocal organs to give them expression; and this accounts for the origin and growth of language. It is true a few animals like the parrot possess the power of imitating articulated sounds; but it is mere imitation without the slightest understanding of what they mean. 'The power', too, is limited and cannot by any amount of training be forced bey ond a certain extent. If these articulations indicated an approash to language, on the transmutation hypothesis, "Natural Selection" committed a serious blunder in not selecting the larynx and lips of the Chimpanzee and Gorilla for the purpose instead of the throat of the parrot.

The languages of the human races vary, there 
being about as many langnages as races; and among the same races there are different dialects in different provinces, often so much marked as to make confusion. Humain languages, too, grow from small and rude beginnings, and become refined and polished.

On the other hand the languages of animals do not essentially vary, each species having its own which never changes or improves to any appreciable extent, and each one is perfect in it without tuition, grammer or dictionary. The dog expresses what ideas and emotions he has by growls, barks, whimpers and wags of his tail now, as he did 3,000 years ago. Similarly the horse neighs and whinnies, the cow lows, and the hen clucks to her chickens; and when any of these animals are removed into different regions, they can hold converse with their kind without the aid of an interpreter. With man the case is widely different. In a supposed primitive state, the first spoken word must have been a sound uttered to express an idea, or an emotion-a sound appropriate to the mind of the utterer; and this became the proper word for the same emotion or idea when adapted by common use. Man thus makes his own language; and the result is a language in one tribe or nationality different from that of another. An Englishman speaks a language different from that of Moses. He cannot converse with a Frenchman without the study of another language, or the aid of an interpreter; nor can he read the Fneid 
or the Iliad without spending a weary period in mastering the words contained in the pages of those works.

Whether primitive man was born, or created, already gifted with a regularly constructed language is one of the questions which have vexed philosophers not a little. I think the weight of evidence, and all analagous reasoning as well, are against it. It is inconsistent with the diversity of languages which now exists; and it is wholly irreconcilable with the fact that every child has to be taught its mother tongue. The truth is, so far as we have any knowledge on the subject, language miversally grows from mere rudimentary beginnings like every thing else ; and changes with the changing currents of thought. An Englishman of the age of Chancer would need an interpreter to be understood by his countrymen of today. It would indeed be as incoifgruous to look for a marble palace in the stone age, as to suppose the men of that day possessed of the polished diction of Milton or Everett.

Languages formed by isolated cognate races would be more or less similar, because the structure and capacity of the mind would be nearly related; and similar sounds would be chosenenough, at any rate, to furnish philologists a plansible show, that the languages had a common origin. This accounts for similar words now found among peoples far separa ted geogra phically; and shows that language alone is not to be relied upon to prove a common origin of race. 
The thoughts and emotions of the human mind will force themselves into vocal expression, with as much certainty as a tree will produce foliage and flowers. If a thousand children of both sexes could be isolated, and left to grow into a community, I apprehend a language would be formed suited to their wants, and grow with their mental development; and their language too, except in some emotional expressions, would differ from that of another community similarly situated in a different locality. How they would be able to communicate their ideas to each other by speech in the first instance we can understand just as easily as we can understand how animals have cries and signs by which they can be understood by each other ; or how each form of life puts on its own appropriate material organism.

Now to apply this to the Darwinian theory. It must be borne in mind, that the advance by natural selection is extremely slow. The distance between the instinctive cries and calls of the highest anthropoid ape and human speech is immense; and to fill it up by slow increments would require a length of time antedating the existence of the most inferior ape. Not only so, there should be found in living apes from the lowest monkey to the gorilla advancing approaches step by step to human language.

In reference to the origin of language, the power of uttering it to express the emotions and thoughts of the mind, must have been given to man as an essential part of his existence. This 
would seem to be evident from the fact that the organs necessary for that purpose are given him, just as organs are given to animals to utter such sounds as are fixed by the animal instinct in each case.

Darwin, after referring to several authors on the subject, says: "I cannot doubt that language owes its origin to the imitation and modification, aided by signs and gestures, by various natural sounds, the voices of other animals, and man's own instinctive cries. In this connection he fancies it-' not altogether incredible, that some mnusnally wise ape-like animal should have thought of imitating the growl of a beast of prey, so as to indicate to his fellow monkeys the nature of the expected danger, and this (he says) would have been a step in the formation of language.'", $(9-I-54-5)$. The fact, however, that monkeys, though adepts in imitating acts, have no genius for imitating sounds, is not quite consistent with this fanciful idea.

The truth is, Darwin is not clear in illustrating the method in which human speech could have originated by evolution from the ape. He says: "The fact of the higher apes not using their vocal organs for speech, no doubt depends on their intelligence not having been sufficiently advanced." (9-I-57.)

The inference from this is that human language cannot be formed without intelligence-an intelligence higher than the ape. Yet we find him saying: "Withont the use of some language, how- 
ever imperfect, it appears doubtful whether man's intellect could have risen to the standard implied by his dominant position at an early period." (9-I-206.)

Evidently here is a confusion in his mind as to whether language is due to intelligence or intelligence to language. Surely, if the formation of language depends on intelligence, then the same thing is essential for its improvement, as is evident from the fact that language remains nearly stationary among races of a limited capacity for improvement. *

Again, as indicating the very initiament of speech, he says: "Although the sounds emitted by animals of all kinds serve many purposes, a strong case can be made that the vocal organs were primarily used and perfected in relation to propagation of the species." (9-I-315.)

*In this connection, it is interesting to note the result of more recent researches among savage tribes: Thus in "The Bible and Science," by T. Laudor Brunton, (p. 242), we are told that animals can " none of them, draw a figure or write a line, whereas the Bushmen draw figures, with considerable accuracy, and group them together so that their fellows who come afterwards may understand the history or train of ideas which the draughtsman intended to communicate."

Again, in the "Origin and Growth of Religion," by Max Müller, (p. 67-68): "Let us examine a few of the prejudices commonly entertained with regard to these so-called savages. Their languages are supposed to be inferior to our own. Now, here the science of language has done some good work. It has shown, first of all, that no human beings are without language, and we know what that, means. All the stories of tribes without language, or with languages more like the twitterings of birds than the articulate sounds of human beings, belong to the chapter of ethnological follies." 
This appears to be wholly without foundation, so far certainly as the animals of the vertebrate class are concerned. In man the sexual appetite is not developed until long after a full development of the voice and language. A chicken has a voice and language as soon as hatched; but its sexual instinct does not appear much snort of three months thereafter; and the same is true of the mammalia, except that with them the manifestation of the like instinct appears at a much later period. It is quite safe to say that there is no instance among mammals in which the sexual appetite antedates the roice.

It seems to me, also, that this great author is equally at fault in reference to the improvement of the animal voice under domestication. Instance again the dog, of whom he says: "It is a more remarkable fact that the dog since being domes. ticated has learned to bark in four or five distinct tones. Although barking is a new art, no doubt the wild species, the parents of the dog, expressed their feelings by cries of various kinds. With the domestic dog, we have the bark of eagerness, as in the chase; that of anger; the yelping or howling bark of despair, as when shut up; and that of joy, as when starting on a walk with his master; and the distinct one of demand or suppiication, as when wishing for a door or window to be opened." (9-I-52.)

The dog has been domesticated for at least 4,000 years, and we have no acconnt, nor is it possible to have any, of the habits, or the vocal expres- 
sions of the wild dog or dogs, from which the varieties of the species have been derived. When, therefore, Darwin speaks of barking being a new act, it appears very much like assumption; nor is there any evidence that the five kinds of barks specified have not been the normal and usual barks of this animal at and since the time of its first domestication. *

Suppose these barks to have been the effect of domestication from the more rude cries of the wild race, they are, after all, only so many varieties of tone, expressive of different emotions; and if they furnish any proof of the method of introducing human speech, they should be found more distinctiy developed in the Lemurida, and from thence increasing in variety and complexity in the monkey tribe, in each advance by natural selection towards man. But this is found not to be the case. On the contrary, the ape race seems to have less-certainly not more-of this supposed variability of the voice than the dog. Yet, when we come to human speech even among savages, the difference is so radical, as to have induced the belief of its divine origin. F. Von Schlegel says: "In those languages which appear to be at the lowest grade of intellectual culture we frequently observe a very high and elaborate de-

* On the subject of the descent of dogs from one or more original stocks, Darwin says that "at a period between four and five thousand years ago, various breeds, viz., pariah dogs, greyhounds, common hounds, mastiffs, house dogs, lap dogs and turnspits existed more or less resembling our present breeds." (33-I-30.) 
gree of art in their grammatical structure.' $-\mathrm{I}-59$.

Nevertheless, Darwin cannot see in articulate speech "any insuperable objection to the belief that man has been developed from some lower form," on his theory.

Dr. W. Lauder Lyndsay, in a work in two volumes (1880), entitled "Mind in the Lower Animals," shows himself an enthusiast in the idea of the existence in animals, of that which we call mind in man. The work is of ability and extended research, in which it would seem that all the facts in the way of humanizing animals have been brought together. Yet he makes the following remarkable admissions :

Civilized man possesses the following elements of superiority over other animals :

1. 'Ihe power' of speech.

2. 'The use of hands.

3. The knowledge of the arts of: $(\alpha)$ writing, (b) printing, (c) metallurgy, (d) glass making, (e) cooking.

4. The production and application of fire.

It is impossible for man to realize the magnitude or importance of these advantages in the development of his moral and mental nature, and to make due allowance of the disadvantages under which other animals labor in the non-possession of these accomplishments. (Vol. II-119.)

This is substantially an overthrow of his theory. The lowest man is capable of civilization to a certain extent; and to that extent possesses these elements of superiority over the highest animal. 
Hence between what we call mind in man, and instinct in animals, there is a gulf which cannot be bridged over. It is difficult, too, to understand how animals are subject to disadvantages in consequence of not possessing these elements of superiority. Of what benefit world speech and writing be to a monkey in the absence of that degree of mind requisite for their use? The substance of the author's idea seems to be that animals suffer great disadvantages because they are not men! 


\section{CHAPTER VII.}

Difference between Men and Animals in Brain Capacity. Difference as to the Marriage Relations.

In connection with the remarkable distinction between men and animals in respect to language may be regarded the difference between the animal and human brain. The development and growth of the brain from its initial point, is one of the most interesting subjects of inquiry in natural history.

The amphioxus lanceolatus, which has a spinal cord without any skull or brain, appears to be the introduction to vertebrate life. In advance of this, certain fishes develop a cartilagenous primordial cranium, with or without organic ossification, but withont cranial bones (18-24). And generally the brain of a fish is very small compared with the spinal cord. The relative size is increased in reptiles. The lowest mammals, such as the opossums and kangaroos, advance in this respect. In placental mammals a new structure appears between the cerebral hemispheres connecting them together, called the great commissure, or corpus callosum. By this connection the progress of the brain, step by step, is traceable from the lowest rodent to man. 
In the lowest and smallest placental mammals the surface of the cerebral hemisphere is smooth or rounded, but in the elephant, porpoise, higher: apes and man, it becomes a labyrinth of tortuolis foldings (18-60). The more tortuous the foldings, - the larger the cerebral surface; and it is a question how far this extent of surface, in connection with bulk, is an index of mental superiority.

'I'he brain of the elephant exceeds that of man in size; but the body of the former is of much greater bulk than the human body. The comparison of brain size, therefore, it would seem, must be made in connection with the size of the body, when the comparison is between the human and animal brain.

When we compare one animal with another, the general rule is that the one having the largest brain in proportion to the bulk of the body, is the most sagacious. This comparison, however, should be between animals of the same class, otherwise it might, with much show of reason, be claimed that the brain of the ant is larger than that of the elephant, inasmuch as the marvellons display of sagacious instinct in the former seems to compete successfully with that of the latter.

When we compare man with man, it will be found that some men have distinguished themselves above others, having larger brains. Butwe must consider that the comparison can be fairly made only when the circumstances and opportunities are equal. Men having large brains and great capacities are often prevented from a full manifesta- 
tion of their mental forces by circumstances beyond their control. How many men of superior qualities in statesmanship are compelled to give place to their inferiors by popular partisanship! How many, in advance of their time, originate a great principle in mechanics, which they are prevented from ultimating by want of means and other hindrances, and die in obscurity, while some one more pretentious, but of smaller capacity and brain, makes himself famous as the supposed original inventor!

But whatever may be the success or failures of individual men in competition with each other, the broad fact stands out prominent that the larger brained peoples best succeed in all that distinguishes mankind in government, literature, art, science, and all that belongs to civilization.

In reference to the size of the brain Prof.Huxley says: "So far as I am aware no human cranium belonging to an adult man has yet been observed with a less cpbical capacity than 62 cubic inches. the smallest cranium observed in any race of men by Morton measured 63 cubic inches, while on the other hand, the most capacious gorilla skull yet measured has a contents of not more than $34 \frac{1}{2} \mathrm{cu}$ bic inches, (16-93).

The lowest man's skull therefore has nearly twice the capacity of the highest anthropoid ape. The anthropoid apes, so called, are the Gibbon, Grang, Chimpanzee and Gorilla ; and they advance in cranial development in the order here named. The cranial capacity of man ranges from 63 to 114 cubic inches-Morton having found a sknll of the 
latter size-showing a difference of 52 cubic inches, or a little more than double. Huxley says: "The difference in the volume of the cranial cavity of the different races of mankind is far greater, absolutely, than that between the lowest man and the highest ape, while relatively it is about the same." That the relative difference is about the same-that is, that the difference between one ape and the other next above is about the same as that between a man of one race and the one next above-is a fact of much significance. It shows that there is no such immense gap between ape and ape, and between man and man, as between the highest ape and the lowest man.

That the distance between the gorilla and the Bosjesman is far less than that between the latter and Morton's large-brained 'Teuton is not much to the purpose. The gulf between the gorilia and Bosjesman is insuperable-that between the latter and the 'Teuton is not. Between the former it is a. difference in kind-between the latter it is one of degree. Even Büchner says: "those parts of the "brain engaged in the function of thought in no "animal can reach the size and shape of the cor"responding portion of the human brain." (12107.) In fine, the difference betwcen the lowest man and the highest ape is so great that natural selection wholly fails to account for it.

A certain class of naturalists, in support of Darwin's theory; urge that man, considered from a purely zoological point of view, differs much less from the higher apes than these differ from 
the lower. But this is an unfair view of the subject. Man is to be regarded as ore species, though of, perhaps, five or six different varieties or races; whereas, apes, from the lowest to the highest, are of a greater number of species than there are different races of men.

The difference between the brain of the highest developed Teuton and tho lowest Bosjesman should be compared with that between the highest and lowest Gorilla, or that between the highest and lowest Chimpanzee; and not between the Gorilla and the lowest monkey.

This will appear more evident when we consider the number of the divisions of the monkey race. According to Huxley the Simiadre aredivided into three families-the Arctopithicini, the Platyrrhini, and the Catarrini. The first are the Marmosets. The Platyrrhini are the American apes and are made up of about six generic groups. The Catarrhini or apes of the old world "fall into two very distinct groups, the Cynomorpha and the Anthropomorptha," to the former' of which belong five sub-generic groups, and the latter are divided in to three well marked genera. (18-392.)

Accorting to St. George Mivart, the Orang resembles man the nearest as regards the brain, for though slightly inferior to that of the Chimpanzee in absolute mass, yet the height of the Orang's cerebrum in front is greater in proportion than in either the Chimpanzee or the Gorilla. So, too, the folds of the urain substance, called the "bridging convolutions," which in man are con- 
spicuously interposed between the parietal and occipital lobes, appear much reduced in the Orang, but do not appear at all in the Chimpanzee or Gorilla. He adopts the idea of Gratiolet, that the Gorilla, in spite of its size, is the lowest and most degraded of the latisternal apes-a mere enlarged Baboon.

His conclusion is, that the difference between the brain of the Orang and that of man, as far as yet ascertained, is a difference of mass of degree -and not of kind; but that the psychical differences are of kind and not of degree. Yet in point of mind apes are very similar to each other. He says: "Not only the lowest Baboons of Africa (as e. g. the famed 'Happy Jerry' of Exeter Change), can be taught various and complex tricks and performances, but the less man like American monkeys - the common Sapajous-are habitually selected by peripatetic Italians for the exhibition of the most clever and prolonged performances" (17-425).

This is certainly in conflict with the idea of the gradual development of the mind of man from the ape, which of course is founded on the supposed gradual growth of the ape mind from the lowest to the highest.

- Darwin contends that man is descended from Catarrhine monkeys of the Old World; and that the "Semnopithicus," a genus of that gromp, is connected with the "Macacus" by a fossil of the Miocene found by M. Gaudry (9-188-9). Be this as it may, the monkey race is proved to be of great 
antiquity. In living species we find a line of descent from one species to another presenting no remarkable gap between-nothing more than such increased enlargement of the brain as harmonizes well enongh with the transmutation theory. But how account for the immense gap between the Gorilla and the Bosjesman, in which the brain is double? This chasm is altogether too wide to be bridged over by the imperfection of the geologic and zoölogic records, so often appealed to by Darwin. There should be found, if not fossil remains of man, at least fossil apes, in the Miocene or Pliocene periods, or living species between the Gorilla and man.

Again, look at the immense cranial distance between the lowest and highest man-SS cubic inches-and consider the timeit must have taken to reach the highest by the exceedingly slow increments which lie at the very foundation of the theory. It would seem to require a period reaching back to the Eocene. Look again at the Engis skull, dating as far back as the Post Pliocene. It was of the average European capacity, and covered a brain which, according to Huxley, might have been that of a philosopher. If this brain were indeed the result of the slow Darwinian gradations, it would require its primeval monkey progenitor to have lived long before there was an inch of land on which the foot of an animai could rest.

When we regard the comparative weight of the brain we arrive quite as emphatically at the same 
result. The brain of the full grown Gorilla is found to weigh $1 \tilde{5}$ oz. avoirdupois by Prof. Owen, whereas that of man ranges from 35 to 65 ounces; that of the lowest weighing more than double that of the Gorilla.

There is another mode of stating the same fact in the language of Hugh Miller. He says: "It is of itseif an extraordinary fact, withont reference to any other consideration, that the order adopted by Cuvier in his 'Animal Kingdom,' as that in which the four great classes of vertebrate animals, when marshalled according to their rank and standing, naturally range, should be also that in which they occur in the order of time. The brain which bears an average proportion to the spinal cord of not more than two to one, comes first-it is the brain of the fish ; that which bears to the spinal cord an average of two and a half to one succeeded it-it is the brain of the reptile; then came the brain averaging as three to one-it is that of the bird. Next in succession comes the brain that averages as four to one-it is that of the mammal; and last of all appeared a brain that averages as twentythree to onereasoning, calculating man has come upon the scene." (Foot Prints of the Creator, p. 283).

The lowest vertebrate is a fish, Amphioxus Lanceolatus, having a spinal cord but no distinct brain. The next above, Lamprey, Myxine, etc., have brains. The average fish brain accord. ing to Miller is two to one of the spinal cord; and that of the mammal four to one; whereas the 
average of man is twenty-three to one. From this it would appear that the arerage distance in development from the mammal to man is from four to five times greater than that of the average fish brain to the mammal; and it would seem as if the slow steps required by the theory to connect the two ends of the series, would require a distance of time equal if not greater, than between the Siinrian and Glacial periods. Well may the objector ask for the long serics of anthropoids between the Gorilla and the Bosjesman which should, if the theory be true, be found still living. There is a regular series from the lowest monkey to the Gibbon, and from the latter to the Gorilla-why should it stop there?

Another marked distinction between men and animals is the marriage relation as it has existed, and as it now exists in civilized lands, and in some uncivilized as well. This relationship is an institution peculiar to the human race. In its best form and according to the Christian idea, it is the union of one man and one woman, as husband and wife in mutual fidelity, until separated by death. To conjugal affection is added the mutual love of children, which often descends to grand childien. It thus forms the family, made up of parents and children; and the family stands as the basis of all regular and stable government.

When we regard animals in this connection we find the most marked contrasts with mankind.

In the first place, the growth of the sexual in- 
stinct is radically different. In man it does not appear until the judgment has sufficiently matured to exercise some control over it, and then it remains comparatively constant. Tith animals it shows itself rery much carlier; and then only appears periodically, and under no kind of restraint.

In the next place, there are marked contrasts in regard to the existence and continuance of conjugal and parental affection. Certain classes of birds, as the robin, for example, pair together for the purpose of procreation, and separate after weaning their brood. The male feeds the female during incubation, and aids in providing for the young until they are dismissed from the nest; and so far they present an image of a true marriage. After these offices, howerer, are performed, the parents become indifferent to each other and to their ofispring.

On the other hand, the gallinaceons fowls are polygamous, and, taking the common domestic fowl as a sample, we find some marked peculiarities. The cock does not in the slightest degree aid the hen during incubation, and manifests no love of offspring whaterer. The hen shows an intense love for her brood until they are weaned, and then she becomes wholly indifferent to them. In some of the gallinacr-the peacock - the hen is even compelled to protect her young from the ravages of the male.

The mammalia are generally polygamous, and 
the same rule as to conjugal and parental love prevails as with the gallinaca.

In tracing the history of marriage, it is a question of much interest whether it prevailed with primitive man, and if so, in what form. On this subject there is some confusion among those who have given it consideration. Sir James Lubbock, and others, from accounts given by travelers, allege that there are tribes at the present day which practice"Communal marriages; that is, "all the men and women in the tribe are husbands and wives to each other." (9-i - -342).

This is another name for promiscuous intercourse.

Darwin, in reviewing the evidence thus furnished, is evidently somewhat in doubt. He siys, after referring to these anthors: "The licentionsness of many savages is no doubt astonishingly great, but it seems to me that more evidence is required before we fully admit that their existing intercourse is absolutely promiscuous. Nevertheless, all those who have closely studied the subject, and whose judgment is worth much. more than mine, believe that communal marriage was the original and universal form throughont the world, including the intermarriage of brothers and sisters."

Again: "from the foreroing, and several other lines of evidence, it seems certain that the habit of marriage has been gradually developed, and that almost promiscuous intercourse was once extremely common throughout the world." Yet, 
he adds: "Nevertheless, from the analogy of the lower animals, more particularly those which come nearest to man in the series, I cannot believe that this habit prevailed at an extremely remote period, when man had hardly attained to his present rank in the zöological scale." (id. 345 ).

Again: "If we go back far enough in the stream of time, it is extremely improbable tbat primeval man lived promiscuously together. Judging from the social labits of man as he now exists, and from most savages being polygamists, the most probable view is that primeval man aboriginally lived in small communities, each with as many wives as he could support and obtain, which he would have jealously guarded against all other men." (9-II-346).

If such had been the state of aboriginal man, (who according to the theory of natural selection was only a shade above the ape), he would have been in a state of internal warfare from which he never could have emerged. No one man could have obtained a plurality of wives without overcoming his rivals; and the same scenes must have been enacted in those communities which we witness in every barn-yard where there are too many cocks. But Darwin himself refers to evidence which goes far to disprove his view of the subject. He says: "Nevertholess, there are tribes standing "almost at the bottom of the scale, which are strictly monogamous. This is the case with the Veddabs of Ceylon. They have the saying, ac- 
cording to Sir J. Lubbock, that death alone can separate husband and wife." (9-id.-347).*

If tribes are now found "standing almost at the bottom of the scale," so strictly monogamous, as to regard death alone sufficient to dissolve the connection, they furnish stronger evidence of the habits of primeval man, than those tribes which practice polygamy, and stronger still than those others, said to practice sexual communism.

How much reliance is to be placed on the researches and speculations of those who are said to have closely studied the subject, may be seen by a reference to them as given by Lubbock. He says: "Bachofen and McLennan, the two most recent anthors who have studied this subject, both agree that the primitive condition of man socially was one of pure Hetairism, where marriage did not exist; or as we may perhaps for convenience call it, communal marriage, where every man and woman in a small community were regarded as equally married to one another. Bachofen considers that after a while the women, shocked and scandalized by such a state of things, revolted against it, and established a system of marriage with female supremacy,

*Wallace, in an article on "New Guinea and its Inhabitants," (I-Xr-6I), cites the following from Lieut. Bruyn Kops, in reference to the domestic relations in New Guinea : "Respect for the aged, love for their children and fidelity to their wives, are traits which reflect honor on their disposition. Chastity is held in high regard and is a virtue that is seldom transgressed by them, A man can only liave one wife, and is bound to her for life. Concubinage is not permitted. Adultery is unknown among them." 
the husband being subject to the wife, property and descent being considered to go to the female line, and women enjoying the principal share of political power." (26-67).

Aside from the moral certainty that any tribe practicing promiscuons intercourse must soon have died out, the idea of women (just emerged, Darwinially, from apehood) who were brought up in that kind of intercourse being shocked or scandalized at anything, can only be entertained by those having credulity enough to believe anything! The same credulity, too, would accejt the idea, that those shocked and scandalized women had sufficient energy and knowledge of statecraft, to bring about a radical rovolution in the tribe!

But Dr. Bachofen's imagination does not end here-he fancies a third period when " the ethereal influence of the father prevailed over the more material idea of motherhood."

By means of this ethereal victory man was restored to his supremacy, and the litigants complacently came to the conclusion that "The father" in fact was the author of life, and the mother a mere nurse." (26-6\%.)

McLennan like Bachofen starts with a state of communal marriage, which he thinks was succeeled by polygarny, "in which brothers had their wives in common." To this followed Terirate, "under" which when an elder brother died, his second brother married the widow;" and from this succeeded endogamy in some tribes and exogany in others. (id. 69.) 
Darwin's supposition that primitive man practiced polygamy is not in harmony with his own theory of the origin of the human race. He al. leges that the structure of man in his dentition, his nostrils, the size and convolutions of his brain, the absence of a tail, etc., prove that he is an offshoot from the Old World Simian stem; and that under a generalized point of view, he must be classed in the Catarrhine division. The Orang belongs to a sub-group of that division, and is the nearest in structure to man; and if there be any truth in the theory, this ape must have been the evolutionary progenitor of man. The Orang however is monogamous (9-II-345), and man just emerged from this ancestry ancestry would have been of similar habits.

The terrible consequences of promiscuous intercourse by disease and otherwise, resulting from its practice in the slums of all great cities, prove it to be an unnatural condition of mankind. Its universal practice would at novery remote period bring the race to an end.

Its practice at the ontset must have resulted in the same way, or at least, have kept mankind in a state Jower than the worst of brutes; for it may well be doubted whether any animals can be found (above some insects), in which every male belonged to every lemale, and every female to every male promiscuously.

In regard to polygamy, it may be considered as a departure from the original habits of mankind, as, in fact, a licentious abuse of the marriage principle. 
That it is an unnatural and abnormal condition of human society may be inferred from the following considerations:

(1) The sexes are numerically about equal. It is true the census returns do not show an exact eqnality, because no such returns can be exactly correct. But the evidence from that source so uniformly approximates to an equality, as to leave scarce a doubt of its existence. The result from this would generally be, that one man having fifty wives, would prevent forty-nine from having any; or one-half of the marriageable males having each two wives, would deprive the other half of any.

(2) The effect of polygamy is to destroy the unity of the family. Every additional wife is an element of discord.

The husband of fifty wives cannot feel or mani. fest an equal attachment to each, hence continual jealousies leading often to terrible crimes.

(3). The children of this kind of concubinage necessarily receive less care than those of monogamous marriages.

The father, aside from the indifference naturally growing out of his dilnted affections, would, under ordinary circumstances, be compelled to leave to each mother the chief burden of attending to her brood, and as a consequence a greater number of children die in infancy : polygamy, therefore, is a check to population.*

* See the author's conclusions from personal observation in Utah in $1852-3$, in his work entitled "Utah and the Mormons." 
Owing to the numerical equality of the sexes, polygamy can never universally prevail in any country-for example, it is well known that a large mass of the male population of the empire of 'Turkey, who can obtain wives, a re monogamous from necessity, if not from choice. Its evils therefore, though great, are far less than those resulting from promiscuous intercourse.

If primitive man had been polygamous, it is not likely that any of the race could have advanced beyond a state of semi-barbarism. The most enterprising and advancing nations have been and are those in which monogamy has prevailed. The Greeks, who gradually advanced from a state of uncivilized obscurity into the formation of regular and stable governments, and who made advances in literature, philosophy and the arts, which are still the admiration of the world, practiced monogamy. Such was the practice of the Romans, the founders of the most powerful empire of antiqnity, and distinguished for civilization as well. Such, too, the numerous tribes occupying middle and northern Europe, known in Roman history as Northern Barbarians, from which were founded the modern civilized nations of Europe and America.

Looking back beyond historic time, is there any reason to believe that the remote ancestors of the Greeks and Romans, or of those Northern tribes were polygamous? There is no historic evidence of any people changing from polygamy to monogamy-the changes would most likely be the 
other way, growing ont of the licentiousness of some one man who had become the chieftain of his tribe. The Mormons are an example of this kind. Their founder, a vulgar debanchee, after having by his superior cunning obtained a fanatical control over his followers, established polygamy as a quasi-religious institution by a pretended revelation.

Something similar to this feat of the Mormon prophet must have taken place among the Vedic races of India, instituting a kind of polyandry, if we are to take as gospel a translation of the great epic, the Nahab-Narata. In this it is represented that Draupadi was the wife of five Panharati princes. The father of Draupadi was shocked at the idea of all these princes marrying his daughter, saying: "You who know the law must not commit an unlawful act which is contrary to usage of the Vedas."

The reply to this was: "The law, O King, is subtile; we do not know its way. We follow the path which has been trodden by our ancestors in succession." One of the princes then cited their precedents: "In an old tradition it is recorded that Jatila, of the family of Gotama, that most excellent of moral women, dwelt with seven saints, and that Varkopî, the daughter of Muni cohabited with ten brothers, all of them called Prochetas, whose souls had been purified by penance." The old King seems to have been completely befooled by these traditions, though contrary to law. 
The substance of this is taken from an essay on "The Early History of Man" (N. Am. Rev., July, 1869), in which the author is trying to prove that monogamy was not practiced by primitive man. Epics, founded on tradition, are not the most reliable of authorities in grave questions of fact. We, none of us, believe in these days that Jupiter kept house on Mount Olympus, or kicked Vulcan out of Heaven, or suspended the ox-eyed Juno from its battlements with a golden chain. We do not even believe that a race of Amazons ever existed whocut off their right breasts to enable them to draw the bow in battle with greater efficiency.

According to the Vedic traditions these poly. andric connections were not only exceptional cases, but contrary to law; and, so far as they furnish any proof, it is in favor of the general practice of monogamy among the Vedic races.

The general conclusions are: That primitive man, of all races, was monogamous; that promiscuous intercourse never existed to any considerable extent, and never without a rapid deterioration and probable extinction of the tribe; that polygamy has been a lapse from monogamy, growing out of the licentiousness of ruling men; and that in countries where it has become established it has retarded population and produced more or less degradation. 


\section{CHAPTER VIII.}

\section{ANTIQUI'Y OF MIN.}

The Old Idea. First traccs of Man in the Pliocene. The Pre-thistoric Ages. Ancient Iitcrature. Brain and montal capacity of primitive Man. John Fiste on the Evolution of Brain and Nind. Primitive man uncivitized, but not inferior. General Conclusions.

The antiquity of primitive man, his cerebral development and mental capacity, and whether he was civilized or savage or in a state of uncivilized simplicity are points, which have a material bearing upon the question of his evolution.

The old idea still lingering in the minds of many is that the first man, Adam, was created about 6,000 years ago, at the highest point of civilization; and that all the barbarism and savagery found to exist are but cases of degeneracy. The writer of the article "Adam" (Ency. Britt. p. 121, 8th Ed.), says:

"It is evident upon a little reflection, and the closest investigation confirms the conclusion, that the first human pair must have been created equivalent to that to which all subsequent human beings have had to reach by slow degrees in growth, experience, observation, imitation, and 
the instruction of others; that in a state of prime maturity, and with an infusion, concreation, or whatever we may call it, of knowledge and habit, both physical and intellectual, suitable to the place which man had to occupy in the system of creation, and adequate to his necessities in that place."

That is to say, the first man, by the mere fact of his creation, was profoundly versed in all the arts and sciences. He knew how to construct and put into operation railroads, steamboats and telegraphscould rival Phidias in sculpture-Michael Angelo in painting-Milton in Poetry-Webster in oratory, \&c. But this does not seem to have been the extent of his intuitive qualifications. He was not only master of all the artistic and scientific results of modern times; but of all the improvements and discoveries that will be made in all coming time-such we may be permitted to suppose as examining the fauna and flora of the plannets through improred telescopes-the navigation of the air--the concoction of the veritable elixir. vitc-the manufacture of genuine diamonds-and so on ad infunitum. If such indeed were his qualifications, if he knew all, and more than all his postelity have grasped by slow processes, the student of modern science may well be amazed at the extent of the cataclysm which could so completely obliterate every trace of his works. Science, however, is dealing sharply with old beliefs; and giving to the earth and the human race dates 
so far in the ages of the past as to be beyond the reach of definite calculation.

Traces of the existence of man are found in the Post Pliocene; and the evidence consists of the rude flint knives and stone hatchets, discovered mostly in the river drift gravel in France and England. These implements are found in connection with the bones of certain extinct mammalia of which the mammoth, wooly-haired rhinoceros and cave bear, are the most common. This was the "Earlier Stone Age," so called." From this there was an advance to the "Second Stone Age," exhibiting the same implements greatly improved in being ground to a smooth surface and cutting edge, in place of the rough chipping of the former period, found in the lower level drifts of the valley of the Somme, and similar drifts in other localities.

There is also found a greater variety of manufactured articles, such as axes, wedges, chisels, poniards, hammers, etc.

The next advance was to the age of bronze in which the metal was used for arms and cutting instruments of all kinds. To this succeeded the age of iron, in which man became acquainted with that metal, forming the last pre-historic epoch. These ages, so called, are not sharply defined but glide into each other, the use of the ruder instruments being gradually discontinued, after the invention of superior ones, as at the present day.

* There are evidences of the existence of the stone age in Egypt, India and other countries. 
This brief statement embraces merely the results of the elaborate works on the subject by Prof. Lyell and Sir John Lmbbock.

The finding of the rude flint implements in the Post Pliocene does not necessarily negative an earlier date to man.

Lyell says: "Had some other rational being, representing man, then flourished, some signs of his existence could hardly have escaped mnnoticed in the shape of implements of stone or metal, more frequent and more durable than the osseous remains of any of the mammalia" - (Ant. Man, p. 399.)

So far as it goes, this is unanswerable. But the learned professor makes no allowance for that period of time, necessarily great, which elapsed before man learned to manufacture the rudest stone instruments. Judging from the interval between stone and bronze, and from that to iron, the primal period must have been longer anterior than that elapsing between the different ages; and the first man, therefore, may date as far back as the Pliocene.

Prof. Wallace, in an article published in "Nature" (20), estimates the bronze age 3,000 to 4,000 years ago, and the stone age of the Swiss lakes at from 5,000 to 7,000 years. "A human skeleton found at a depth of 16 feet below four buried forests superimposed upon each other, has been calculated by Dr. Dowler to have an antiquity of 50,000 years." 
Those races which advanced from one Stone age to another, and from that to bronze and iron, by this kind of progress furnish evidence that they are the founders of the civilized nations of the earth. Other races, however, have not shown the same capacity for improvement. A large portion of the Indian tribes of America were in the Stone age at the time of Columbus; nor have they shown much capacity to advance. Another class of low races, such as the Australians, Papuans, \&c., were found in the same primitive condition, and they remain about stationary.

Among the improving races, some emerged from their primitive condition much earlier than others. Thus in Vedic poetry written 4,000 years ago we find that marked advance in civilization indicated. by a division of labor. One of the lyrics of that period (Rig-Veda-Ix.-112), closely translated, reads as follows:

"How multifarious are the views which different men inspire!

"How various are the ends which different crafts clesire!

"The leech a patient seeks; the smith looks out for something cracked, "The priest seelis devotees, from whom he may his fees extract; "With feathers, metals and the like, and sticks decayed and old, "The workman manufactures wares to win the rich man's gold. "A poet I, my sire a leech, and corn my mother grinds;

"On gain intent, we each pursue our trades of different kinds. "The draft horse seeks an easy car, of gallants girls are fond;

"The merry dearly love a joke; and frogs desire a pond (2I-227).

Quite a modern picture-laborers, rich men, tradesmen, mechanics, manufacturers, doctors, poets and priests! 
And one may well marvel why the ditty did not wind up with the legal profession, with something like the following:

"The lawyer gulps the oyster, as shrewd old codgers tell, "And gives to hungry litigants each one half the shell."

'The following from the Sanscrit, written by a nameless poet 1600 years B.C., exhibits a delicacy of poetic conception and expression which, as Prof. Holden says, "would not seem childish if 'Tennyson had written it' (1-rux-335).

\footnotetext{
“ Like as a plank of drift wood,

" Tossed in the watery main,

"Another plank encounters,

"Meets, touches, parts again;

" So toss'd and drifting ever,

“ On life's unresting sea,

"Men meet, and greet and sever,

" Parting eternally."
}

Homer flourished abont 806 years later; and his great epics, written in Greek, are among the few which bid fair to live through all time.

The book of Job is a very old one-how old can probably never be ascertained; and it will always be read.

Here, then, are three languages - Hebrew, Greek and Sanscrit, brought at very early periods to a high state of cultivation; and as languages are of slow growth, from very simple beginnings; the primitive people's, from which they had their origin, must have existed long before the dawn of history. 
What was the brain development and mental capacity of primitive men? It lies at the foundation of the Darwinian theory that the brain of the first man was but a shade above that of the highest a pe-a difference so small as to make it difficult to determine where the ape ended and the man began. And irrespective of this theory, the idea extensively-nay, almost universally prevails - that the size of the human brain and as a sequence the mental capacity, varies to the extent of the distance which now separates savage and civilized races.

Those who adhere to the old notion that Adam was created in full matnrity of body and mind, and in full proficiency in all human science, believe that the savage races are cases of degeneracy by reason of "the fall," and that such degeneracy has produced the inferior brain development, of the Bosjesman, the Negro, the Australian, and other so-called inferior races.

On the other hand, an influential portion of the ethnologists maintain, that primeval man, whether of one or of several distinct creations, was but little removed in brain capacity from the ape, and that such capacity lias gradually increased in those communities which have become civilized. Thus, while one class adhere to the idea that Adam was not only the first man, but the representative standard of cerebral development and mental perfection, from which his descendents have fallen, and to which they can be restored by civilization; the other class are quite sure that man started 
with the cerebral and mental derelopment of the lowest modern savage: and that by culture such capacity has been gradually increased until it has reached the condition of the present civilized races, and that it only needs a similar training to bring the savage up to the same standard.

In regard to the Adamites, it is sufficient to say, their faith is founded upon a literal construction of the first two chapters of Genesis, which, being inconsistent with the discoveries of modern science, leaves the fair conlusion that those chapters have not been correctly understood.

When we carefully examine the facts furnished by archælogical researches, it must, I think, bring us to the conclusion that the size of the brain and the mental capacity of any given race of men remain permanent-at least that they vary only within fixed limits above and below a certain average.

Unfortunately, human bones are so much more subject to decay than those of other animals, that very few prehistoric skulls have been found; but these few furnish important evidence.

Two very ancient skulls the Neanderthal and Engis--so-called, from the Belgian caves in which they were found, have been subjected to close and critical examination by both Lyell and Huxley. The former is of long elliptical form (dolicho. cephalic); and from its depression, thickness and other peculiarities, is pronounced by Huxley to be "the most pithecoid human cranium yet discovered." Yet its capacity is about 75 cubic 
inches; and therefore-_"very nearly on a level with the mean of the two human extremes, and vary far above the pithecoid maximum (22-84).

And it is admitted by both these learned professors (though they have adopted the transmutation theory), that it can in no sense be regarded"as the remains of a human intermediate between man and apes." Darwin is compelled to say-" it must be admitted that some skulls of a very high antiquity, such as the famous one of Neanderthal, are well developed and capacious" (9-I-140).*

The Engis skull was found associated with the Elephasprimigenius and Rhinocerus tichorinus; it is brachy-cephalic; and approaches near to the highest or Caucasian type. After a close and critical examination Huxley says: "There is no mark of degradation about any part of its structure. It is in fact a fair arerage human skull, which might have belonged to a philosopher, and might have contained the thoughtless brain of a savage." (16-181.)

* Quatrefages refers to the skull of Robert Bruce, the Scottish hero, as a reproduction of the Constadt type (to which the Neanderthal skull belongs), and also to that of Kay Kykke, a Danish gentleman of some note in the I 7 th century, and concludes that "the indi"vidual whose remains were found in the Neanderthal cave was " capable of possessing all the moral and intellectual qualities conpati"ble with his inferior social condition" (40-3II). The same author also mentions the discovery by M. Lartet of human remains at Cramagnon (France), belonging to the Quaternary, of which the skull of one was remarkable for its fine proportions, and having a capacity of 96-99 cubic inches-a number above the mean of modern European races (id. 3 IO-II). 
"These two skulls," says Lyell, "have given rise to nearly an equal amount of surprise for opposite reasons-that of Engis because of being unequivocally ancient, it approaches so near to the highest Caucasian type; and that of Neanderthal that becanse it has no such decided claims to antiquity, it departs so widely from the normal standard of humanity." (2-94,95.)

Wallace speaks of a skull of the stone age found in the lake dwellings of Meilon, corresponding exactly to that of a Swiss youth of the present day. (23-336.)

But perhaps the most important piece of evidence yet found bearing upon this question is the human skeleton discorered by M. Riviere, in 1872, in one of the nine caves near Mentone, and now known as "The fossil man of Mentone." It was found twenty feet below the floor of the cave, which was composed of ashes mixed up with the remains of various animals no longer existing in Europe, some of which are extinct, such as the Rhinocerus tichorinus, Cervus corsicanus, \&c. The implements were of bone, deer's horns, and such of stone as belonged to the advanced store age. IXis status as to brain and mental capacity was, if anything, above the average of the modern civilized man.

Prof. Gill gives important evidence on this point. After stating that the skelet on remains of the man of the same period were altogether too fragmentary to allow of any definite opinions as to his structural characteristics, he adds: "The data for such 
opinion have been rendered available by M. Riviere's discovery; and althongh he has not yet published positive details, the negative results afforded us indicate that the fossil man was, in all respects, a typical man, perhaps even differing less from his snccessors in Enrope than do some other existing races. It is at least very certain that he had no ape-like characteristics. Even more, he was man to excess! The proportions of the fore limbs to the lind, and of the median and distal portions of each to the proximal, so far from proving a condition intermediate between man and the apes, or embryonic or juvenal humanity, or even affinity to the negro, indicate that he was more unlike the apes in such respects than are some of the existing races; nor is this evidence rebutted by any characteristic of the skull, the dentition or otherwise, so far as the testimony allows us to judge." (1-IV-641.)

In addition to the evidences above given, it appears from a lecture of Prof. J. D. Whitney, in Cambridge, Mass., April 27, 1878, that a human skull of a brain capacity equal to that of existing civilized races has been found under the Pliocene lava beds of California. (39-426.)

Much confusion in reference to the difference between the cerebral capacity of men and apes has arisen from the way in which the comparison is made. Mr. John Fiske compares the brain of the Chimpanzee with that of the Australian, showing a less difference than that between the Chimpanzee and the Teuton. He claims that it is in the high- 
I78 A New Theory of the Origin of Species.

est degree fallacious in St. George Mivart and others to make the comparison between the anthropoid ape and the modern civilized man, because as he says: "it involves a host of facts, which when taken into the account, must essentially modify the whole aspect of the case." (14-I.-2-86\%.)

This host of facts all hinge on the assumption that at a certain time in the remote past the higher ape became sufficiently advanced in intelligence for natural selection to work out the commencement of humanity with an ape-like brain ; and that from this initial state the cerebral capacity has been gradually developed in the improving races (the Aryan and Semitic), until it has reached its present dimensions, amounting in one instance to 114 cubic inches.

To maintain the position thus confidentially taken, he says: "But going back to the primeval man we must descend to a lower grade of intelligence than that which is occupied by the Australian. We must traverse the immensely long period during which the average human skull was enlarging from a capacity of thirty-five inches like that of the highest apes, to a capacity of seventy inches, like that of the post-glacial European skulls, of which the one found at Neanderthal is a specimen, and which are about on a par with the skulls of Australians. And when we have reached the beginning of this period, most likely in the Miocene epoch, we may represent to ourselves the individuals of the human genus as animals differing little save a more 
marked sociality from the Dryopithecus and other extinct half human apes. IVe may represent primitive man as an animal in whom physical and psychical changes having hitherto proceeded pari passu, intelligence had at length arrived at a point where variation in it would sooner be seized on by natural selection than variations in physical structure." (14-Ir-294.)

He still further says, that natural selection more readily acts in advancing intelligence than in perfecting the physical structure; and these two ideas, to-wit: that the ape did some how advance in intelligence, and that natural selection then seized upon and worked up the case, appear to furnish the entire foundation for the hypothesis of a greatly enlarged brain from the Chimpanzee man to the modern civilized man.

If we admit these premises to be well founded, the criticism on Mivart and others would be just ; and the comparison of the Chimpanzee with that of the Australian well made. But just here arises the questions: what fact is there tending to prove. or to make it probable, that any anthropoid ape ever advanced beyond the average intelligence belonging to it? And what proof is there that natural selection more readily acts in advancing intelligence?

It is true, Mr. Fiske undertakes to prove his case by tracing the progress made by the improving races from low civilized conditions during the historic period, and from wholly uncivilized and barbarous states during pre-historic periods. And on 
these data he assumes a point of time, when the sole progenitor of the entire human race had just sufficient intelligence above the ape, to be regarded as human.

In following out this course of reasoning he reminds us, "that as we go backward in the stream of time we find the progressiveness of ciyilized man continually diminishing. No previous century ever saw anything approaching to the increase of social complexity which has been wrought in America and Europe since 1789. In science and in the industrial arts the change has been greater than in the ten preceding centuries taken together. Contrast the seventeen centuries which it took to remodel the astronomy of Hipparchus with the forty years which it has taken to remodel the chemistry of Berzelius and the biology of Cuvier. Note how the law of gravitation was nearly a century in getting generally accepted by foreign astronomers, while within half a dozen years from its promulgation Darwinism became the accepted creed of almost all naturalists. How enormous the revolution in philosophic thinking since the time of the Encyclopediastes in comprehending the slow changes which accrued between the epoch of Aristotle and the epoch of Descartes." (14-II290).

The obvious conclusion from this view of cerebral growth is, that the human brain has expanded to a greater degree since 1789, than during the ten previous centuries. 
To realize the full force of this conclusion, it must be borne in mind that natural selection, as its advocates allege, works by extremely slow degrees; and that Fiske is illustrating the growth of the brain and of the mind through its agency, from the ape fountain. TVe then plainly see that the only inference to be drawn from the facts here stated, is, that the cerebral and mental capacity of each preceding discoverer in science and the industrial arts must have been inferior to that of each succeeding one who has improved upon prior discoveries. Thus, in the far distant past an uncivilized man invented a stone axe. In long ages afterwards a civilized man invented an iron one. According to the theory under consideration, there was about as much difference between the brain and intellect of the two inventors as between the utility of the instruments invented. Thales, Pythagoras, Hypparchus and others made important discoveries in Astronomy, but following the same rule, they must have been inferior in brain to Copernicus, and he in turn must fall below Proctor. The sickle was a very useful implement in its day and generation. It was invented long enough ago to be mentioned in the Bible, and it held its own till the present century; yet under this hypothesis, how greatly inferior must its inventor's brain have been to that of McCormick who invented the modern reaper?

The man to whom the bright thought occurred of signalizing a whole conntry of danger by beacon fires on hill tops, would be similarly inferior 
to Morse, of telegraph fame. Hero, the mathematician, more than 100 year's B. C., invented a machine which revolved by steam, in the form of a modern reaction engine. This though regarded for ages as a mere curiosity, contained the germ of the modern steam engine (24-311), and the difference between the two, measures the brain expansion for, at least, sixteen hundred years from Hero to Watt!

If the Drain has increased from a pehood to the present time, the growth must have been by almost imperceptible increments. It would be a simple question of time; and there can be no greater absurdity in supposing the brain of Descartes superior to that of Aristotle, and that of Proctor to that of LaPlace, than in supposing the inventor of the flint knife superior in mental capacity to the anthropoid animal, at the point when the ape was ending and the man beginning.

Mr. Fiske, however, brings other things into the account which do not well harmonize with his theory.

It seems that while the Aryan and Semitic races have, by a kind of arithmetical progression, been favored with enlarging brains, other races have early come to a dead halt.

He says: "The capability of progress, however, is by no means shared alike by all races of men. Of the numerous races historically known to us, it has been manifested in a marked degree only by two, the Aryan and Semitic. To a much less conspicuous extent it has been ex- 
hibited by the Chinese and Japanese, the Copts of Egypt, and a few of the highest American races. On the other hand, the small-brained races-the Australians and Papuans-the Hottentots and the majority of the tribes constituting the wide-spread Malay and American families, appear almost wholly incapable of progress even under the guidance of higher races. The most that can be said for them is that they are somewhat more imitative and somewhat more teachable than any brute animals." "The two great races of middle Africa, the Negroes and Kaffirs, have shown by their ability to endure slave labor, their superiority to those above mentioned; but their career, where it has not been interfered with by white men, has been but little less monotonous than the career of a "brute species," (14-II-289,29()).

There can be no dispute about the facts here stated, but they lead to very different conchusions from those drawn by Mr. Fiske. If the ape had a capacity for intellectual improvement, which under the manipulation of natural selection developed into the negro as we find him pictured on the monuments of Egypt 4,000 years ago, and as we find him to-day, why shonld this race have come to an intellectual torpor so profound and obstinate, as to be beyond remedy, though brought into contact with civilization?

Similarly, why should the Australians, the Papuans, the Hotten tots, and the major part of the Malay and American tribes come to a point where the possibility of improvement has ceased, under any kind 
of selection, which has yet been propounded? Such a terminal point reached by so many races, proves that their small brain capacity is owing to some other canses, beyond the purview of the Darwin. ian theory of evolution. Instead of having resulted from an advance of ape intelligence, it is a strong argument in favor of the independent creation of so many different races with a brain capacity adapted to their needs in each case, and which has remained permanent.

It is not a question of education and refinement, but of cerebral capacity; and it is yet to be proved that there is any greater difference between such capacity of the primeval Aryan man and the ape, than between the modern man of that capacity and the ape. At present the weight of the evidence is to the effect, that if a primeval Aryan child could be born amongst us now, it could be educated and refined to the same extent, and be capable of performing as much in the battle of life as the average modern child. In other words, every man at birth is, to all intents and purposes, a primitive man; and if isolated or brought up among savages, would give no better or higher manifestation of civilized life or of mental capacity than that exhibited by the man of the stone age.

It by no means follows, that because the primeval ancestor of the 114 cubic-inched Teuton was wholly uncivilized, he had therefore a brain next to that of an imbecile. No doubt primeval man of whatever race was wholly uncivilized. But it 
does not follow that though without civilization he was therefore a savage or barbarian.*

The implements first found would seem to indicate that the first men did not make war on each other; war being more the results of organized states and governments. They were simply uncivilized, a condition not inconsistent with innocence of life. Traditions of this kind were current among the ancients. Virgil in his સneid (Connington) says :

"This forest ground from time's first dawn

Was held by natives Nymph and Faum,

Men who from stocks their births had drawn

And oaks of hardest grain;

No arts were theirs : they lnew not how

To couple oxen to the plough,

To store their treasured goods or spare;

The teeming boughs supplied "their fare,

And beasts in hunting slain."

Had the first man, as supposed by many, been completely master of all science, he must with the advantage of lives prolonged from the 930 years of Adam to the 969 of Methuselah, have left works of great magnitude and durability; and such as could not have been utterly destroyed. In the second place the cranial capacity, and-as a se.

* It is curious to note in this connection the following in Swedenborg's Arcana Coclestia, No, 286: "This and the preceding chapters to the verses now under consideration treat of the most ancient people and of their regeneration: primarily of those who had lived like wild beasts, but at length became spiritual men."

Sir Charles Lyell reasons that they were not cannibals inasmuch as no human bones are found with the spoils of the chase (22-I6). 
quence-the mental capacity of the first man of any race, (as for instance the Caucasian) was in no sense inferior to that of the same race of the present day. The Engis man is supposed to have existed in the Post Pliocene with the brain of $\approx$ philosopher. No one has the right to assume that his skull was the maximum of the men of his time-it is only one which has survived thous. ands if not millions. $\dagger$

It is quite evident that a long period must have elapsed prior to the commencement of the stone age, during which men probably lived upon the spontaneous productions of the earth, without regular habitations, and with only such protection from the weather as may have been afforded by caves and sheltered nooks. The stone age appears to be the earliest period in which mankind have any history, dimly enongh exhibited in flint knives and stone hatchets, but still a history. From that time there has been a steady advance through the bronze and iron ages to the time of written history.

The inventive genius of man then, as now, was stimulated by the necessities of his condition. I really required more brain work to invent and manufacture a stone hatchet, than it cost the man who invented and manufactured the modern axe. The advance from stone to bronze was very great because bronze is an alloy of nine parts of copper

+ I assume that the ancient man would compare favorably in respect to the number and depth of convolutions and the resulting extent of the gray matter, as well as bulk. 
and one of tin. The latter does not occur in a native state. To detect it therefore, separate it from its matrix, blend it with copper, and cast it in a mould indicate sagacity and skill. Bronze weapons and instruments, too, are more ornamented; and therefore show an advance in taste as well.

To bronze succeeded iron, which was another great advance, inasmuch as this metal, except as meteorites, is not found native, and requires close observation to discover the ore. To separate it from the matrix by means of the requisite intense lieat also implies the invention of some suitable machinery, however rude. (Lyell Ant. Man. p. 10.)

There was no ink shed over these great strides in human civilization, but doubtless plenty of boastful talk about "the progress of the age," and the acme of perfection to which society had arrived.

There were no patent laws either to protect or hamper genius; and the ancient inventor had at least the advantage of not being exposed to various law suits growing out of supposed infringements.

We forget that in the marvellons inventions and discoveries of the present day we have the vantage ground of the accumulated wisdom of all past historic time, upon which to build. It is as if, between two runners of equal swiftness, one should have nine-tenths the start in the distance to be run. There are multitudes in civilized communities, who, if all implements and machinery now in use, and all the inventors, artisans and scientists, were suddenly destroyed, would be in about as poor condition as the men of the stone age, except from the 
knowledge of the previous existence of such implements and machinery. They would know there was such a metal as iron; and that it could be smelted and made into axes. For the time they would be in a more helpless condition, for they would not even have a stone axe. Science is relative. In the stone age it consisted in the knowledge of the manufacture and use of stone implements; a business too limited to need much division of labor. Who can say that in only one thousand years hence the men of the present time may not be regarded quite as uncivilized as those of the first pre-historic age seem to us. In view of these facts and considerations it is safe to say, that it required quite as much close observation, skill and genius to invent a flint knife, compound tin and copper into bronze, produce iron from the ore and fashion it into implements of peace and war, and so on, as in modern times to discover and invent the art of printing, the mariner's compass, the uses of steam, etc. If the mental calibre increases by advancing civilization, there ought to be some evidences of it in a lapse of three or four thousand years.

These facts and deductions cannot of course be reconciled with the transmutation theory. According to that theory the man of the Post Pliocene instead of possessing "the brain cf a philosopher," should have been accommodated with one just past the imaginary line between him and apehood-and from thence there should have been a gradual increase of cranial and mental capacity to 
the present time. and it would seem too that the matter could notstop here but that the brain must go on enlarging with the increase of mental activities, in obedience to the same law for an illimitable period.

In this connection it is pertinent to advert to the question (though treated of more fully hereafter), whether the human family are descended from a single pair, or from several distinct creations. The advocates of the transmutation theory are nearly unanimous in opposition to the idea of the diverse origin of man, for the reason that it does not harmonize with the notion that the brain of the man of the Stone Age was of greatly inferior capacity to that of his scientific ascendants of modern times.

Those who believe in the Mosaic account, to be consistent, should accept the diverse theory ; for it is stated that Cain, after the murder of his brother, fled to the land of Nod; and there not only found a wife, but built a city. Yet strange to say, the great majority of professing Christians, while charging the transmutationists with infidelity, are in perfect accord with them as to unity of origin, and in the tendency of the human brain to decrease or enlarge in capacity.*

* Prof. Alexander H. Winchell, thongh a member of the Orthodox faith, in his work entitled "Preadamites," undertakes elaborately to prove that man in a very remote antiquity-as much as a hundred thousand years ago-originated as a black savage race in tbe Orient (356); that in process of time this race branched into distinct races on a scale of advancement; that there is no such thing as a degeneration of 
The author of the "Vestiges" has fallen into some mistakes on this subject. He says: "It is fully established that a human family, tribe, or nation, is liable, in the course of generations, to be either advanced from a mean form to a higher one, or degraded to a lower, by the influence of physical conditions in which it lives. The coarse features and other structural peculiarities of the negro race only continue while the people live amidst the circumstances usually associated with barbarism. In a more temperate clime and higher social state, the face and figure become greatly refined. The few African nations which possess any civilization exhibit forms approaching the Enropeans; and where the same people in the United States of America have enjoyed a withindoor life for several generations they assimilate to the whites, among whom they live. On the other hand, there are authentic instances of a people originally well-formed and good-looking, being brought by imperfect diet and a variety of physical hardships to a meaner form. It is remarkable that a prominence of the jaws, a reces. sion and diminution of the cranium, and an elong-

races (369); that Adam was an offshoot from a branch of the Mongolians called Dravidians, of dark complexion and straight hair, whose habitat was around the Mediteranean sea; that the Adamites exhibited at first a close approximation to the older type than as preserved in the Mediterranean race at present (473); that Adam was wholly uncivilized (294); but was the first Bible man from whom the Jews could trace their descent (4I9); in fine, that Preadamitism means simply that Adam was descended from a black race, and not the black races from Adam (I I 5). 
ation and alteration of the limbs are peculiarities always produced by these miserable conditions, for they indicate the unequivocal retrogression towards the type of the lower animals." (13-145).

It would have been well for the author to have given at least one instance of retrogression produced by the miserable conditions specified.

It is not true that the negroes brought into the United States, or their descendants, have improved or changed by contact with civilization to the extent claimed, or anything like it. It is true they have measurably got rid of some of the grossest African superstitions. They have, too, changed for the better, externally in dress, customs, \&c., in consequence of dissociation from the barbarous practices of their ancestors; bnt substantially they have not advanced otherwiso in any appreciable degree. After faithful effort to educate them they have shown an incapacity to be crowded beyond a certain low standard. It is now over two hundred years since the first cargo of slaves was brought into this country, including at least five generations from the original stock, yet there has not been the slightest change in color or structure, there remain still the same prognathous jaws, thick protruding lips, flat nose and limited cerebral development. There is not, probably, a single negro in the United States to-day, with a brain capacity or mental calibre beyond the maximum of those originally landed. Heredity has held them close to their original type. What is here 
said relates to the Negro, pure and simple, excluding the hybrid progeny resulting from the interconrse with the whites; excluding, too, those Africans of other stocks, such as the Ethiopians, who have nearly the same features as the European (excepting color), and who under similar conditions are capable of an approximate degree of advancement. A few of this latter class have occasionally found their way into the United States, and have led to erroneous conclusions in regard to the negro.

Haeckel says: "The Ulotrichi (woolly haired) are incapable of a true inner culture and of a higher mental development even under the favorable conditions of adaptation now offered to them in the United States of North America. No woolly haired nation ever had an important history." (3-II-309).

The foregoing review in reference to brain capacity leads to the following conclusions:

1. The brain of the primitive man of any given race, was of the full capacity of that exhibited under the most favorable conditions of modern culture in the same race.

2. The modern man is superior to the primitive of the same race neitherin organism or mental capacity; and all the evidences of modern civilization, as now exhibited, are but the results of human ingenuity from the beginning-each generation improving upon the advances of its predecessor.

3. 'There is an average size of the human brain, as of every other organ, and in any given race it 
cannot be developed beyond a certain limit by any amount of mental training. An individual man may by assiduous culture rise above, or by inactivity fall below this average, but beyond this range, like the oscillations of the pendulum, it never rises or falls. An infant now, of the most eminent parentage, knows nothing, and if suffered to grow up aniong savages would be an ignorant savage. But train and educate him, he may become the foremost man of his time.

4. A contrary theory involves the conclusion, that there is no limit to brain development-that the skull of the Aryan man of a million years lience would be simply monstrous, and if the corporeal structure enlarges in proportion, the age of Anak wonld be immeasurably distanced.

5. The fact that there are races of men which manifest an incapacity for improvement beyond a certain limit proves that they are of independent creations. 'The probabilities are, that the first men appeared upon the land first elevated from the ocean as soon as it became fit for human life; and as there were islands elevated, one after another, successive creations of man must have been accomplished, suited to the environment in each case. As the islands first emerging were only suited to low conditions of life, the most inferior races would be those which were first created, and subsequent races must have appeared in succession of superiority; in other words the lowest in the human scale are the oldest in creation. 


\section{CHAPTER IX.}

IS THERE AN INTELLIGENT FIRST CAUSE ?

General View of the Question-Theories on the Subject ExaminedPain and Suffering not Inconsistent with Design - Evidences of Design in Nature - Universality of Belief in a Personal Deity.

Much fault has been found with Darwin for not having more distinctly referred to the agency of an intelligent First Cause in the creation of new forms. The answer to this on the part of the advocates of his theory is, that the question of the production of organic forms is one of science, to be investigated and discussed by scientific methods, without reference to the existence or nonexistence of God. The answer is certainly pertinent, so far as scientific questions generally are concerned. It is sufficient for the chemist to test the question whether an alkali will neutralize an acid; or for an astronomer to resolve the milky way into stars; or for a naturalist to determine whether a newly discovered animal belongs to one group or another, without going into an inquiry of how all these subjects of study came to exist. And so far as the criticism relates to the interests of a theology of creeds, as distinguished from 
religion, I quite agree with the disciples of Dar. win, that science must be permitted to pursue its course withont let or hindrance.

But the subject of the origin of species belongs to a different categoly. It involves the distinct question of how species came to exist, or to be created. It puts in issue the very point whether species have been created by a train of natural causes alone, or whether those causes are intermediate only, and have been originated, and kept in continual and harmonious operation by a Creator.

Any theory of the origin of species without a distinct acknowledgement of a first and final cause, orjginating, and working by intermediate causes, must lack a foundation. on which to rest. 'The subject reaches beyond secondary causes. We might as well propose to lift the earth with a lever without a resting place-an effort which Archimedes himself would not have essayed, had his lever extended to the planet Uranus.

It would really seem as if the profoundly scientific men of the day were so intensely learned in natural things, as not to be ab]e to look beyond. God cannot be tested in a crucible, or examined through a microscope, or looked at through a telescope; and therefore he belongs to the " $\mathrm{un}$ thinkable and unknowable," - - he is to be profoundly ignored. But when the question is as to how those things which we see in the sphere of nature came to exist, and we trace back from man through a long series of causes down to the lowest 
zoöphyte, we get to the end of our tether, and are left to sink down into a hopeless materialism, unless we can find some evidence in physical nature hy which the existence of a personal Creator may be fairly inferred.

It is a question of evidence. The Creator is not visible to the external senses-therefore, says the materialist, he does not exist. But a great many things, withont being seen by corporeal vision, are proved to be, or to have been in existence, by a process of reasoning on admitted facts. We are permitted to reason from the seen to the unseen. The flame of burning iron gives a peculiar color in the spectrum which never varies-that we see. The same color appears in an analysis of the solar rays, and by this we gain a knowledge of the unseen vapor of iron in the sun.

Has the soul of man ever been seen? Yet who doubts its existence? A plant grows because it has life; yet no one has ever'seen its life; nor does any one doubt it has life. All that we see are the phenomena exhibited by it through its external covering-and the same may be said of every living organism.

Who has ever seen a molecule? Yet it is an induction of science that every material substance is made up of minute particles called molecules, no one of which has ever been obvious to the senses. Science itself, therefore, deals with invisable things, and is estopped from disputing a similar method of proving the existence of Deity. Mr. John Fiske, one of the most earnest advo- 
cates of the prevailing theory of evolution, concludes in reference to all attempts to acconnt for the origin of the universe, that, "the human mind is incapable of obtaining satisfactory conclusions concerning the first cause, the ultimate nature of things, the infinite and the absolute." (14-II-10.)

It may be conceded that the human mind cannot fully comprehend a first cause, or the infinite; but that we cannot draw satisfactory conclusions concerning the existence of a first cause, which is both infinite and absolute, may well be doubted. The human mind possesses an amazing power of reasoning and drawing conclusions from effects to causes; indeed, without such power there would be very little scientific knowledge.

How there came to be a first canse is wholly beyond human comprehension. It is useless to speculate on that subject, as to inquire why there should be existence instead of non-existence, or something instead of nothing. That there is $e x$ istence is obvious to external sensation, but that mind is yet to be found which can comprehend a condition of universal non-existence.

Granted that the existence of a First Cause is incapable of scientific proof-it is equally incapable of disproof. Nor does it follow that such a cause does not exist, or fall within the grasp of human belief, because it cannot be proved by scientific methods. It is just as difficult to comprehend the idea of an endless chain of causes, as that of a First Cause. The mind can grasp the idea of an end, or of a beginning of time, no easier than that 
of an eternity of time; and of an infinity of space, no easier than of an end of space. The one is just as unthinkable as the other; yet we can see that there can be no end of time or space.

Imagine, after passing through billions of miles in space, coming to a barrier to further progress-the mind would at once speculate as to its component material, how far it extended, and what there might be beyond.

It is certainly true that if there be no first cause, there must be an endless chain of causes. From this there is no escape; and it is for the exclusively materialistic philosopher to consider which is most rational, or which most absurd.

It follows, too, that a subject may fall into human belief which is too great for human comprehension.

The same anthor strenuously objects to the idea of a personal God, because "Personality and Infinity" are terms expressive of ideas which are mutually incompatible (14-II-40); because by reason of permitting pain and suffering such a being is deficient either in power or goodness ( $I d .40$ ); because the doctrine of a final cause assumes that God entertains purposes resembling those entertained by man; and this is inconsistent with the overthrow of teleology by science (Id. 382); becanse to represent the Deity as a person who thinks, contrives and legislates, is simply to represent him as a product of evolution; because the definition of intelligence being "the continuous adjustment of specialized inner relations to outer 
"relations," to represent the Deity as intelligent, is to surround it within an environment and thus to destroy its infinity and self existence ( $I d$. 394$5)$.

If the existence of a personal God is to depend upon the prevailing ideas of evolution, or upon the definitions and formulas of professors in science; or upon the fancied overthrow of teleology, it is quite easy to see how the question is to be disposed of. Mr. Fiske accordingly undertakes to shape an idea of Deity, which shall be consistent with the demands of science, resulting as follows:

"Combining therefore these mutually harmonious results, and stating the theorem of the persistence of force in terms of the theorem of the relatirity of knowledge, we obtain the following formula-There exists a Powne, to which no limit in time or space is conceivable, of which all phenomena as presented in consciousness are manifestations, but which we can know only through these manifestations" (14-II-415).

In arriving at this result, he has asseverated and re-asseverated against the idea of a personal God. He has told us in so many words, that this ideal power is inscrutable; and that it is unintelligent follows from the assumption that teleology has ceased to be a factor in solving the problem of creation. This scientific Deity therefore, thus formulated, is impersonal and ignorant-in fact neither more nor less, it would seem, than the blind forces of nature, such as attraction, gravitation, 
heat, electricity, etc., which in combined inscrutability and ignorance have created and now govern the universe: and this, we are assured, restores the harmony between theology and science, and justifies the religious sentiment.

Before coming to this Deistic formula he had said: "That there may be such a thing as disembodied or unembodied spirit will be denied by no one, save those shallow materialists who fancy that the possibilities of existence are measured by the narrow limitations of their petty knowledge." (14-II-395).

What he means by spirit existing without a body, a disbelief in which incurs the fearful penalty of shallowness, does not very clearly appear. Does it constitute one mass, like the vital reservoir of Averroes, or has it individual differentiation?

Is it identical with the "inscrutable power" manifested in the "phenomena of nature; or the "inscrutable existence of which the universe of phenomena is the multiform manifestation?"

Is it the force which gives life to plants? Does it, when embodied, become an instinct in animals and mind in man? Is it to be distinguished from matter, and how?

He says: "The term matter does not stand for any real existence, but only for one of the modes in which an Inscrutable Existence reveals itself to us within the limits of onr terrestrial experience" (id. 455-6); and in this he professes to follow Berkeley. We are, too, informed that the "In- 
scrutable Existence" manifested in the world of phenomena is quasi-psychical" rather than quasimaterial," and that "the intimate essence of such existence may conceivably be identifiable with the intimate essence of what we know as mind."

Now, if we may be permitted to regard "Inscrutable Existence" and "Inscrutable Power" as identical, we reach the point, at least, that the mind of man is spirit, and that it is quasipsychical, rather than quasi-material (id. 448). And inasmuch as unembodied spirit is unintelligent, we must infer that all intelligence is confined to that portion of spirit found embodied as instinct in animals and mind in man-in other words, that there is no supreme and infinite intelligence.

The style of this cosmic philosopher is so exuberant and kaleidoscopic, and his ideas so flash to and fro, like insects in the sunlight, on the most abstruse and recondite subjects, as though they were the mere playthings of fancy, that the reader is, on some points, sorely puzzled to find any resting place for his judgment, and may well be lield excusable for the bewildering conclusion, that the entire region of existence, whether scrutable or inscrutable, psychical or material, is one liuge Doubt.

It is worth consideration to note how much has been the advance of the quasi scientific theology of the present time, beyond that of former ages.

According to the Stoics, as summarized by Dr. Draper: "There is an invisible principle, but 
not a personal God." "There is no such thing as providence, for nature proceeds under inevitable laws, and in this respect the Universe is only a vast antomatic engine. The vital force which pervades the world is what the illiterate call God." The soul of man is a spark of the vital flame, the general vital principle. Like heat it passes from one to another, and is finally reabsorbed or reunited in the universal principle from which it came" (24-24, 25).

'The Vedas believed in a mniveral all-perrading spirit or intellect. "There is in truth but one Deity, the Supreme Spirit, he is of the same nature as the soul of man." "The soul is an emanation therefrom, and is clestined to be eventually absorbed therein."

Averroes, who flourished in the 11 th century of the Christian era, commented upon and systematised prior dogmatic theology with the following results :

"This system supposes that at the death of an individual his intelligent principle, or soul, no longer possesses a'separate existence, but returns to, or is absorbed in the universal mind, the active intelligence, the mundane soul which is God, from whom indeed it had originally emanated or issued forth. The universal, or active, or objective intellect is nncreated, impassible, incorruptible, has neither beginning nor end; nor does it increase as the number of souls increase. It is altogether separate from matter.

"The individual, or passive, or subjective in- 
tellect is an emanation from the universal, and constitutes what is termed the sonl of man. In one sense it is imperishable and ends with the body, but in a higher sense it endures, for after death it returns to and is absorbed in the universal soul, and thus of all human souls there remains at last but one, the aggregate of them all. Life is not the property of the individual, it belongs to nature. The end of man is to enter into union more and more complete with the active intellect, reason. In that the happiness of the soul consists. Our destiny is quietude" (24-139).

This retrospect shows that modern evolution, as expounded by Mr. Fiske, has not succeeded in constructing a science of Deity essentially different from prior conceptions on the subject for the last 2,500 years. An impersonal Power, which has no limit in time or space, and which neither thinks or legislates, is no improvement upon the idea of a grand reservoir of souls dreamed of by the stoics, and reburnished by Averroes. If our souls are only sparks projected, like Roman candles, from a grand reservoir of the vital forces of nature to which they are destined to return and remain in a state of beatific quietude, the illiterate may well query why they are sent out at all--why temporarily interrupt their state of rest for the sake of passing through a life of toil and suffering in a physical body? The same class of persons might also be inclined to think that a reservoir made up of the souls of all the knaves and murderers of 
the universe, intermingled with those of the honest and virtuous, would form a seething mass of fermentation in which there could bo neither rest nor happiness.

This miversal Intellect (or Animus Mundi) is alleged to be "uncreated." If so it would be a First Cause, inasmuch as it would have existence without creation: and if it be philosophical to believe in it as a First Cause, why should it be absurd to believe in a personal God as such?

According to Haeckel the sense organs are the true springs of our mental life, and exceed all other parts of the animal body for extremely delicate and complex anatomical contrivances, coüperating for a direct philosophical aim-so much so, indeed, as to seem to indicate a premeditative design. Nevertheless on mature consideration he thinks the Creator "on this conception does after all play the part of an ingenious mechanic, or a skillful watch maker, just indeed as all these cherished teleological conceptions of the Creator and his creation are based on childish anthropomorphism" (2-234).

Upon the premises here stated, it is difficult to conceive how a conclusion so ntterly at variance with any known system of reasoning (to say nothing of common sense) could be drawn by any one, much more by a distinguished professor in science. He admits that, at first sight, the teleological explanation seems to afford the simplest and fullest interpretation of these very apt contrivances, but insists that the history of evolution 
proves that these organs have developed without premeditated aims - that it is purely a mechanical process by natural selection. But then arises the question-how did the mechanical process of nat. ural selection come to exist?

It would be just as absurd to say that the watch put itself together as that the one-celled moner could exist of itself and become the starting point of those vast processes of evolution by which the world is filled with evidences of de. sign.

The idea of personality does not necessarily preclude that of omnipresence. The mind or soul of man has its seat in the brain, yet by its nervous connections it is present in every part of the body. The sun has its position in the center of its system, yet it is present everywhere in that system by its heat and light, which are its essential components, as well as by its power of attraction. It is, too, the proximate creator of all its planets and of all the forms, animate and inanimate, which pertain to them.

Who or what is the sun's creator we can form no idea (aside from revelation), except by closely observing the phenomena of the visible universe in connection with that of mind. In doing this we must take things as they are rather than as we would have them. Being in the sphere of nature, we can only approximate the truth as to the why and the wherefore of creation. That there is a power above or superior to matter is recognized by most cosmic philosopher's under the terms 
"Absolute Power," "Inscrutable Existence," "Inherent Powers," and the like. But they deny personality and intelligence to be any efficient cause of creation, because of the existence of pain and suffering; because it implies design in the work of creation; because it is not consistent with the origin of species by natural selection, \&c., \&c.

Of conrse we are all of us on this subject somewhat in the condition of the fly upon the wheel, which can neither understand its composition nor mpon what principle it revolves; or more to the point still, we are like the ox in a scant pasture separated by an inclosure from a rich meadow, which may be supposed to marvel why he is not permitted to feed upon the luxuriant herbage within view, not knowing that such indulgence would insure starvation the ensuing winter. But we have minds immensely in advance of the fly and the ox, by which we have been able to push our investigations to the ontermost limits of nature's domain, and stand face to face with "The Unknowable.'

The author of Cosmic Philosophy, with the air of one who thinks he cannot be mistaken, says:

"A scheme which permits thousands of genera. tions to live and die in wretchedness cannot, merely by providing for the well being of later ages, be absolved from the alternative of awkwardness or malevolence. Il there exists a personal creator of the muiverse, who is infinitely intelligent and powerful, he cannot be infinitely good; if, on the other hand, he be infinite in goodness, then 
he must be lamentably finite in power or intelligence. By this two-edged difficulty Theology "has ever been foiled."

Mr. Spencer, in controverting the dogma of special creation, pursues the same method of reasoning, as applicable to animal life. He finds that the earth is largely peopled by creatures which inflict on themselves and each other pain and suffering; that animals are endowed with countless pain inflicting appliances and instincts; that universal carnage-a ceaseless devouring of the weak by the strong-has been going on from the earliest geologic era; that whoever contends that each kind of animal was specially designed asserts the deliberate design of the Creator to produce these results, or an inability to prevent them; and he asks, why they were not constructed in such a way as to aroid these evils. (5-I-341.)

The subject here involved is by no means new. How evil originated, or why pain and suffering have been permitted under the govermment of a Creator infinite in power and goodness, are questions long known to polemics.

Yet conceding that Theology, as usually systematized, has been foiled by it, the alternative of resigning the control of the unverse to an "Absolute Power" destitute of either identity or intelligence is not reassuring, and the logician may well ask how the situation has been improved.

It follows from the train of reasoning adopted by these critics, that creation founded upon de- 
sign, whether through the process of evolution or. otherwise, subjects the Creator to a philosophic indictment for malevolence or imbecility, and to escape censure he should have created animal organisms wholly devoid of nervous sensation; and as we can have no idea of a capacity for pleasure withont a capacity for pain, creation should necessarily have begun and ended in globules of protoplasm.

Starting with the existence of an all-good, allwise and all-powerful Creator as a postulate, we may, I think, as consistent therewith, infer the following :

(1.) The immediate existence of the Creator is in the sphere or world of primary causes, from which the physical world, or world of secondary causes and effects, has been created, and in which the Creator is always mediately present.

(2.) As between Creator and created the latter is inferior and relatively imperfect.

(3.) The laws of the relation between secondary causes and effects, as we see them manifested in the visible universe, are laws of the Creator's providence, and are uniform.

(4.) It was no part of the scheme of creation that man should always live in the sphere of nature, as is evident from the fact that the earth has not the capacity of sustaining a continuous propagation of a human race not subject to physical death.

(5.) Physical death being thus a foregone conclusion, the earth must be regarded as a seminary 
of preparation, in which man is, so to speak, in a chrysalis state, from which his spiritual or imperishable part emerges into the world of causes; and that which we call death is really a birth, and is as much a necessary incident of his being as that of his physical birth.

These standpoints may enable us to form a more rational view of the vicissitudes through which animal existence must pass in this world, in connection with the idea of a personal and intelligent Deity.

In an orderly state of human existence, physical death would probably occur from the gradual decay of the material body. There have been instances of persons living to a ripe age passing into the world of causes, as if falling asleep, without pain. But the physical world is full of disorder, arising from the unlimited freedom of the human will. Hence suffering and death occur in the countless instances in which the laws regulating the forces of nature are disregarded, and in which those providing for the safety of social systems are violated.

A man is shot through the heart and dies. What killed him? Proximately death ensued by his heart being pierced by a bullet propelled by the explosive force of gunpowder in a gun ; and the latter was in the hands of another, and fired with intent. Here was a train of secondary causes put intoactivily by a human will; and in common speech, the man was killed by his fellow man.

The murderer, in his turn, is hanged by the 
sheriff. He had a fair trial, was convicted by the jury and sentenced by the judge. Who of these several agencies occasioned the death of the criminal? Proximately it was the executioner. Yet he is no more accountable for the act than the judge, or the jury, the whole trio being only the agents of the law. Here again is a mere sequence of cause and effect, put into motion by the man himself, when he violated the law in committing the murder.

There is as much necessity for uniformity in the operation of the forces of nature as for freedom of action in living creatures. Suppose they were not uniform; suppose the hand, in the flame should burn on one day and freeze the next; suppose heavy bodies should start off into space at one time and remain fixed at another; suppose one stream of water should flow up hill and another down. It is easy to see that no state of orderly existence could be framed or maintained under such chaotic surroundings.

Mr. Spencer's argument against the idea of cretion from design, because of the ceaseless carnage by predatory animals, is not as well-founded in fact as in appearance. That any class of animals shonla prey upon another is, of nocessity, to keep duwn over production and keep up equilibrium; of this therecan scarcely be a question. But as to the suifering produced by this carnage, there are grounds for believing that very little, if any, is inflicted, the animals in this way being de. stroyed for food. The attack is always violent 
and the victim is suddenly killed. A soldier instantly lilled on the battlefield feels no pain whaterer; those who are wounded feel little or 110 pain until some time has elapsed. The celebrated African explorer, Livingstone, was attacked and severely wounded by a lion, and bears testimony that he was insensible to pain until a short period after he was rescued. The conclusion is fair, that in this kind of carnage the victim feels less (certainly not more) pain than in dying a natural death.

Those who see a want of design in creation by reason of pain and suffering, do not take in to acconnt that there can be no enjoyment or pleasure without nervous sensation, and that necessarily involves the liability to suffer pain. Pursuing this a little further, it may be said that we can scarcely form an idea of anything without its opposite, that, in fact, we learn about everything, either by direct contrast, or by those differences which exist, and by which we are able to compare one thing with another. Suppose the thermometer to stand ever at $75^{\circ}$ Fahrenheit, what possible idea could we form of heat or cold? Suppose the sum to be always at meridian, unobscured by a cloud, the sensation of light or darkness would never be felt. Suppose there to be and to have always been but one uniform color thronghout the entire realm of nature, the words white, red, black, blne and green, would never have formed a portion of hnman speech. Suppose sound limited to one unvarying tone, the human ear would 
never be charmed by music nor pained by discord. The sense of beauty would be wholly wanting without these differences, by which one thing can be compared with another, in a scale ranging from beauty to deformity.

Without liability to the infliction of pain in its various gradations from annoyances, vexations and discomforts to positive suffering, it is difficult to see how the mind of man could ever be roused to any effort whatever. Surely, the unchanging and nniform monotony which is demanded by the opponents of creative design would have resulted in a degree of mental torpor which belongs to the lowest organism known to zoological science.

An impersonal Deity, made up of the aggregate of physical phenomena, and destitute of intelligence is equivalent to regarding Nature as God. Such a Deity is formless, and for that reason, if none other, the mind can form no definite idea of it. Subjectively we reason about gravity, force, beauty, power, benevolence and so on; but objectively we can only know, or form an idea of these qualities except as connected with some distinct object or personality. Gravitation we only know as it belongs to ponderable bodies; force is manifest to us in machinery, vital actions \&c., beauty we can admire as we see it in the human form, paintings, statuary and innumerable other connections; and truth, honor and benerolence are only manifested to us as personal qualifications.

As already noted, there is nothing in the visible 
universe which does not owe its existence to some adequate cause, or chain of causes; and the relation of causes to their effects are so uniformly regular and constant, that the like cause is always known to produce the like effect. So unchanging is this relatively, that it forms the basis of niost subjects of human thought and of human actions as well. Upon this basis is built up the various mechanical devices, showing innumerable evidences of design which can be traced to a personal author. The bird builds its nest, and each one its own peculiar nest, of which the design is obvious. So the spider weaves its web, and the bee fashions its honey cells. When we see the nest, the web, and the honey comb, we know them to be the work, in each case, of an animal having a personal identity.

In like manner, the wonderful and varied works of man are at once traced to the agency of individ. ual men. If, then, we see design in the machinery of the material universe, it is a fair logical deduction that the power which put it in motion had and has a personal identity.

We may, I think, go a step farther, and gain some idea of the grade of mind, or life, from the nature and extent of the work. Animal architecture, as we know, is confined and restricted within well defined limits. One kind of bird constructs one kind of nest, and no other; nor does it ever improve upon the original pattern. But in man's case there is a constant improvement; nor is there 
any apparent limit to his capacity to build on the former works of his race.

The question then forces itself upon the mind: Is there no evidence of design anywhere in creation except that exhibited by men and animals? Upon this point the reasoning of some of Darwin's followers is, to say the least, somewhat extraordinary. The watch was made to keep time-that was the purpose and intent of the one who made it - a fact beyond dispute. Well, say I, the eye was made to see with-at any rate it does not appear to be good for anything else; and in fact it is a better sight-seeing machine than the watch is a time-keeping one. But, says the sceptic, there is no personal creator-therefore the eye was not originally designed for that purpose. 'This leads to the inference that the eye was constituted, or constructed itself, without any design at all-its sight-seeing qualities being merely an accident.

All particles of matter are attracted to each other with such persistent force that the earth is kept together in a form convenient for motion through space, and sidereal systems are maintained so orderly, permanent and vast as to constitute a standing wonder. Yet upon the same assumption, it is all without design, though a personal human mind originates machinery founded upon the same relativity with design. Surely this logic is faulty. Reasoning from a relation of cause to its effect, the inference is just as fair that the sidereal machinery is the result of an intelligent purpose, 
as in the case of the human machine-the latter, in fact, furnishing the basis for such inference.

When we are able to connect evidences of design with a personal and intelligent author visible to us within the sphere of nature, we may rationally draw the conclusion that similar manifestations of design found in the structure of organic forms, or in the movements of the heavenly bodies, furnish proof of the existence of an intelligent personal power above nature, and therefore not visible to the natural eye.

The works of man require the exercise of thought-and there can neither be mind $\mathrm{Or}^{\circ}$ thought without personality. A man constructs a lamp to give light when needed. The office of the sun is to give light and heat; and it is never extinguished or burned out, like the human lamp. The conclusion is just as logical, that the sun owes its creation to a personal creator, as that the lamp was constructed by human personal agency. Experience shows that the greater the worls the greater the mind which produced it. Therefore, as the works of man are in a certain sense infinitely above those of animals, so the human is infinitely above the animal mind. Apply the same rule to the created universe, and make the same relative comparison, and we gain some idea of a personal God, with a mind infinitely above the human.

Mr. Robert G. Ingersoll, whose onset upon those of the Christian faith reminds me of a fierce charge of cavalry, in one of his efforts in that di- 
rection says: "I know as little as any one about the plans of the universe, and as to the 'design' I know just as little. It will not do to say that the universe was designed, and therefore there must have been a designor. There must be proof that it was 'designed." (North Am. Rev., Tol. 133, p. 479.) Does Mr. Ingersoll mean that the machinery of the universe, with all its clock-like regularity of movements, and of its uniform obedience to the laws of cause and effect, is of self-existence or the offspring of chance? If so, it would be quite as pertinent to ask him to prove this "plan" of existence as to require of his adversary proof of the existence of a designor. To the scientific mind there is inferential proof of design in the construction of the mniverse, which in strength falls so little below the evidences of design in human works as to render a contrary inference next to an absurdity.

One of the fancied achievements of modern science is the total demolition of the doctrine of Teleology as applied to the created universe. $\mathrm{Mr}$. Fiske, by an accommodating logic, proves it is untrue because it is inconsistent with Darwin's theory of evolution. Mr. Spencer indulges, with lively badinage, in saying that if a watch could leason it would call the Deity an infinite watch, as the man calls it an infinite man. ${ }^{*}$ And Huxley, in a similar vein, caps the climax by supposing

* The inference is illogical. If the watch could reason it would deify man, because it would recognize man as its creator. 
that cats-were designed to catch mice, and are therefore perfect mousing a pparatuses. $(7,303$.) But Haeckel, in a more sober view, finds conclusive evidence agairist Teleology in the existence of rudimentary organs. He says: "If a man and every other organism had been designed for his life purpose from the beginning, and had been called into existence by an act of creation, the existence of these rudimentary organs would be an incomprehensible enigma, and it would be impossible to understand why the Creator should have laid this useless burden on his creatures in this life journey, so arduous at the best." (2-439.) It would have been better if this learned professor had cited a single instance of a burdensome rudimentary organ. Is the rudiment of the mammx, or of a tail, or of hair, burdensome to a man-or of that of a second or third toe to a horse? On the other hand the power of the organism to adapt itself to changing conditions, by which many of these organs have been produced, would tend to show evidence of design.

The avowed basis on which the argument against teleology rests, is the assumption that organic life, being the product of evolution, contains no evidence of design. If this be true, it follows that the force or process by which evolution is effected is without design; and then we haye presented to us in nature this singular want of harmony, to wit: That whereas there is stronger evidence of design in the mechanism of the stellar universe than in that of a steam engine, yet there is no evidence of 
design in the wonderful mechanism of the human body.

The underlying difficulty with the modern scientific theorist, is in failing to have any conception of that power which puts into activity all the, so. called, forces of nature, including that which effects evolution. The truth is there is stronger evidence of design in the evolution of organic structures than in the machine constructed by man, because the animal, within certain limits, has a power of adaptation to changing circumstances, which the machine has not.

It is difficult to see how the belief in the existence of a personal Diety could have obtained a lodgment in the mind except upon the basis of its truth. The belief may now be regarded as universal, save with those men of science who have reasoned themselves into disbelief. If nothing really existed beyond or above the sphere of nature, including the reservoir of beatitudes mentioned by Averroes, then it is reasonable to suppose our ideas would be limited and bounded by it, as a stream never rises above its fountain; and the idea of a personal God would be utterly impossible.

It is true, certain savage tribes are mentioned by travellers as being atheists, and destitute of any idea of religion or of a future life. 'Thus, in Sir John Lubbock's "Origin of Civilization" (158), "it is said of the Australians:* They have noidea

\footnotetext{
* The Australians are regarded as among the very lowest in the human scale.
} 
of creation, nor do they use prayers; they have no religious forms, ceremonies or worship. They do not believe in the existence of a Deity, nor is their morality in any way connected with their religion, if it can be so called."

But the subsequent patient investigation of mis. sionaries has shown these statements to be wholly unreliable. Thus, Mr. Tylor in a work on Primitive Culture, quotes the Rev. IV. Ridley, to the effect that whenever he has conversed with the aborigines, he found them to have quite definite traditions concerning supernatural beings, as Baime whose voice they hear in thunder and who made all things."

Another missionary (Stanbridge) is quoted as asserting that, so far from the Anstralians having no religion, they declare that Jupiter, whom they call "Fount of Day," "(Chinabong Beary) was a chief among the old spirits, that ancient race who were translated to heaven before man came on earth." (25-r-378). In relation to other savage tribes Mr. Tyler says: "The statement that the Samoan Islanders had no religion cannot stand in the face of the elaborate description by the Rev. G. Turner of the Samoan religion itself, and the assertion that the Tapinombas of Brazil had no religion is not to be received withont some more positive proof, for the religious doctrines and practices of the Tapir race have been recorded by Lery, DeLaet and other writers." (25-I-387). 
It is now discovered that fetichism in Africa is something very distinct from the real religion of the Negro. "There is ample evidence to show that the same tribes who are represented as fetish worshipers, believe either in Gods, or in a supreme good God, the creator of the world, and that they possess in their dialects particnlar names for him." (41-103-4). So the Kaffirs and the Congo races (who are distinct from the negro), are represented as having well defined languages, and religions ideas of great sublimity. (Id-66).

Quatrefages, in chapter 34 of his very interesting work entitled, "The Human Species" (published 1880), conclusively shows from the latest researches, that there is no human race yet found destitute of some lind of religious belief in a Deity, or in a lile after physical death. And he ascribes much of the misrepresentations on the subject to the high opinion which the European traveller has of himself, and his intolerance of beliefs differing from his own. He says:-

"A traveller who as a general rule speaks the Janguage of the country very badly, interrogates a few individuals upon the delicate question of the Deity, future life, \&c., and his interlocutors not understanding: make a few signs of doubt or denial, which have no reference to the question asked. The Enropean in his turn mistakes the meaning. Having in the first instance merely regarded them as beings of the lowest type, incapable of any conception however triffing, he concludes without hesitation that these peoples have 
no idea, either of a God, or of another life." ( $p$. 473).

In reference to faith in a personal Deity, the scientific mind has departed from former land marks to a greater extent in this than in any former period; and from its minnteness of research and subtlety of reasoning, has presented grounds for scepticism not easily overcome. It is gratifying, therefore, to find some evidence that the tide of unbelief is beginning to ebb, in the following conclusion arrived at by Prof. Wm. B. Carpenter: "As a physiologist, I most fully recognize the fact that the physical force exerted by the body of man is not generated de novo by his will, but is derived from the oxidation of the constituents of his food, holding equally certain, because the fact is capable of verification by every one as often as he chooses to make the experiment, that on the performance of every volitional movement, physical force is put, directed by the individualities or ego. I deem it just as absurd and illogical to affirm that there is no place for God in nature, originating, directing and controlling its forces by his will, as it would be to assert that there is no place in man's body for his conscious soul." (1-vi-625). 


\section{CHAPTER X.}

The order of Creatzon, from the lowest form to Man.

The order of the creation of animal life upon the earth has almost uniformly been from rudimentary and imperfect forms, in regular succession, to those which luave been more and more perfect-perhaps it would be more correct to say - from generalized to specialized ty pes.

There are indeed cases, or supposed cases of retrograde metamorphism, in which some animals at birth show resemblances to a somewhat higiner grade than at its adult state; but these (alluded to hereafter) do not essentially conflict with the general rule.

WV do not precisely know what was the elementary appearance of the sun; but we know enough reasonably to infer that it was an immense nebula of fire, which by rapid motion has thrown off successively the planets. In what way the planets were thrown off is of course matter of speculation; but we may suppose them to have been in the form of rings, which, as a general rule, 
being of irregular shape, broke up and ran to. gether into globes. That such was the case receives confirmation in the facts that their axial and orbital motions are alike in direction. The earth gradually cooling and condensing, became finally fit for the reception of life; and what is true of the earth, we have every reason to believe is the case with all the planets of this, and of every other solar system.

The history of creation, as written in the rocks, gives us the successive order of the introduction of all such animals as are capable of being fossilized. This history commences in the Laurentian, a formation of immense thickness underlying the Cambrian, and shows a progress of life from the lowest to the highest forms.

According to Principal Dawson the lowest known fossilized evidence of life is the Eozoon Canadense, discovered by him in the Lower Laurentian (Canada), and so named by him from its possible connection with the dawn of life $(2 \%-23)$. It could thus be preserved, for the reason that it was able to cover its gelatinous body with a thick crust of carbonate of lime. But the very dawn of animal life must have been manifested long prior to the Eozoon, in the lowest of the Protozoa, which conld not leave their impress upon the rocks. Probably the very first appearance of Iife was in the vegetable Diatomaca, still perpetuated at the bottom of the seas. The remains of this primitive vegetation, together with the Protozoan animals which subsisted upon it, 
may well be supposed to enter into the formation of the Laurentian limestone beds.

The Upper Laurentian, so far as known, contains no remains of organic life, though it must have existed and advanced during the deposition of those immense beds.

The Cambrian (or Primordial as heretofore designated) immediately overlies the Lamentian, and is a series of sandstones, limestones, slates, \&c. In those beds are found the evidences of a continuous creation of low forms of life in the Protozoa, and in the great types below the vertebrate. The Articulates are represented by hundreds of species including Trilobites and sea worms. Among the Molluscs, Brachiopods appear in great abundance in the Lingula Slates, and are the only evidences of Mollusc life in that period, except some species of Lamellibranchs, Pteropods and Cephalopods, found in the Upper Cambrian. A few speries of star fishes represent the Radiates. Some Fucoids-the impression of fuci-a class of low sea plants, are found in the Skiddaw Slates.

To the Cambrian succeeds the Silurian fomation in beds of great thickness, divided into upper and lower.

In the Lower Silurian among the Radiates is the commencement of Polyp life, whose swarming millions subsequently built up the vast coral reefs, which have excited so much wonder and admiration. Graptolites also appear in great abundance-also the Cystidea, a low crinoidal 
form with tentacula, being introductory, in order of time, to the true Crinoidea-resembling star fishes at the end of a flexible stalle with numerous tentacles. The additions to the Molluscs are Bryozoans, the Nautilus, and several species of Orth. ocera, one of which had a shell from 12 to 15 feet in length, and took the lead of the Trilobite as the most important animál of the period.

In the Upper Silurian there is a continuation of the same groups among the invertebrates, with some changes and additions, in which appear a number of Crustaceans. But what peculiarly distinguishes this formation is the appearance near its close of the first introduction to vertebrate life. According to Prof. Dana - "They are fishes, and have been found in the Ludlow beds of Great Britain. There are teeth, scales and other relics, chiefly of the shark-like species" (28-98). Principal Dawson says-"They appear to have bad cartilaginous skeletons, and in this and their shagreen-like skin and strong bony spines, and trenchant teeth, to have much resembled onr modern sharks, or rather the dog fishes, for they were of small size. One genus-Pteraspis-apparently the oldest of the whole, belongs, however, to a tribe of mailed fishes allied to some of those of the old red sandstone" (27-74).

It is not, lowever, safe to assume that becanse the remains of these incipient sharks or dogtishes are found in the mpper Silnian, they are therefore the beginning of vertebrate existence. The lowest known form of vertebrate life is the Amphioxus 
lanceolatus of the modern seas-an animal having a spinal cord, but no differentiated brain. The next above are the Hag fishes \& Lampreys, which have brains. These animals, like the Rhizopod, are not capable of fossilization-yet from the uniform succession from lower to higher forms, it is fairly to be inferred that they both existed prior to the Pteraspis, or shark.

Looking back at the close of the Silurian, it will be seen that life commenced in a formation below that which has heretofore been regarded as the Primordial, and in an organism scarcely removed from the inorganic, a mere drop of shapeless jellyand advanced from thence in different types to the dawn of vertebrate life in the upper Silurian. During this process, and rising from lower to higher, more than 10,000 species of animals are estimated to have appeared. Land also must have been upheaved, inasmuch as in the Oriskany beds are found the remains of terrestrial species of plants related to the Lycopods or Ground Pines.

Prior to the Amphioxus, or of the shark-like Pteraspis, the only animal existences were the miscellaneous Protozoa, and the three great typesRadiates, Molluses and Articulates.

The next great geologic age is the Devonian, which includes the celebrated Old Red Sandstones of Great Britain. In the United States it appears in the Hamilton, Chemung, and Catskill groups. In this age large numbers of old species drop out, giving place to more advanced ones. Its distinguishing features are an extensive increase of land 
developments, and a great abundance of corralines, fishes, forest trees and some species of insects. The fishes were sharks, Ganoids and Placoderms. The two first were highly predaceous and checked overproduction in more peaceable animals.

One genus of Ganoids (Holoptychius) appearing at the close of the era and passing into the next, had several characteristics approaching reptile life-such as a lung-like structure of the air bladder-and hence may be regarded as the medium of introduction to the Amphibia and Reptitia.

A new type of Cephalopods is found in the middle Devonian. Among the Articulates, the Trilobite disappears and gives place to the Eurypterid, a monster crustacean some six feet long, thus described by Dawson:

"Its antennæ were, unlike the harmless feelers of modern crustacea, armed with powerful claws. Two great eyes stood in front of the head, and two smaller ones on the top. It had four pairs of great serrated jaws, the largest as wide as a man's hand. At the side were a pair of powerful paddles, ca pable of urging it swiftly through the water as it found its prey, and attacked by a predaceous fish, it could strike the water with its broad tail, terminated by a great telson and retreat backward with the rapidity of an arrow." (27.94.)

In plant life the conspicuous features were forests upon the low marshy gromnds of cryptogamons or flowerless plants. Among these were Lycopods of the size of forest trees, now only four or five fect high, and having leaves like the spruce 
or cedar. There were also Calamites, or tree rushes, twenty feet or more high and six inches in diameter, now extinct. Among the flowerless plants there were Conifers, related to the common pine and spruce.

'To the Devonian succeeded the Carboniferous, a remarkable era in the history of creation, in which are found stored in the bowels of the earth those vast collections of coal and mineral oil, to serve the purposes and advance the civilization of man in after ages. It is divided by geologists into sub-carboniferous and carboniferous proper, the latter of which contain the coal deposits. It is proved beyond a doubt, that the coal beds have been produced by the carbonization of vast accumulations of the rank, marshy vegetation of the period, somewhat after the manner of the formation of peat. The earth at this period seems to have been a vast forcing bed watered by almost continuous rains, by which plants, now dwarfed to a few feet highl, were stimulated to a growth of forest trees. The distinctions of climate must have been wanting; and the famma and flora of the poles probably rivalled those of the tropics.

Animal life in this era followed the prevailing law of the decline of the old, and the introduction of new, more numerous and more adranced species. Of the articulates among insects appeared may and shad flies of gigantic size, some species measuring seren inches long in expanse of wing. There were also locusts and cockroaches-beetles of the Curculio family, so troublesome to the 
modern horticulturist, and Millipedes resembling worms, but more nearly allied to insects. There were also spiders, centipedes and scorpions. Of the Molluses, two species of land suails appeared, and there was an increase of Brachiopods and Bryozoans.

But the most marked feature of animal life in this age was the introduction of Sanrian reptiles among vertebrates. According to Dawson these reptiles bridge over the spaces between fishes and birds. "I an sure," he says, "that there were animals in those days which were Batrachians in some points and true reptiles in others, while there are some of them in regard to which it is quite uncertain whether they are nearer to the one group or the other (27-144)."

The most fish-like were the Archegosanrus found at Saarbruck. Their large heads, short necks, supports for permanent gills, feeble limbs, and Jong tails for swimming, show that they were aquatic creatures, presenting many points of resemblance to the Ganoid fishes with which they must have associated; still they were ligher than these, in possessing lungs and true teeth, though perhaps better adapted for swimming than even for creeping $(27-145)$." From these is a divergence to gigantic Saurians, ending finally on the one hand in the modern crocodile, and on the other in a small, delicate lizard like species, living on land and feeding on insects.

Of the Saurian class are the Baphetes and Eosanrus of the Nova Scotia coal fields, and the Anthra- 
cosaurus of that of Scotland, and the Protosaurus of the Permian. Of the lizard is the Hylonomus, from hollow fossil trees of Nova Scotia, imagined by Dawson to be "a little animal six or seven inches long, with small head, but with a raised forehead, giving it an aspect of some intelligence $(27-148)$.'

Geologists have generally divided geologic time into four great elas: 1. Archaan (beginning). 2. Paleozoic (ancient life). 3. Mesozoic (midale life); anc Cenozoic (recent life). The Laurentian beds were deposited in Archaan time (the Eozoic of Dawson). The Silurian (including the Cambrian), D vonian and Carboniferous, completed Paleozoic time.

Mesozoic time is divided into the Triassic, Jurassic and Cretaceous periods. In the Triassic and Jurassic there was not much change in plant life. There were no forests of Lepidodendrids and Sigillarias as in the Carboniferous-though there were numerous Ferns, Calamites and Conifers. But during these periods Cycads, a species of plants partaking of the character of Ferns, Conifers and Palms, became prominent.

In Mesozoic time the sub-kingdom of verteblates was represented in all its classes of fishes, birds and mammals. The fishes were still cliefly Ganoids and Selachians. The Reptilia were more fully developed than any other form of animal life. The Labirynthodont succeeded the Alchegosaurus minor of the Carboniferous, and was a frog-like amphibian of great dimensions, having a skull 
two feet in length, teeth three inches long and body covered with scales, and seems to be a transition type between the fish-like batrachians, lizzards and crocodiles.

The Enaliosaurs (swimming reptiles) were the first true reptiles, and more than fifty species have been found in the Jurassic division of Mesosoic time. The most comm on of their class were Ichthyosaurus and Plesiosaurus, both animals of extraordinary size, measuring from twenty to thirty feet in length, thongh differing from each other very much in detail. The Ichthyosaurus is found in the Lias, the lowest of the Jurassic deposit. It had enormous eyes, rivalling in size the ordinary dining plate, a short neck, large head and long powerful jaws armed with strong teeth, and must have possessed a capacity for destruction beyond that of any other predaceous animal.

The Plesiosaurus resembled its congener in the structure of the back bone, limbs and tail; but it evidently foreshadowed the serpent in its long, flexible neck and small that head. "In comparing the two (says Agassiz) it may be said that as a whole the Ichthyosaurus, though belonging by its structure to the class of reptiles, has a closer resemblance to the fishes, while the Plesiosaurus is more decidedly reptilian in character" (35-21\%.) The Pliosaur, a relative of the Plesiosaurus, is thus described by Darson-. "The head in some of the species was eight feet in length, armed with conical teeth a foot long. The neck was not only long, but massive and powerful, the pad- 
dles, four in number, were six or seven feet, in length, and must have urged the vast bulk of the animal, perhajos forty feet in extent, through the water with proligious speed" (27-215).

The Dinosauria, found in the IVealden beds, were an advance gromp of the Samian family, and appear to initiate the diverging line between mammals and birds. Some of the species vere of gigantic size and others comparatively smallsome herhivorous, others carnivorous. One species, the Iguanodon, a gigantic biped, was "twenty feet or more in height, with enormous legs, shaped like those of an ostrich, but of elephantine thickness. It strides along, not by leaps, like a kangaroo, but with slow and stately tread, occasionally resting and supporting itself on the tripod formed by its hind limbs and a huge tail like the inverted trunk of a tree" (27-202). Its feet were three-toed, like birds, and it is supposed to have grazed on trees along the borders of marshes, estuaries and streams. *

Another species, the Megalosamrus, was a carnivorous animal, found in tile latter part of the Jurassic and of a size fully equal to that of the Iguanodon. This huge beast appears to have a compound of bird and mammal-bird in the structure of its limbs and pelvis-mammal in its circulation and respiration; and its general habits are

* - This monster is cast into the shade by Prof. Marsh by the discovery in Colorado of the Atlantosaurus, a land animal of over 60 feet in length and 30 feet in height. 
supposed to have been similar to those of the Kangaroo.

Another advance bird-wise was the bat-like Pterodactyl of the Jurassic, a flying reptile. It resembled a bird in its hollow bones, circulation and general form adapted for flying; but it had no feather's, its wings were something like those of the bat, and its mouth was full of teeth. 'To a certain extent it bridges over the space between reptiles and birds.

The next step in the same direction is the $\mathrm{Ar}$ chæopteryx, a genuine bird, found in the quarries of Solenhofen (Jurassic). It has feathers, and the expanse of the wing was made by long quill feathers, instead of an expanded membrane. But at the same time it showed its reptilian descent by its long vertebrated tail and finger-lilie claws on the fore limb or wing, like those of the Pterodactyl. In fine, the one may be said to have been three parts reptile and one bird, while the other was three parts bird and one reptile.

In the same connection may be mentioned the Rhynchosaurus of the Trias, having the body of a reptile and the beak and feet of a bird; and this animal, it is believed, preceded certain species of the ostrich tribe, of which a living species-the Apteryx-is found in Austraila. This last has imperfectly developed wings, a diaphragm, and feathers somewhat resembling hair.

There are strong grounds for believing that the diverging lines from the reptilia to birds and to mammalia start in the Monolremata, composed of 
two genera, Echidna and Ornithorhynchus, of which the common peculiarities are, a kind of clavicle common to both shonlders, placed in front of the ordinary clavicle, and analogous to furcula among birds, five claws on each foot, the male having a spur on the hind legs resembling that of a cock, and a single exterual opening for the alimentary canal and the genito-urinary organs. With these bird-like peculiarities are mited a quadrupedal form-lungs freely suspended-a diaphragm-rudiments of teeth-and a general agreement of the skeleton with that of other manmiferous animals. The Ornithorhynchus has a broad flat beak like that of a duck, with molar teeth in the gums on each side of both jaws; the posterior toes are united as far as the nails and the body covered with hair. (1-xrr-76.)

Darwin says: "The Monotremala have the proper milk-secreting glands with orifices, but no nipples, and as these animals stand at the very base of the mammalian series, it is probable that the progenitors of the class possessed in like manner the mill-secreting glands but no nipples." (9-r-200.) It is highly probable, therefore, that the early progenitors of these animals existed immediately prior to the marsupials.

Over thirty-three species of a low grade of marsupials have been found, all closely allied to modern ones in Australia, and some of them are not so low as the Ornithorhynchus and Echirna.

Prof. Dana, in his Text Book, says: "As marsupials are semi-oviparous mammals, and there- 
fore are the intermediate between ordinary mammals and the inferior and oviparous rertebrates, it follows that both the birds and mammals of the Mesozoic were in part, at least, comprehensive or intermediate types, and partook of reptilian features in the Reptilian age." (28-180.)

The first geologic evidence of mammalian existence is the genus Microlestes, found in the red sandstone of the Trias in England-a small insectivorous quadruped resembling the Mrymecobius of Australia. In the Lias next above is the Dromatherium, approaching still nearer Iryrmecobius. The Phascolotherium, found in the lower' Oulite, resembles the Opossum. The lower jaw of the Stereognathus was found in the same formation, and Prof. Owen, after a very critical examination, says: "We can only infer it to be more probable that the fossil was a herbivore than. an insectivore, or a mixed-feeding carnivore." Yet he concludes it cer'ain that it was not hoofed (Encyclopedia Britt., Vol. 17, p. 15, 8th Ed.) If so, it would appear to be an introduction to the mammalia.

Further up in the Oolite series are the remains of extinct species of mole; also the genus Plagiaulax, a carnivorous marsupial. These marsupials, now represented by the kangaroo and opossum, it thus appears, occupy an important and interesting position in the creation of animals. "The name marsupialia is derived from the presence of a large Marsupium, or pouch, fixed on the abdomen, in which the fœtus is placed after a. 
very short period of uterine gestation, and remains suspended by its mouth nntil sufficiently matured to come forth to the external air. The discovery of animals of this kind, both in the secondary and tertiary formations, shows that the marsupial order, so far from being of more recent introduction than other orders of mammalia, is in reality the first and most ancient condition under which animals of this class appeared upon our planet; as far as we know, it was their only form during the secondary period; it was coexistent with many other orders in the early part of the tertiary period." (34-I-64).

In respect to the maternal and fotal peculiarities of these animals, Prof. Owen regards them as owing to the inferiority of the brain and nervous system in comparison with the fuller development of the higher order of mammalia; the more simple form and inferior conditions of the brain in the marsupial being attended with lower intelligence and less perfect condition of the organ of voice.

"As this inferior condition of living Marsupialia shows this order to hold an intermediate place between viviparous and oviparous animals, forming, as it were, a link between mammalia and reptiles, the analogies afrorded by the occurrence of the more simple forms of other classes of animals to the earlier geological deposits, would lead us to expect also that the first form of mammalia would have been marsupial." (34-I-65, note.) 
Darwin says: "The maisupials stand in many importart character's below the placental mammals They appeared at an earlier geological period, and their range was formerly much more extensive than what it is now. Hence the Placentata are generally supposed to have been derived from the Implacentata or marsupials; not, however, from forms closely like the existing marsupials, but from their early progenitor's." (9-I-194.)

The Cretaceons or chalk formation makes up the closing period of Mesozoic time. These beds are supposed to be formed by the shells of Rhizopods, the simplest of Protozoan animals, with sponges, and "the minute cell-walls of the minute one-celled plants called Diatoms." This, by means of the modern system of deep sea dredging, and the aid of the microscope, is discovered to be the process now going on at the bottom of the ocean. In other words, we are now living in a Cretaceous period; and it proves that the same Protozoan forms existed in both periods. Natural selection does not appear to have had any effect either on Rhizopods or Diatoms.

In this closing period of Mesozoic time there was an advance in plant life to oak, beech, maple, poplar, and some other Angiosperms; and to palms among Endogens. The Cycads, nevertheless, continued to be the characteristic plant. Animal life advanced to the osseous among fishes allied to the modern perch, salmon, pickerel, \&c. The Mosasaurs-great snake-like reptiles-from 15 
to 75 feet long, and holding an intermediate place between tire Monitor and Iguana, were added to the Saurian group.

Crocodiles among the more modern kind of reptiles, appeared in many species both in Europe and America, of which one found in Kanses is described by Cope as fifteen feet broad, between the tips of the extended flippers. Turtles also were found, snch as the ordinary fresh water, snapping and softshelled.

The birds of the American Cretaceous included Divers, Waders and two which had pointed teeth like a reptile, and probably, as Marsh, the discoverer, suggests, a long tail, like the Archæopteryx (28-178). Of these birds, Prof. Marsh makes a sub-class, which he names Odontornithes. The Ichthyornis, of this sub-class, had biconcave vertebræ, with well developed and numerous teeth in both jaws, planted in distinct sockets. This bird was about the size of a pigeon-was carnivorous-and probably aquatic. The Ichthyornis celer was about the same size, had biconcave vertebræ, and probably teeth. These with the Archæopteryx go far to break down the old cistinction between birds and reptiles (30-12).

It may thus be generally observed, that Mesozoic time was eminently the age of reptiles. Not only did the reptilia proper develope and expand in huge proportions, but almost every divergence towards birds and mammals partook of a reptilian character.

The era was noted too, for the commencement 
of those families of animals and plants, which characterized Cenozoic time, such as the oak, maple, apple, \&c., among plants, and Crocodiles, osseous fishes and mammals. At the same time the closing period witnessed a wide extermination of species. "Besides the destruction of species, there was the final extinction of several families and tribes. The great family of Ammonites, and many others of Mollusks-all the genera of reptiles excepting crocodiles and others in all departments of life came to their end at the close of the Cretaceous or soon after." (28-200).

In the Tertiary age-made up of the Eocene, Miocene, and Pliocene formations - a great advance was made towards the modern forms of life. Among plants Angiosperms became prevalent; and the leaves of the oak, poplar, maple, hickory, dogwood, mulberry, magnolia, \&e., are found in the European and American strata.

Among invertebrates there is a marked approach to modern srecies, including the familiar oyster and clam. Among the reptilia, the first of the snakes are found in the Eocene. The birds lose their reptilian features, and are related to the modern pelican, waders, pheasants, perchers, vultures, owls, wood-peckers, \&c. Bats take the place of the Pteroctactyls, and the ostrich makes its first appearance in the Miocene.

The age was most remarkable for its mammalia, of which the herbivorous largely belonged to the pachydermic, or thick-skinned animals; the first whale (Zeuglodon) is found in the Eocene of Ala- 
bama, and outstrips the modern whale in dimensions. Of land animals Herbivora, Carnivora, Rodents and Monkeys, appear for the first time.

The Cory phodon, a tapiroid animal (Eocene), was a representative pachyderm. This was succeeded by the paleothere (Middle Eocene), related to the modern tapir; and the more slender Xiphodon, somewhat resembling the stag. The Deinoceras, found by Marsh in the Green river basin (same formation), of elephantine size, was related to the Rhinoceros; and of the same character was the Broncotherium, with the addition of a pair of great horns.

The Mastodon, a hog-like elephant, appeared in the Eocene. The Arctocyon in the same formation, related to bears and raccoons, was introductory to the ordinary carnivora.

The Oreodon in the Miocene is intermediate between the deer and hog; and in the same formation in Upper Missouri are the remains of Carnivora, related to the hyena, dog and panther ; and of Herbivora approaching the tapir, peccary, deer, camel and horse; and among the mammals of the European were elephants, mastodons, deer and monkeys.

The incipient horse-Eohippus-found in the lowest American Eocene, was a small animal, not exceeding in size an ordinary dog, with the peculiarity of having four well developed toes and the rudiment of a fifth.

Ruminant animals allied to the giraffe, antelope, sheep and ox, are first found in the Miocene; 
and the earliest of the ox group occur in the European Pliocene. The Sivatherium was a gigantic four-horned antelope, and seems to be a connection between Ruminants and Pachyderms.

The Monkey, making its first appearance in the Wyoming Eocene, was succeeded in the Miocene by two generic types related to the gibbon. 'I'he Lemurida, a sub-family of the ape tribe probably succeeded the marsupials. *

In the Pliocene of the Upper Missonri occur still other species in camels, a rhinoceros, an elephant, horses, deer, a wolf, a fox and a tiger.

The Champlain period of the Quaternary witnessed the culmination of the Mammalia and sub. stantially ends the history of progressive life, so far as it is recorded in the rocks. An appendix to this history is found in cave, lacustrine and sea-border deposits; marshes in which animals were mired; and permanent collections of ice in which the bodies of some animals have been preserved.

The plants and invertebrates were nearly all identical with existing species. The mammals were not only much more numerons, but in many instances of much larger size than in the present age; and those which have become extinct were allied to those now existing. Some species, such as the reindeer, narmot, ibex, chamois, elk, wild

* It is to be noted, however, the Lemurs are now regarded by some as a kind of stem form of the placental mammals, branching out inlo several orders, as Rodents, Insectivora, Carnivora and Quadru. mana. 
boal, goat, stag, auroch, nrus, wolf, brown bear, and others, are still in existence.

Among the extinct species were the Mastodon, Elephas primigenius, Megatherium (an immense sloth), the Cave Hyena, the great cave Bear, the woolly-haired rhinoceros, an immense Armadillo, Diprotodon and Nototherium (gigantic marsupials), not to mention many others.

The Quaternary age-consisting of the first Glacial, the Champlain, the second Glacial and recent periods-succeeded the Tertiary, and brings the history of creation down to the present time. It commenced with the first Glacial-a period of low temperature, producing great accumulations of snow and ice. To this succeeded the Champlain - a season of high temperature-by which accumulations of snow and ice were rapidly melted, producing the Champlain deposits, and the fluviatile and lacustrine drifts. At the close of this season, the second Glacial set in with far greater severity than the first.

Prior to these sudden changes the climate of the earth was so nearly uniform, that the fauna and flora of Greenland and Siberia were similar to that of the sub-tropics; and large numbers of elephants, rhinoceros, \&c., roamed into extreme northern regions. Bodies of these animals, completely preserved in ice, have been found in great numbers. During the second of these icy reigns, the regioms now known as temperate became fit only for arctic animals, others being driven farther south. In proof of this are the remains of 
musk ox, reindeer and other arctic animals, found in the temperate zones. Gradually this temperature became modified, until the second Glacial closed, and the present climatic divisions became permanently established.

The destruction of species by reason of these events of cold was only partial, and not much, if any, beyond what had taken place at the close of other great geologic epochs - certainly not enough to interfere with the orderly and successive developement of organic life. What occasioned the prevalence of these boreal periods is a question about which there is much difference of opinion. Some have supposed them to be due to a change in the inclination of the earth's axis. But this is manifestly untenable for the reason that it involves the idea of a series of such changes-one at the introduction of the Champlain and Drift periods, another at the second Glacial, and a third when that closed. Others have supposed the cause to be found in the sudden elevation of mountains into regions of cold. This, however, would scarcely be sufficient to account for the vast sheets of ice which extended far enough to overlap the present temperate zones. It would be quite as feasible to suppose the phenomena due to the initiament of a planet, younger than the earth. A fiery mass thrown from the sun of sufficient mag. nitude to produce Mars or Venus, or the Asteroids, might well produce a temporary diminution of the sun's heat to account for almost any degree of low 
temperature. The wisest conclusion probably is, we don't inow.*

In this sketch of the succession of life it will be seen that as the earth progressed in its formation, while a few species of low animals have been perpetuated, others have ceased to exist, and given place to new ones. As a general rule all forms of organic life possess a certain degree of elasticity, by which they are adaptive to changing conditions, Thus the hair of hairy animals becomes thicker in winter, as a protection against the cold; and on the return of summer, the thick coat is shed, giving place to the summer clothing. The elasticity, or power of adaptation, has a tendency to produce varieties, which remain permanent, so long as the new environment continues.

The general law of creation appears to have been the production of animals which were adapted to

* The reader is probably aware of the theory of Mr. James Crowl, the substance of which is as follows: The orbit of the earth is not quite circular, whereby the distance of the sun is greater at one time of the year than another; and this varies from century to century. Just now it is very small, and the summers of the northern hemisphere happen when the earth is at the greatest distance from the sun, producing a moderate climate. But the longitude of the pcrihelion is constantly changing and the line forming the solstices moves around the orbit in about 21,000 ycars. Hence, about every Io, ooo years the winter of the northern hemisphere will occur when the sun is in aphelion; and if at that time the earth's orbit is very eccentric, the two causes combined will produce a severe climate. This continuing for a series of years produces such an accumulation of ice as to change the centre of gravity; and the oceans in accommodation to this change, will recede from the Southern hemisphere, and submerge, more or less, the Northern. 
the conditions of the period, and their extinction as such conditions became changed beyond the power of adaptation.

In obedience to this law the evolution of life shows that in each age there was an advance in regular order from lower to new and higher forms. There appear, however, to be a few exceptions to this law of advance from lower to higher-at least, there are some eccentric cases, which are claimed as such. Of these Professor" Wilder, treating of "Exceptions to Rules," says: "The larra, or tadpole, of the frog, resembles the grown salamander. This is regarded as not only confirming the anatomical conclusion, that frogs are higher in rank, but also, according to the doctrine of evolution, as indicating that frogs are descended from some prior salamander-like form. So we conclide that the young of higher forms always resemble the adults of lower, and usually it would seem that the rule holds good. But the youngest known Manatee resembles, not the whales and porpoises, which are lower forms, but some of the hoofed quadrupeds-the pig, hor'se, and hippopotamus-which are already regarded as higher than the manatee. We must either conclude that this relative rank should be reversed, or admit that the young of lower forms may resemble the adults of higher, for here the young of a lower form resemble the adult of a higher.

"But it is evident the idea of evolution includes the possibility of degradation as well as advance; of a literal descent as well as the more common 
ascent. In this case it appears that some of the fossil forms related to the manatee are of higher rank than itself in some respects. If these consiclerations warant the supposition that the Sirenia have undergone a retrograde metamorphosis by which quadrupedal forms like hippopotamus have gradually become better fitted for a purely aquatic existence, by the loss of the hinder limbs, and the conversion of the arms into flippers, then it will be less difficult to understand why the liead of the very young manatee looks like that of its hippopotamus-like remote ancestor" (29).

This is certainly a very interesting and curious case, and I will not say that the conclusion is unauthorized. How much it may be modified by further investigation remains to be seen. Let us in supposition go back to the period when in the order of creation the production of the hippopotamus became necessary. Stippose, further, numbers of an animal intermediate between the porpoise and hippopotamus, simnltaneously created in different localities, and that in some of these localitics owing to cataclysmal changes, the young of the new creation were compelled to live altogether in the water. In such case, on the principle of adaptation, some reversion wonld be likely to take place, though the embryo wonld exhibit the ungulate features, just as rudimental eyes are found in the embryo of the cave fishes.

The earliest evidence of the existence of man appears in the rude stone implements found in Europe in caves, river drift gravel and shell 
mounds in juxtaposition with the cave bear and other extinct species of animals. That he existed much earlier there are good grounds for believing, but this subject is fully considered in a former chapter. 


\section{CHAPTER XI.}

\section{TIIE NEW TIIEORY.}

A matrix necessary to reproduction. Evidence of Embryology. Extraordinary Generation. Male and Female elements in Creation. Miraculous Conception. Psychological mreparation for MFan. Multiple Creation of Organisms.

It follows from the remarkable linking together of created things, and from the order of succession from lower to higher forms, as detailed in the preceding chapter, that there is a necessary connection between them - that the creation of the prior form is necessary to that which is to follow.

All theories of the origin of species exclusive of the old and now generally discarded idea of "Special Creation," assume that they originated from causes which do not interfere with the ordinary process of generation or reproduction. It was that of Lamark, and of the anthor of "The Vertiges of Creation" -it is, as we have seen, that of Darwin. There is much of minor detail, but none go back of this process. The Duke of Argyl says: "If I am asked whether I believe that every sepirate species has been a separate creationnot born, but separately made-I must answer that I do not believe it." "There is one idea 
which has been common to all theories of development, and that is the idea that ordinary generation has somehow been producing from time to time extraordinary effects, and that a new species is in fact simply an musual birth." (Reign of Law, pp. 214, 236.)

We see that creation as it goes on under our observation is by the ordinary process. From this we are able to erolve, not merely the general, but the invariable rule, that every living organism, within historic times, has required a receptacle or matrix, for its conception, gradual development and final birth. Surely from what we thus see, we should be able to find a general law for the production of new species. If species are reproduced by this ordinary process, then it is fair to conclude that they must have originated not by an "unusual birth," but by an extraordinary generation, and herein, I apprehend, may be found the krey to the whole mystery.

I have stated that so far as all animal forms within the historic period are concerned, a receptacle or matrix has been used, and therefore found necessary in their creation. It may be added, that there is no fact known to science, or any reason by analogy, by which the inference is warranted, that any different mode has been adopted in the production of the ancestrai lypes of the sereral species which have existed and still exist.

It may indeed be stated as a general and invariable rule, that nothing can be created without a womb or matrix. 'The Sun was the matrix of the 
Earth. The Earth is the universal matrix of the vegetable kingdom; -it was that of the lowest of the animal lingdom; and after the lowest forms of the animal lingrom were created, they furn. ished the matrices of those higher, and so on to the lighest.

No more striking proof of the order and laws of creation can be found than appears by certain known facts in Embryology.

"All organisms, vegetable as well as animal, commence with a simple cell, of which it is impossible to tell in any case to what form it is destined to advance. A series of changes take place. First, of an animal embryo-we can distinguish whether it is destined for the radiate, molluscous, articulate, or vertebrate sub-kingdom. Take an embryo of the vertebrate sub-kingdom-we next trace it in the change which will determine whether it is to belong to the fish, reptile, bira or mammal class. Take an embryo of the mammal class - the character of the particular order are next determined. Afterwards those of the family, genus, species, sex and individual are evolved in succession." (13-130.)

"It is a truth of very wide, if not universal application, that every living creature commences its existence under a form difierent from, and simpler than, that which it eventually attains." (16-74.)

Huxley, after tracing the embryology of the dog in connection with some other animals, says in regard to man: "Is he something apart? Does 
he originate in a totally different way from dog, bird, frog and fish-or does he originate in a similar germ, pass through the same slow and progressive modifications-depend on the same contrivances for protection and nutrition, and finally enter the world by the help of the same mechanism? The reply is not doubtiful for a moment, and has not been donbtful any time these thirty years. Without question the mode of the origin and the early stages of the development of man are identical with those of the animals immediately below him in the scale;---without a doubt in these respects he is far nearer the apes than the apes are to the dog." (16-80,81.)

Bischoff says that the convolutions of the brain in the human fotus at the end of the seventh month reach about the same stage of development as in a baboon when adult. (9-I-16.)

Darwin mentions the curious fact that in the fifth and sixth months of pregnancy the human fœtus is thickly covered with wool-like liair. In the fifth month it is first developed on the eyebrows and face, and especially around the mouth, where it is much longer that on the head. "The whole surface, including even the forehead and ears, is thus thickly clothed." (9-I-25.)

From this, with the further fact that the palms of the hands and soles of the feet are naked, he infers that this woolly covering is-- "the rudimental representative of the first permanent coat of hair in those mammals which are born hairy."

Granting the inference to be correct, so far from 
favoring his theory, it is adverse to it, inasmuch as mnder the operation of natural selection, every child should be born hairy at birth. It is however in entire hamony with the idea, that the ovum of the ape mother was used by the Creator for the infusion of human life, which in its embryological development became hairy, when it reached the ape stage, and nude afterwards. According to the same hypothesis of descent from a common progenitor under the operation of natural selection--"the similarity of pattern between the hand of a man or monkey, the foot of a horse, the flipper of a seal, the wing of a bat, \&c., is utterly inexplicable, for "it is no scientific explanation to assert their construction on the same plan" (9-I-31.) The old idea of special creation, which Darwin had in his mind, would fall short of an explanation. But these similarities are in perfect accord with the theory of direct creation through pre-existing organizations. If these embryonic changes have no deeper significance than that afforded by his theory, why are there not births at some of the prior stages? For instance, why do not female dogs occasionally give birth to reptiles? $\mathrm{Or}^{*}$ a human mother to a gil)bon?

The human ovum is about $\frac{1}{12} 5$ of an inch in $\mathrm{di}$ ameter, having the same essential structure of that of any other vertebrate animal; and in its embryological development, after impregnation, it resembles, as above stated, a fish, reptile, dog; ape, and, finally, is born a man. Huxley states 
the further embryological law, that "the more closely any animals resemble one another in adult structure, the longer and the more intimately do their embryos resemble one arother'; so that, for example, the embryo of a snake and of a lizard remain like one another longer than do a snalie and a bird; and the embryo of a dog and a cat remain like one another for a longer period than do those of a dog and a bird." (16-SO.)

According to this rule the human embryo resembles that of an ape a much longer perior than it does that of a fish or a reptile, and it seems to indicate, that at this stage there was an effort in the organism to produce an ape, which was finally overcome by the higher grade of life. It is linown that the new-born babe appears strikingly like the ape in its general outlines, having no waist, and turning the soles of its feet together.

According to the author of "Vestiges," "the brain, after completing the series of animal transformations, passes through the characters in which it appears in the Negro, Malay, American, Mongolian nations, and finally becomes Caucasian." The leading characters, in short, of the various races of mankind are simply representations of particular stages in the derelopment of the highest or Caucasian race. $(13-213,214$.

Another remarkable fact is that every human fotms, before birth, develops the female first; the male principle being subsequently produced, provided it be a male embryo. The same embryonic changes occur in the animals below man; 
but as water never rises above its fountain head, so the fotus of a lower animal, (as a dog for instance, ) develops only the resemblances to organisms below the dog.

Starting with the fact of the existence of a Creator-God--by whom all things are and were created, let us see if, in the phenomena of matter, and the order in which things have appeared in succession, He loes not permit us to form some rational idea of the modus operandi of creation.

The questions here suggested are of the gravest character. How does the Creator work, in the creating of those animals and piants of the time being? How is the power exerted, which gives efficiency to the intermediate causes falling under our observation? Is it spasmodic and fractional, or uniform and incessant? Science teaches that the Earth is an out-birth of the Sun, having been thrown off as a nebulous mass, which, gradually cooling and contracting, has been reduced to its present dimensions; and we know, too, that it contains nothing, of which the original elements do not exist in its great central parent. TVe likewise know that not a blade of grass, not a shrub or a tree, can grow, not a flower can blossom or a fruit ripen, not an animal organism can be formed or developed, without an influx of light and heat from the Sun.

If we had no faculty of reasoning and speculating in reference to a power abore nature, from which material things originated and are governed, our conclusion would doubtless be that the 
Sun was the creator of all the forms of matter within the solar system. Starting with such a postulate, it would not be very difficult to explain the modus operandi of creation, in the incessant outflow of light and heat. Not only is this outflow unceasing, but in every direction; and if it sometimes appears not to be uniform, it is becanse the Earth's axis is not perpendicular to the plane of its orbit.*

IVe find, however, this postulated creator to be within the range of human examination and analysis. We find it within the domain of physics, however attenuated or sublimated it may be.

* In a paper read before the Royal Society, by Mr. C. William Siemens, on "The Conservation of Solar Energy," (I-Xxi-223), it is shown that "the amount of heat radiation, from the Sun, has been approximately computed at $\mathrm{I} \$, 000,000$ of heat units from every square foot of it surface per hour;" and further, that "if the Sun were surrounded by a solid sphere of a radius equal to the mean distance of the Sun from the earth (95,000,000 of miles), the whole of this prodigious amount of heat would be intercepted; but considering that the earth's apparent diameter, as seen from the Sun, is only I7 seconds, the earth can intercept only the 2,250 millionth part. Assuming that the other plantary bodies swell the amount of intercepted heat by ten times this amount, there remains the important fact that $224,999,999-$ $225,000,000$ ths of the solar energy is radiated into space, and apparently lost to the solar system, and only I-250,000, oooth utilized or intercepted."

On this subject, there has been much speculation, resulting in various theories, leading generally to the disastrous conclusion that the time would come when the heat and light of our great central luminary would be extinguished. But, notwithstending this prodigous waste and in despite of these dismal forebodings, there has been no apparent diminution of solar energy during the entire historic period. The Sun, it scems, will not accommodate itself to these theories; hence the necessity of a theory which will accommodate itself to the Sun. 
It is a burning mass manifestec by light and heat. Light and heat, howerer, are only intermediate causes, mere agents in the prodnction of creative lesults, since it is not to be supposed they have original power in themselves to perform the work. We can see that the flow of heat and light is incessant and uniform, and we can easily understand why it should be so. But when, in scientific investigation, we exhaust the agency of physical causes, we are then at the topmost round of the ladder of science, and neither the crucikle, the telescope, nor the spectroscope will aid us farther.

We may, however, safely infer that the Sun is proximate to the Creator; in other words, that it was the first proximate proceeding, or projec. tion from IIim, in the creation of the material unirerse. The Sun is everywhere present in the solar system, by its ceaseless flow of light and heat; and, in this respect, affords a striking illustration of creative omnipresence.

We see how the Sun worlss as an agent, and, beyond this, we do not see; but reasoning from the seen to the unseen, we are prepared to say that creative energy or power flows ceaselessly from the Creator, in creation, first of the material Sun, next of the Earth through the Sun, and next of animals and plants through the sun and the Earth, producing one after another the numberless detail of reated things; and the farther we go, the longer the chain of intermediate causes. Unless this be so, we must, fall into the absurd be- 
lief, that the principal has less power than his agent - that the Sun exhibits greater omnipresence and activity, than the Sun's Creator.

This creative energy is an outflow from the Creator and an influx in to space, and it must necessarily be incessant. Its interuption for a moment is no more supposable than that the sun should be suddenly extinguished . and the effect of such a catastrophe is beyond the power of the imagination to conceive.

As a question of design it can hardly be supposed that the creation of suns and planets, and satellites was merely to exhibit the power of gravitation, and the harmonions working of sideral systems for the amazement or amusement of empty space, as Christmas toys are made to amuse children. On the contrary it is apparent that the ultimate purpose was to create life-first animal and finally human life-as the crowning work of creation. All the precediug work is but the preparation for this grand result; and the same creative influx, which has step by step pro. duced the physical universe, is adequate to infuse life into appropriate forms of matter, from the lowest to the highest; and this influx is unceasing as well in the one case as the other. This omnipresent and ceaseless action of creative power seems not to have been sufficiently considered by those who have speculated on the origin of species.

Assuming the lowest Rhizopod found in a bed of rocks, lower than the Silurian, to be the first ap- 
pearance of animal life upon the globe, it must have been created by direct infux inío a protoplasmicreceptacle of earthly materials. It was merely a shapeless mass; yet it had life, and its formation was the birth of a species from dead matter; the matrix and the ofispring being separated by whatever separates and divides the inorganic from the organic kingdoms of nature, and this must certainly be granted to have taken place in at least this one case. Darwin, as we have seen, substantially asserts that it took place in four or five different instances.

In this lowest form of life, the mode of creation is easily comprehended. But the creation of an elephant by infux into crude earth would not much more readily fall into belief than to suppose a house built without a foundation, and suspended in the air. The logic of creation has a more consistent and practical basis. The Moner, low and useless as it seemed, conld nevertheless serve as a matrix for the creation of an advancespecies; and so on up. And the rule will be found to prevail throughout, that the higher and more complicated the life and structure, the higher and more complex the matrix needed for its original creation and protection.

Creative energy flows gestatively into every liv ing organism, not only for original creation, but to reproduce. Life, as we have already seen, is always infused, and puts on and controls its appropriate form. The life of a new species puts on its corresponding structure, varying radically, 
though by easy gradations, from the receptacle which gives it birth. Thus the first of the mammalia abore the marsupial we may suppose as an example, was infused into the latter not by sexual connection, but by direct creative influx; and this conception and birth was a new creation, by extraordinary generation, and ordinary birth.

The distinction here claimed may be more clearly seen when we look at the initiament of the life of an animal of any given species by ordinary generation. The female ovum is nothing of itself, except that it is capable of being impregnated by the male sperm-in other words it is a mere receptacle into which life is infused through the action of the male. This sperm, under the microscope, appears to be alive with low organisms resembling microscopic Protozoans. This then is the seed of an animal, and indicates that life is initiated in the male, the father representing the active, and the mother the passive principle in ordinary generation. Life flows into the ovum through the male sperm, and is clothed with a body derived from the female; and the process is one of simple reproduction.

In these ordinary impregnations the law of like producing like prevails, with the controlling tendency to perpetuate the general characteristics of the male, as already shown in the cross of the horse with the ass, \&c. So unilorm are the facts bearing upon this subject that it may bo stated as a general law, that though the animal organism of any given species may be used as the mother, 
it can never be the father of a species superior to itself-in other words the process of reproduction can never result in the creation of a new species.

But in extraorinary generation, the female ovum is used by the Creator for the inflow of life into a new species without the intervention of the male, whenever, in the orderly progress of changing circumstances, a new species becomes necessary; and there is no moreinconsistency in supposing this than that a Moner or Rhizopod was produced by a similar influx into an earthy receptacle. In firct, Darwin admits something akin to this when he supposes the creation of four or five primordial types, with which he starts his theory.

The sun, as a proximate creator, comes to us in the form of heat and light, both produced by the combined elementary substances-oxygen, hydrogen, iron, sulphur, etc.--of which it is composed. Ihe incipient earth, thrown off primarily in a nebulous form, was composed of these same substances; and superadded to this primal condition, it is by the endless combination of such substances, as they necessarily come to us in the solal heat and light, that the entire physical universe is made up. So far, however, all is matter, withont a single trace of mind or thought. 'There is abundance of elementary cerebral matter, but no blain.

The sun, as stated above, is nothing but a combination of inanimate matter, within the range of louman examination and analysis; and it would be just as rational to suppose that a bed of iron 
ore could design and manufacture a steam engine, as that the sun, with all its tremendous physical energies could, unaided by mind, produce a family of obedient planets. The sun, therefore, must be regarded as an intermediate cause--a mere agent of a still higher cause.

My theory, in short, is, that at each step in the creation of species, a prior living organism is used by the Creator as an ovum or matrix to produce a new species, withont the aid of the ordinary patcrnily required in reproduction; and precisely in the same way, that the lowest animal was produced by creative influx into a matrix of crude earthy materials. Reproduction requires the cooperation of the animal sexes, while original creation does not.

There seems to me no midale ground between this theory and that of "Special Creation," so called. Either the ancestral type of each species was specially created, according to the old belief, or there was a prepared organization adequate to the reception and protection of the infant being.

Is there anything more incongruous or inconsistent in supposing that organic beings are evolved from prior forms by successive creative processes, than that the planets should be evolved from the sun, or that the earth should, by a like orderly process of cause and effect, proceed frrm an elemental to a finished state? Is the conception, gestation, and birth of an animal any less a creation, because it seems to be due to natural causes which are gradual and orderly in their operation? 
It is quite certain that nothing has ever been created, and as a sequence, nothing ever can be created. without the conjunction of two elementary principles-the male and the female. In physics these two principles appear in the light and heat of the sun; either being ineffective in the production of life; but in conjunction they are efficient intermediate causes in the work of creation. This dual principle exists potentially in the Creator, and flowing forth in conjunction, produces the distinctions of sex, which appear in the animal and vegetable kingdoms. Without this there could be neither production nor reproduction.

It is a fair inference, that the male and female principles are equal factors in energy, from the fact that about equal numbers of each sex, in the various forms of life, are produced. If they operated unequally, if one exerted more energy than the other, reproduction would be less rapid. Whenever in the human races inequalities have occurred from destructive wars and other causes, not only has reproduction been interfered with, but more or less demoralization has followed. Similarly, when an inequality occurs in the reception of light and heat in winter, vegetable life is dormant or destroyed. It may further be said, that it is from this combined quality of creative inflow that each sex lias the rudiments of those organs which distinguish the other, such as the mammoe in the male mammalia.

Precisely at what time, or in what organism 
the sexes became differentiated, it is perhaps impossible to determine, but it was probably in a very low form.

Darwin appears to have no definite idea of the fundamental character of these two principles; nor does he undertake to fix the time of the separation; or to give the process any further than intimating that it may have been produced by the necessity of a aivision of labor. W We can easily comprehend the great use of a division of labor in the social economy; but in what possible way natural selection could so operate upon the animal form as to produce such results, is certainly among the mysteries. Did the primitive hermaphrodite give birth to twins of different sexes? Or did one member of that family give birth to a male, and another to a female? And if so, what had natural selection to do with it? It will hardly be supposed that the lowly moner could have reasoned apon the necessity of the case, and produced the separation by sheer force of will. (See note, p. 60.)

I have stated that every human fœtus before birth developes the female first. This has been disputed, and as embryology, as a science, is comparatively in its infancy, and that pertaining to mankind is less known than that of animals, owing to the difficulty of obtaining subjects in all stages of fœtal changes, it is a question which cannot at present be fully solved. Nevertheless, the rule, as I have stated it, is not altogether without proof. The anthor of "Vestiges," 
in the first edition of his work, says: "Sex is fully ascertained to be a matter of development. All beings are at one stage of embryotic progress female; a certain number of them are afterwards advanced to the male." (13-161). In his eleventh edition he illustrates this law by the manner in which bees, by checking the development of a certain number of larva, produce, first, the queen bee in sixteen days; second, the neuters in twenty days; and lastly, the male in twentyfour days (13-143). After describing the manner in which this is produced, by the remarkable instinct of the bee, he adds (144-5): "IVe have, it will be admitted, a most remarkable illustration of the principle of development, although in an operation limited to the production of sex only. Let it not be said that the phenomena concerned in the generation of bees may be very dilferent from those concerned in the reproduction of higher animals. There is a unity throughout nature which makes the one case an instructive reflection of the other."

Further proof of the same law is found in the statement of Darwin in relation to the Orthoptera, "which assume their adult state not by a single metamorphosis, but by a succession of moults. The young males of some speeies at first resemble the females, and acquire these distinctive characters only during a later moult." (9-I.-282.) The same thing occurs in the case of certain male crustaceans $(I C,-282)$.

To this may be added the admitted fact, that 
generally among mammals and birds the young of both sexes resemble each other, and the secondary characteristics of the male do not appear till near the age of reproduction (Id., 2S3). And, too, it is of familiar observation that woman matures at an early period than man.

Under the prevalence of such a law, the first created organism having sex was female; and there is as much reason for believing this to be so, as that the fish was created before the reptile, or the ape before man. The rocks tell us that this is true in regard to the fish and the ape, and so does embryology, the evidences of the one corroborating that of the other; and if the rocks could speak in reference to the prior organic existence of the female principle, the evidence would doubtless be in equal harmony. That the first fish, first reptile, \&c., and the first of every newly created species as well, was female, illustrates still further the law repeatedly alluded to, that the starting point of every form of life is in a matrix prepared for the purpose.

In reproduction, or propagation, the law of heredity prevails; that is to say, individuals of species always produce their like, with minor differences. Acorns have always produced oaks, and always will. 'The offspring of dogs have always been dogs; that of horses, horses; and so on through the whole animal and vergetable record. It is true there are minor differences withont number, as there never have been, or can be, any two things exactly alike. The type of a species is 
well represented by a straight line, and the variations are departures from it, up or down, with a constant tendency to return to it, and keep in near proximity. This is the historic record; and there have been no experiments, by domestication or otherwise, by which it is substantially contradicted.

Man, the last creation, having physicaily the highest and most complete organization, according to this theory, could only be formed throngh the medium of the highest animal structure next below him-the ape-and his ape birth furnishes the strongest proof of the truth of the theory. The difference between the mind of man and that of the most intelligent animal is so great, that the idea of his propagation by the sexual connection of apes is utterly absurd. Nothing short of direct divine Influx into the ape ovum could liave produced the wonderful result.

The author of the "Vestiges of Creation" seems to have had some idea of this method. He says: "The production of the organic world is, we see, mixed up with the production of its physical" "Life, as it were, pressed in, as soon as there were suitable conditions, and once it had commenced, the two classes of phenomena went hand in hand together"' (13-103).

Again : "TVe contemplate, in short, a universal gestation of nature, analagous to that of the individual being; and attended as little by circumstances of a startling or miraculous kind, as the 
silent advances of an ordinary mother from one week to another of her pregnancy" (13-158).

St. George Mivart expresses an idea akin to this in urging that frequently similarity of structure may arise without there being any generic affinity between the resembling form; but that it is much more owing to an internal cause or principle than to any action of surrounding external conditions, that the origin of new specific forms is due (33\%1.)

The evolution of man throngh the ape is too well established to be met will ridicule or affecteil disgust. Human nature at best is none too good, and in its low states in civilized, as well as sarage lands, is so much on a par with the most of biutes, as to make such criticisms out of place. Those who are nervous on this point may find relief in regarding the difference in dignity, between being created directly from the crude dust of the earti, or by means of dust organized into a complete structure of flesh and blood. 'The world -the Christian world, at least-has witnessed, historically, the exhibition of that which is called the "miraculous conception" in the production of a IIuman so infinitely above common humanity as to he capable of complete one-ness with Divinity. Even in that grandest display of divine benerolence, involving the salvation of mankind, God lias seen fit not to depart from His established laws of creation. And thus has been completed the mighty cycle of being, which begins and ends in Himself. 
Darwin. with that candor for which he is most remarkable, says: "There can be no doubt that the difference between the mind of the lowest man and that of the highest animal is immense. An authropomorphous ape, if he could take a dispasionate view of his own case, would admit, that though he could form an artful plan to plunder a garden-though he could use stones for fighting or for breaking open nuts, yet that the thought of fashioning a stone into a tool was quite beyond his scope. Still less, as he would admit, could he follow out a train of metaphysical reasoning, or solve a mathematical problem, or reflect on God, or admire a grand natural scene."

Novertheless he insists, that the difference is one of degree only and not of lind; and refers to "the various emotions and faculties, such as love, memory, attention, curiosity, imitation, reason, \&c., of which man boasts," as being, "found in an incipient, or even sometimes in a well developed condition, in the lower animals" (9-I-100).

But it seems to me, that in my theory of creation, there is a more rational and satisfactory explanation of these phenomena. There is a manifest preparation in the animal kingdom for the production of man in reference to his mind as well as body. Suppose him born of the ape as to body-if the ape mother had no higher psychological qualities than an oyster, there would have been no basis for human mentality, and he might just as well have been created from a lump of earth. But he has a dual existence-he is both 
animal and man; and in this double character, he dominates the entire animal kingdom. The lower part of his mind is, primarily, inherited from the ape, and forms a basis for the higher or human part; and the necessity of this explains why the incipient "emotions and faculties," referred to are found in certain of the higher animals. Let us notice some of the most impoitant.

Conscience is that faculty of the mind which determines upon the quality of an act, as to whether it is right or wrong--and which makes regret or remorse a possible result of the commission of a wrong act. Those who have no moral sense have no conscience, and from them are "all the dangerous classes" --the tigers and hyenas--of society. This important human faculty has a basis in what appears to be an incipient conscience found in some animals, a few interesting incidents of which are mentioned by $G$. J. Romanes, M. A., in an article in the Quar. Journal of Science for April, 1876.

So, too, we find some glimmerings of reason, as exemplified in the case of the monkeys, which, on first being given eggrs to eat smashed them, thereby losing much of their contents; but afterwards hitting one end gently against a hard body, and picking off the broken pieces of shell with their finger's $(9-I-45)$.

Again, apes are abont the only animals in existence which possess the power of imitating the acts which they see performed. Monkeys are often caught by putting on boots in imitation of their 
captors, being thus prevented from running or climbing. The first lessons to very young childrein are by this faculty inherited primarily from ape motherhood, in the lower plane of the mind, and before the development of the higher.

But, probably, the most important of these rudimentary qualities is the development of sympathy and affection in the ape for their young and towards each other. Mr. Romanes, in the article above referred to, states a case of sympathy in monkeys witnessed by himself at the Zoological Gardens. It seems that an Anubis baboon was badly bitten in the hand by a dog-headed baboon, and retired to the middle of his cage moaning pite. ously, and holding the injured hand against his chest, while he rubbed it with the other. An Arabian baboon then approached and took the wounded one in its arms, making a soothing sound very expressive of sympathy, as a mother wonld to her child. This sympathetic expression had a dicidedly quieting effect upon the sufferer, whose moans became less piteous; and the manner in which he laid his head upon the bosom of his friend, was as expressive as anything could be of sympathy appreciated.

Now let us suppose human children to be born of ape mothers by the direct inflow of life from the Creator, they would find protection during infancy in the maternal affection and sympathy. 'They would inherit in the lower region of the mind the rudimentary qualities and faculties common to the ape; and as the higher and strictly 
human faculties derived from the Creator became developed, they would become not only gradually emancipated, but in the end obtain the mastery and control over their animal parentage.

Another question intimately connected with the main subject is whether there was created a single pair only of each species-as a single pair of fish, dogs, apes, or man-from which they have since been propagated; or whether they were created in numbers more or less large. The popular belief has been, and to a great extent now is, in favor of a unity of races in original creation; and on this, in a measure, rests the development theory.

Darwin says: "It is generally acknowledged that all organic beings have been formed on two great laws-unity of type and the conditions of existence. By unity of type is meant that fundamental agreement in structure, which we see in organic beings of the same class, and which is quite independent of their habit of life. On my theory, unity of type is explained by unity of descent. The expression of conditions of existence, so often insisted on by the illustrious $\mathrm{Cu}$ vier, is fully embraced by the principle of natural selection." (2-183-4.)

That is to say, natural selection and conditions of existence are substantially one and the same thing; and all organic beings are formed on unity of type and natural selection. That they are in each great class formed on the same plan, and that in that sense there is a unity of type, is con- 
ceded. It is also true that organic beings, as already noted, have a limited degree of adaptation to changing conditions; and that such adaptability does not interfere with mity of type. The principle here contended for by Darwin evidently presents the point of divergence between his own theory and that of distinct creations through prior forms. Instance the hmman race,-his idea of unity of type, and descent means the birth of a man and woman, wholly from ape parentage, having an intellect just above apehood. This pair is supposed to propagate a family; and the increase to go on, intact, of course, from ape mixture, to prevent degradation-and this is unity of descent.

The entire weight of evidence appears to me to be the other way. Nothing probably in the vegetable or animal world ever made its appearance except for some necessary use, though we may not always comprehend it, nor until the time when it was needed, and the conditions were in adaptation. This follows from the idea that all creation has been from an original intelligent design to effect certain definite purposes. Life, as we have seen, in all its forms, flowed from the Creator into receptacles prepared for the purpose; and these preparations must have been on a scale of magnitude corresponding to the design.

Take the case of the Polypiaria-doesitnot seem preposterous that the swarming millions of that animal were propagated slowly from a single pair? Is it likely that all the oak trees that have ever existed descended from one acorn? 
Or that all the clover has been propagated from single parent seed? On the other hand, it is much more in accordance with all that we are capable of seeing and comprehending of creative force, to suppose that at the proper time, and in the suitable localities, millions of clorer plants started into growth, as we see firewood in a burnt district. Creative power is exuberant, and not sparse or stingy, or poured out in small measure.

St. George Mivart says of apes: "Not only is there abundant reason to believe that apes and half-apes have not much, if any, closer affinity than they have either with lions or with whales; but there is much evidencc to support the belief that the apes of the old and of the new worlds respectively (the Simiadre and Cebidæ) have been created independently one of the other, and that the various common characters they exhibit are but parallel adaptive modifications, due simply to similarity as to the exigencies of life to which they are respectively exposed" (17-431).

We know very well that land emerged from the seas at different periods, and in widely different regions. Suppose Africa to have been first elevated, and made fit lor the girowth of plants, and for the existence of vertebrate land animals. What necessity was there for waiting until land everywhere else emerged, before peopling it with a fauna and flora suited to its conditions? What probability is there, that any such delay took place? Suppose Australia, or some considerable portion of it, to have been next elevated. Is there 
any good reason why a fauna and flora should not have been created there adapted to the environment, quite independently of that alleady existing in the Alrican Continent? And so of America and Europe.

When the proper time came for the origin of a species, creative intlux into the receptive forms already in existence may just as well have produced numerous pairs as one. And this would easily account for all the allied species, as well as for many of the differences between individuals of the same species. Such variations would necessaly spring from the differences of the environment. The tiger of the Eastern jungle, for instance, is not so well suited to an American forest as the panther ; the dogs of the American Indian differ greatly from those of the Esquimaux, and these again from those of Europe; and we well know the Negro can live in miasmatic African localities where a Caucasian would quickly perish. This view of the subject supersedes the necessity of speculating on the problem of the migration of animals, to account for the existence of allied species.

If this rule be true of plants and animals, it must be true of man. 'The same influx that could impregnate a single ape ovum with human life conld a thousand as well, in contiguous areas, and about the same time. A single pair of human beings would be far less able to protect themselves from wild beasts, and whatever else there might be of adverse circumstances than a commu- 
nity. This idea of simultaneons creation of considerable numbers explains many of the various and marked sub-types, which everywhere apjear in communities of the same race. And especially does the creation of communities at different periods, and widely distant areas, account for the broad distinction between the Negro, Indian, Mongolian, and Caucasian races. Ultimately, as we see, these different races, and sub-types, commingling produce still further varieties.

It follows that men created upon the lands first elevated, as Africa for instance, are the oldest; and the youngest are those of the lands which last became adapted to the needs of human life.

There are some moral considerations connected with this point which cannot be better expressed than in the language of the late Professor Agassiz: "To assume that sexual relations determine the species it should be further shown that absolute promiscuousness of sexes among individuals of the same species is the prevailing characteristic of the animal kingdom; while the fact is, that a large number even of animals, not to speak of men, select their mates for life, and rarely have any intercourse with others." * * *

"For my own part I cannot now conceive how moral philosophers, who urge the unity of the origin of man as one of the fundamental principles of their religion, can at the same time justify the necessity which it involves of a sexual intercourse between the nearest blood relations of that assumed first and unique luman family, when 
such a connection is revolting even to the savage."

"The facts, with other facts which every day go more extensivly to show the great probability of the independent origin of individuals of the same species in distinct connected geographical areas, force us to remove from the philosophic definitions of species the idea of a community of origin and consequently, also, the idea of a necessary geological connection. The evidence that all animals have originated in large numbers is growing so strong that the idea that every species existed in the beginning in single pairs may be said to be given up almost entirely by naturalists." (On Classification, pp. 253-5).

It would be strange indeed, if the Supreme Being, whose laws of order lie at the foundation of all human prosperity and happiness, should have made their violation absolntely necessary in the first propagation of the race.

This theory of creation by the inflow of life into prior forms has been criticized as miraculous. If so, all living forms, animal and plant, which depend on the constant inflow of life are standing miracles. A miracle, according to the popular idea, is an arbitrary interference with the usual operation of the laws of cause and effect. Can there be any such thing? If so, it would seem to imply that the machinery of the universe was so defectively constructed as to make such interference occasionly necessary; and this would appear to justify the further implication of a want 
of foresight in the establishment of such laws. I do not believe these laws have been, or ever will be interfered with in a way to justify the popular idea. A mechanic constructs a machine which successfully fulfils the purpose intended. There is, however, an unavoidable wear and tear of material resultir-g in its ultimate uselessness. But the machinery of the universe is perfect, and never needs any interference beyond that which supplies the motive power of its opera. tions. Yet there have been seeming miraclesseeming because the effect has been produced by forces not obvious to the observer.

Instance, the case of changing water into wine. Wine is made up of water as a basis, mingled with. sugar, tartaric acid, tannin, \&c.; and this combination is produced by a series of intermediate causes which we can to a rertain extent trace. The vine grows by reason of its power to take from the soil, with the aid of the heat and light of the sun, all that it needs to produce and perfect its fruit. In the sphere of physical causes we can trace the eutire process to the sun; and from thence, by a reasonable inference, to the First Cause which predominates the whole. Suppose, then, the First Cause to be brought into immediate, instead of intermediate, contact with the ultimates of nature-then precisely the same results would be produced--and it would constitute just as much a miracle, as the production of a man by the direct inflow of life into protoplasm, and no more. 
Darwin himself, at the close of his work on the "Origin of Species," speaks of life having been originally breathed by the Creator into a "few forms or into one."

In one sense the theory here presented may be said to be one of special creation; but proceeding upon a plan of creative evolution, it is just as free from any feature of the miraculous as the germination and growth of a plant was in ordinary generation. At first creation proceeded by short transitions, as is evident from a study of the lower organisms; but as it advanced the forms became more complicated, the gaps wider and wider, until the appearance of man, and whatever may be claimed as to structural resemblances, the mental differences between him and the ape are immense. 


\section{REFERENCES.}

The following is a list of the works referred to. The first figure designates the number of the work-the last the page, and the middle (in Roman), when it occurs, the volume.

I. Popular Science Monthly......... Conducted by L. L. Youmans

2. The Origin of Species by Nat. Selection..... Charles DARWAN

3. The History of Creation, 2 Vols........... ERnST HAECKEi

4. The Plurality of the Human Race............

5. The Principles of Biology, 2 Vols...........Herber' Si'licer .

6. Silliman's Journal, for January, r869, p. 5 I.

7. Lay Sermons ....................... H. HUXLEI,

8. Quarterly Journal of Science, July, I 875.

9. The Deseent of Man, 2 Vols ............... CHARLES 1)ARWIN

ro. Annuals and Mag. of Nat. History, No. 4I, page 372...LoNuox

I I. Harper's Monthly Mag. Nov. I874, p. 892 .

12. Force and Matter........................ BÜCKNEK

13. Vestiges of the Nat. History of Creation

14. Cosmic Philosophy, 2 Vols.................JoHN Fiske

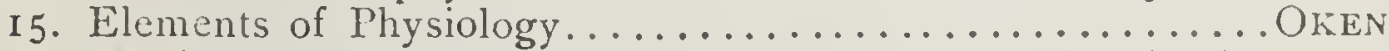

16. Man's Place in Nature................ . H. Huxi.EY

I7. Eclectic Mag. Oct. I873, pp. 425, 431.

18. Anatomy of Vertebrate Animals........... T. H. HuxLEY

r9. What Young People Should Know..........BURT. G. WiLder

20. Nature, Oct., 1875 .

21. North British Review, July, IS69, p. 276.

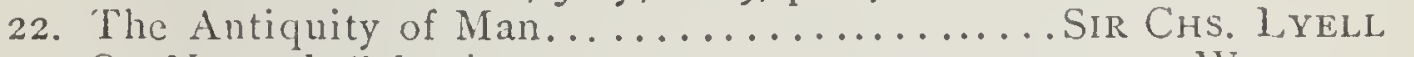

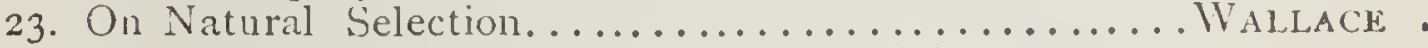

24. The History of the Conflict between Religion and Science....................JOHN W. DRAPER

25. Primitive Culture, 2 Vols................... Ty . . . . . .

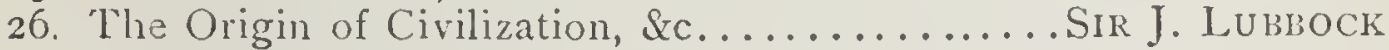

27. The Story of the Earth and Man............. J. W. DAwson

28. Text Book of Geology..................JAs. D. DANA

29. The Atlantic Magazine.

30. The American Naturalist, Feb'y, I873.

3r. Eclectic Mag. Nov. 1875, p. 559.

32. The Genesis of Species.......................... Nivar'T

33. The Varration of Animals and Plants under Domesti-

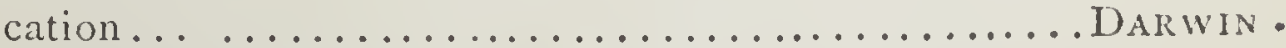

34. Buckland's Bridgewater Treatise, 2 Vols.

35. Atlantic Mag Aug. 1863, p. 217.

36. Natural History of Man.............. DE QuntrefaGes

37. Scribner's Monthly, May, i 87 I, p. $38 \ldots . . . . .$. B. G. WILDER

38. The Evolution of Man, 2 Vols...............ERnst HAECkE.

39. Preadamites........................ WINCHELL

40. The Human Species.................. De Quatrefages

4I. The Origin and Growth of Religion...........MAX MÜLLER 



\section{WORKS PUBLISHED BY}

\section{FOWLER \& WELIS, 753 BROADWAY, NEW YORK.}

\section{PERENOLOGY AND PHYSIOGNOMY.}

American Phrenological Journal and SCIENCE oF HEALTH.-Devoted to Ethnology, Pliysiology, Phrenology, Physiognumy, Psychology, Sociology, Biography, Education, Literature, etc., with Measures to Reform, Elevate, and Improve Mankind Physically, Mentally, and Spiritually. Monthly, \$2 a year; 20 cents a number.

Bell (Sir Charles).-Expression : its Anatomy and Philosopliy. With the original Notes and Illustrations by the author, and additional Notes and Illustrations by SAMUel R. Wells. \$1.25.

Boardman (Andrew, M.D.)-Defence OF PHRENOLOGY; Containing an Essay on the Nature and Value of Phrenological Evidence; A Vindication of Phrenology against the Attack of its opponents. \$1.25.

Bray (Charles).-The Education of THE FEELINGS AND AFFECTIONS. Edited, with Notes and Illustrations, by NELSON Sizer. Cloth, \$I.50.

This work gives full and definite directions for the cultivation or restraining of all the faculties relating to the feelings or affections.

Combe (George).-A System of PHRENOLOGY; With One Hundred Engravings. Cloth, \$I.5O.

Constitution of Man ; Corsidered in Relation to external objects. The only authorized American edition; with twenty engravings, and a portrait of the author. \$I.5O.

The "Constitution of Man" is a work with which every teacher and every pupil should be acquainted.

Lectures on Phrenology; with Notes, an Essay on the Phrenological Mode of Investigation, and an Historical Sketch, by A. BOARDMaN, M.D. \$I.50.

These are the lectures delivered by George Combe in America.

Moral Philosophy; or, the Duties of Man considered in his Individual, Doinestic, and Social Capacities. \$1.50.

Uniform Edition, 4 vols., extra cloth, \$5.00. Library Edition, 4 vols., \$Io.
On Education.-Papers on Educational Subjects. One vol. 8vo, Edinburgh Edition. Cloth, \$5.00.

This volume consists of valuable Essays written by Mr. Combe, and should be found in the library of every teacher.

The Life of. By Charles GibBON. 2 volumes, Svo, with two portraits. London Edition. \$5.00.

These two works are not published in this country, but we can furnish from our stock, or import to order.

Capen (Nahum, LL.D.)-ReminisCENCES OF DR. SPURZHEIM AND GEORGE COMBE, and a Review of the Science of Phrenology from the period of its discovery by Dr. GaLl to the time of the visit of GEORGE COMBE to the Urited States, with a new portrait of Dr. SPURZHEIM. I2mo, extra cloth, \$1.50.

Drayton (H.S., A.M.), and McNeil (JAMES, A.M.)-Brain and Mind; or, Mental Science Considered in Accordance with the Principles of Phrenology and in Relation to Modern Physiology. Ill. \$r.5o. This is the latest and best work published. It constitutes a complete text-book of Phrenology, is profusely illustrated, and well adapted to the use of students.

Drayton (H. S., A.M.)-The IndiCATIONS OF CHARACTER, as manifested in the general shape of the head and the form of the face. Illustrated. I5 cents.

- How to Study Phrenology.With Suggestions to Students, Lists of Best Works, Constitutions for Societies, etc. I2mo, paper, 10 cents.

Fowler (O. S.) - Education and SelfIMPROVEMENT COMPLETE; Comprising "Plıysiology, Animal and Miental," "SelfCulture and Perfection of Character," "Memory and Intellectual Improvement." One large vol. Illustrated. \$3.50.

Self-Culture and Perfection of Character ; Including the MIanagement of Children and Youth. \$1.25.

One of the best of the author's works.

- Physiology, Animal and Mental:

Applied to the Preservation and Restoration of Health of Body and Power of Mind. \$1.25.

Sent by Mail, post-paid. Fowlen \& Wells, Publishers, 753 Broadivay, New York. 


\section{WORKS ON PHRENOLOGY.}

Fowler (O. S.)-Memory and InTLLLECTUAL INPROVEMENT, applied to Self-Education and Juvenile Instruction. $\$$ r.25. The best work on the subject.

Maternity; or, the Bearing and Nursing of Cliildren, including Femaie Eaucation and Beauty. \$r.25.

Matrimony ; or, Phrenology and Plysiology applied to the Selection of Congenial Companions for Life, including Directions to the Married for living togrether Affectionately and Happily. 50c.

-Love and Parentage. Applied to the Improvement of Offsprmg ; including Directions to Lovers and the Married, concerning the strongest ties and the most sacred relations of life. 50 cents.

Hereditary Descent; Its Laws and Facts applied to Human Improvement. lllustrated. \$1.25.

Amativeness; or, Evils and Remedies of Exccssive and Perverted Sexuality; including IVarning and Advice to the Married and Single. 25 cents.

Phrenology Proved, Illustrated, AND AprLIED. Embracing an Analysis of the Primary Mental Powers in thcir Various Degrees of Development, and location of the Phrenological Organs. The Mental Phenomena produced by their combined action, and the location of the faculties amply illustrated. By the I owler Brothers. \$1.50.

\section{Self Instructor in Phrenology and Physiology. With over One Hundred Engravings and a Chart for Phrenologists, for the Recording of Phren- ological Devclopment. By the Fowler Brothers. Paper, $50 \mathrm{cts}$; cloth, 75 cts.}

Synopsis of Pr.renology, and Chirts for Describing the Phrenological Deielopments, for the use of Lecturers and Examiners. Paper, ro cents.

Fowler (L.N.)-Marriage, its HisTORY AND CEREMONIES, with a Phrenological and Physiological Exposition of the Functions and Qualinications for Happy Marriages. Illustrated, \$1.25.

Lectures on Man, as explained by Phrenology, Physiology, Physiognomy, and Ethnology. Cloth, \$I.5O.
Sizer (Nelson).-Choice of Pursuits: or, What to Do and Why. Describing Seventy-five Trades and Professions, and the Temperaments and Talents required or each. IVith Portraits and Biographies of many successful Thinkers and Workers. $\$ 1.75$.

How to Teach According to TEMPERAMENT AND MENTAL DEVEI OPMENT ; or, Phrenology in the School-room and the Family. lllustrated. \$r.50.

Forty Years in Phrenology; em bracing Recollections of History, Anecdoie and Experience. \$1.50.

Thoughts on Domestc Life; or, Marriage Vindicated and Free Love Exposed. 25 cents.

Spurzheim (J.G., M.D.)-Education; its Elementary PRinciples FoundED ON TIIE NATURE OF MAN. With an Appendix by S. R. IVELLS, containing a Description of the Temperaments and a Rrief Analysis of the Phrenological liaculties. Illustrated. \$1.50.

Natural Laws of Man.-A Philosophical Catechism. Sixth Edition. Enlarged and iniproved. 50 cents.

Weaver (Rev. G. S.)-Lectures on ME.NTAL SCIENCE. Accordins 'o the Philosophy of Phrenology. Delivered before the Anthropological Society. Illustrated. \$1.25.

Wells (Samuel R.)-New PhysiogNOMY ; or, Signs of Character, as manifested through Temperament and External lorms, and especially in the "Human l:ace Divine." Witls nore than One Thousand Illustrations. In one $12 \mathrm{mo}$ volume, $76 \mathrm{~S}$ pages, muslin, $\$ 5.00$; in heavy calf, narbled edges, $\$ 3.00$; Turkey morocco, full gilt, $\$$ IO.

"The treatine of Mr. Wells, which is adinirably printed and profusely illu-trated, is probably the inost complete haud-buok upen the sutject in the language." $-N$. Y. I'ribune.

Phrenological Bust.-Showing the latest classification and exact location of the Organs of the Brain. It is divided so as to show each individual Organs on one side; with all the groups-Social, Execu!tive, Intellectual, and Moral-pirperly classified, on the other side. There are two sizes; the largest, not mailable, price $\underset{\wp}{\mathbf{I}}$. The smaller, 50 cents.

Sent by Mail, post-paid. Fowzer \& Wells, Publishers, 753 Broadway, Nez Jork. 


\section{PHRENOLOGY AND PHYSIOGNOMY.}

UVells (S. R.)-How to Read Char- The Phrenological Miscellany; or, ACTER.-A New lllustrated Hand-book of Illustrated Annuals of Phrenology and Phrenology and Physiognomy, for Students and Examiners, with a Chart for recording the sizes of the different Organs of the Rrain in the Delineation of Chararter; with upwards of 170 Engravings. Paper, \$1.00; Cloth, \$1.25.

- Wedlock ; or, the Right Relations of the Sexes. Disclosing the Laws of Conjugal Selections, and showing Who Miay, and Who May Not Marry. A Scientific Treatise. \$1.50; fancy gilt, $\$ 2.00$.

New Descriptive Chart, for the Use of Examiners in the Dclineation of Character. 25 cents; cloth, 50 cents.

Harmony of Phrenology and the BIBLE, including the Definition of the Organs, their uses, excess, and deficiency, with Quotations from the Bible recognizing every faculty and passion, sanctioning their use and warning against abuse. Ioc.

Physiognomy, from 1865 to 1873 rombined in I volume, the nine containing over 400 illustrations, many portraits and biog. raphies of distinguished personages, together with articles on "How to Study Phrenology," "Resemblance to Parents," "Bashfulness," "Diffidence," "Stammering," etc., an elaborate article on "The Marriage of Cousins," "Jealousy, its Cause and Cure." 450 pages, \$I.5०.

Phrenology and the Scriptures.Showing the Harmony between Phrenology and the Bible. By Rev. J. PIERPONT. Paper, 15 cts.

The Annuals of Phrenology and Health Almavac for $1874, ' 75,76, ' 77$, '78, '79, 'So, '8I, and ' 82 in one vol. $\$ \mathbf{I}$. The current year, ro cents.

Symbolical Head and PhrenoLOGICAL M.AP. On fine tinted paper, IOC. Phrenology, its History and Important Principles. By T. TURNer. IOC.

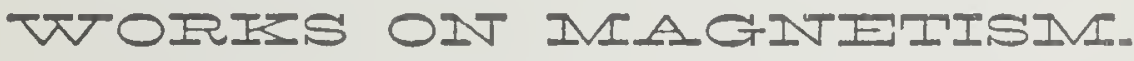

There is an increasing interest in the facts relating to Magnetism, etc., and we present below a list of Works on this subject.

Practical Instructions in Animal Magnetism. By J. P. F. Deleuze. Translated by Thomas C. Hartshorn. New and Revised edition, with an appendix of notes by the Translator, and Letters from Eminent Physicians, and othe:s. $\$ 2.00$.

History of Salem Witchcraft.-A review of Charles W. Upharn's great Work from the Edinburgh Review, with Notes; by Samufl R. IVells, containing, also, The Planchette Mystery, Spiritualism, by Mrs. HARRIFT BEECHER STOWE, and Dr. Doddridge's Dream. $§ I$.

Fascination; or, the Philosophy of Charaing. Illustrating the Principles of Life in connection with Spirit and Matter. By J. B. Newain, M.D. \$I.00.

Six Lectures on the Philosophy of M ESMERISM, delivered in Marlboro' Chapel, Boston. By Dr. John Bovee Dods. Paper, 50 cents.

The Philosophy of Electrical PsyCHOLOrY, in a course of Twelve Lectures. By the same author. I2mo, cloth, \$r.25.

The Library of Mesmerism and PsYchOLOGY. - Comprising the Philosophy of Mesmerism, Clairvoyance, Mental Electricity.-Fascination, or the Power of Charming. Illustrating the Principles of Life in connection with Spirit and Matter. - The Macrocosm, or the Universe Without : being an unfolding of the plan of Creation, and the Correspondence of Truths.-The Pliilosophy of Electrical Psychology ; the Doctrine of Impressions ; including the connection between Mind and Matter; also, the Treatmert of Diseases.-Psychology; or, the Science of the Soul, considered Physiologically and Philosophically; with an Appendix containing Notes of Mesmeric and Psyclical experience, and illustrations of the Brain and Nervous System. I vol. $\$ 3.50$.

How to Magnetize; or, Magnetism and Clairvoyance.- - A Practical T reatise on the Choice, Management and Sapabilities of Subjects, with Instruitions on the Method of Procedure. Ry JAines Victor Wilson. I8mo, paper, $25 \mathrm{cts}$. The Key to Ghostism. By Rev. Thomas Mitchel. \$I.jo.

Sent by Mail, pest-paid. Fowler \& Wells, Publishers, 753 Eroadzay, Nezu York. 


\section{HEALTH BOOKS.}

This List comprises the Best Works on Hygiene, Health, Etc.

Combe (Andrew, M.D.)-Principles applied to the Preservation of Health and to the Improvement of Physical and Mental Education. Illustrated. Cloth, \$1.50.

Management of Infancy, Physiological and Moral Treatment. With Notes and a Supplementary Chapter, \$1.25

-Physiology of Digestion.-Considered with relation to the Principles of Dietetics. Illustrated. 50 cents.

Fairchild (M. Augusta, M. D.)-How TO BE WELL; or, Common-Sense Medical Hygiene. A book for the People, giving Directions for the Treatment and Cure of Acute Diseases without the use of Drug Medicines; also, General Hints on Health. \$T.00.

Graham (Sylvester).-Science of HUMAN LIFE, LECTURES ON THE. With a copious Index and Biographical Sketch of the Author. Illustrated, \$3.00.

Chastity. - Lectures to Young Men. Intended also for the Serious Consideration of Parents and Guardians. I2mo. Paper, 50 cents.

Gully (J. M., M.D.) - Water-Cure in Chronic Diseases. An Exposition of the Causes, Progress, and Termination of various Chronic Diseases of the Digestive Organs, Lungs, Nerves, Limbs, and Skin, and of their Treatment by Water and other Hygienic means. \$1.50.

For Girls; A Special Physiology, or Supplement to the Study of General Physiology. By Mrs. E. R. Shepherd. \$I.00. Page (C. E., M.D.)-How to Feed the Baby to make her Healthy and Happy. I2mo. Third edition, revised and enlarged. Paper, 50 cents; extra cloth, 75 cents.

This is the most important work ever published on the subject of infant dietetics.

- - The Natural Cure of ConsumpTION, Constipation, Bright's Disease, Neuralgia, Rheumatism, "Colds" (Fevers), etc. How these Disorders Originate, and How to Prevent Them. I2mo, cloth, \$1.00.
Gully (J. M., M.D.) and Wilson (James, M. D.)-Practice OF THE WATER-CURE, with Authenticated Evidence of its Efficacy and Safety. Containing a Detailed Account of the various Processes used in the Water Treatment, a Sketch of the History and Progress of the Water-Cure. 50 cents.

Jacques (D. H., M.D.)-The TemPERAMENTS; or, Varieties. of Physical Constitution in Man, considered in their relation to Mental Character and Practical Affairs of Life. With an Introduction by H. S. liRAYTON, A.M., Editor of the Phrenological Fournal. I50. Portraits and other Illustrations. \$I.5O.

The only work on the Temperaments now before the public, and treats of this important subject in a most comprehensive mascer, showing its bearings on marriage, ed:eation and training of children, occupation, health and disease, heredity, etc., all illustrated with portraits from life. It tells how to cultivate or restrain temperamental tendencies, and is a work which should be in the hands of every student of human nature.

How to Grow Handsome, or Hints toward Physical Perfection, and the Philosophy of Human Beauty, showing How to Acquire and Retan Bodily Synmetry, Health, and Vigor, secure Long Life, and Avoid the Infirmities and Deformities of Age. New Edition. \$r.00.

Johnson (Edward, M.D.)-DomesTIC PRACTICE OF HYDROPATHY, with Fifteen Engraved Illustrations of important subjects, from Drawings by Dr. Howard Johnson. \$I.5O.

White (Wm., M.D.)-Medical ElecTRICITY.-A Manual for Students, showing the most Scientific and Rational Application to all forms of Diseases, of the different Combinations of Electricity, Galvanism, Electro-Magnetism, MaznetoElectricity, and Human Magnetism. x2mo, $\$ 2.00$.

Transmission; or, Variations of Character Through the Mother. By GEORGIANA B. KIRBY. 25 cis.i; cloth, 50 cts.

Sent by Mail, post-paid. Fowler \& Welds, Publishers, 753 Broadzay, New York. 


\section{WORKS ON HEALTH AND HYGIENE.}

\section{Peck (J. L. - The Human Feet.-} Their Shape, Dress, and Proper Care. Showing their Natural, Perfect Shape and Construction, their present Deformed Condition, and how Flat Feet, Distorted Toes, and other Defects are to be Prevented or Corrected, with directions for Dressing them Elegantly yet Comfortably, and Hints upon Various Matters relating to General Subjects. Illustrated. \$I.00.

Pendleton (Hester, Mrs.) - The Parents' Guide; or, Human Development through Pre-Natal Inluences and Inherited Tendencies. Revised Ed. \$1.25.

Pereira (Jonathan, M.D., F.R.S.)FOOD AND DIET. With observations on the Dietetical Regimen, suited for Disordered States of the Digestive Organs, and an account of the Dietaries of some of the I'rixcipal Metropolitan and other Establishments for Paupers, Lunatics, Criminals, Children, the Sick, etc. Edited by Charles A. Lee, M.D. \$I.40.

Shew (Joel, M.D.)-The Family Physician.-A Ready Prescriber and Hygienic Adviser. With Reference to the Nature, Causes, Prevention, and Treatment of Diseases, Accidents, and Casualties of every kind. With a Glossary and copious Index. Illustrated with nearly Three Hundred Engravings. \$3.00.

Letters to Women on Midwifery and Diseases of Women.-A Descriptive and Practical Work, giving Treatment in Menstruation and its Disorders, Chlorosis, Leucorrhea, Fluor Albus, Prolapsus Uteri, Hysteria, Spinal Diseases, and other weaknesses of Females, Pregnancy and its Diseases, Abortion, Uterine Hemorrhage, and the General Management of Childbirth, Nursing, ecc. \$1.50.

-Pregnancy and Childbirth, with Cases showing the remarkable Effects of Water Treatment in Mitigating the Pains and Perils of the Parturient State. $50 \mathrm{cts}$.

Tobacco: its Physical, Intellectual, and Moral Effects on the Human System. By Dr. Wm. Alcott. 15 cents.
Shew (Joel, M.D.)-Children, their Hydropathic Management in Health and Disease. A Descriptive and Practical Work, designed as a Guide for F'amilies and Pnysicians. \$r.5o.

Sober and Temperate Life.-The Discourses and Letters of LOU IS CORNARO on a Sober and Temperate Life. With a Biography of the Author by PIERo MARONCELLI, and Notes and Appendix by JOHN BURDELl. Paper, 50 cents.

The Story of a Stomach.-An Egotism by a Reformed Dyspeptic. 75 cents.

Philosophy of the Water-Cure: a Development of the True Principles of Health and Longevity. By John Balbirnie, M.D. Illustrated. With the Confessions and Observations of Sir Edward Lytton Bulwer. 50 cents.

Chronic Diseases.-Especially the Nervous Diseases of Women. 25 cents.

Teeth: their Structure, Disease, and Management, with Engravings. $25 \mathrm{cts}$.

Consumption, its Prevention and Cure by the Swedish-Movement Cure. With Directions for its Home Application. By David Wark, M.D. 30 cents.

Notes on Beauty, Vigor, and DevelOPMENT ; or, How to Acquire Plumpness of Form, Strength of Limb and Beauty of Complexion, with Rules for Diet and Bathing, and a Series of Improved Physical Exercises. By William Milo, of London. Illustrated. Io cents.

Facts About Iobacco. Compiled by Prof. E. P. 'THWing. 25 cents.

Tea and Coffee.-Their Phy: _al, Intellectual, and Moral Effects on the Human System. By Dr. Alcott. I5 cts.

Heredity.-RESPONSIBILITY AND PAR. ENTAGE. By Rev. S. H. Platt. Io cts.

Special List.-We have in addition to the above, Private Medical Works and Treatises. This Special List will be sent on receipt of stamp.

Sent by Mail, post-paid. Fowler \& Wells, Publishers, 753 Broadway, New York. 


\section{WORKS ON HYGIENE BY R. T. TRALL, M.D.}

Hydıopathic Encyclopedia.-A System of hiydropathy and Hygiene. Embracing Outlines of Anatomy, Illus'ed; Physiology of the Human Body; Hygienic Agencies, and the Preservation of Health1; Dietetics and Hydropathic Cookery ; Theory and Practice of Water-Treatment; Special Pathology and Hydro'Therapeutics, including the Nature, Causes, Symptoms, and Treatment of all known Diseases; Application of Hydropathy to Midwifery and the Nursery, with nearly One Thousand Pages, including a Glossary. Designed as a guide to Families and Students. With numerous Illus. 2 vols. in one. \$4.

Uterine Diseases \& Displacements. A Practical Treatise on the Various Diseases, Malpositions, and Structural Derangements of the Uterus and its Appendages. Fifty-three Colored Plates. \$5.

The Hygienic Hand-Book. - Intended as a Practical Guide for the SickRoom. Arranged alphabetically. \$r.5o.

\section{Illustrated Family Gymnasium -} Containing the most improved methods of applying Gymnastic, Calisthenic, Kinesipathic and Vocal Exercises to the Development of the Bodily Organs, the invigoration of their functions, the preservation of Health, and the Cure of Diseases and Deformities. With illustrations. \$I.50.

The Hydropathic Cook-Book, with Recipes for Cooking on Hygienic Principles. Containing also, a Philosophical Exposition of the Relations of Food to Health; the Chemical Elements and Proximate Constitution of Alimentary Principles; the Nutritive Properties of all kinds of Aliments; the Relative Value of Vegetable and A nimal Substances; the Selection and Preservation of Dietetic Material, etc. "is.?5.

Fruits and Farinacea the Proper Food of Mav.-Being an attempt to prove by History, Anatomy, Physiology, and Chemistry that the Original, Natural, and Best Diet of Man is derived from the Vegetable Kingdom. By JоHN Smith. With Notes by TRaLl. "\$I.5O.

Digestion and Dyspepsia.-A Complete Explanation of the Physiology of the Digestive Processes, with the Symotoms and Treatment of Dyspepsia and other Diso:ders. Illustrated. $\$$ I.OO.
The Mother's Hygienic Hand-Book for the Normal Development and Training of Women and Children, and the Treatment of their Diseases. \$I.oo.

Popular Physiology. - A Familiar Exposition of the Structures, Functions, and Relations of the Human System and the Preservation of Health. \$I.25.

The True Temperance Platform.An Exposition of the Fallacy of Alcoholic Medication, being the substince of addresses delivered in the Queen's Concert Kooms, London. Paper, 50 cents.

The Alcoholic Controversy.-A Review of the Westminster Review on the Physiological Errors of Teetotalism. 50 .

The Human Voice.-Its Anatomy, Physiology, Pathology, Therapcutics, and Training, with Rules of Order for Lyceums. 50 cents ; cloth, 75 cents.

The True Healing Art ; or, Hygienic vs. DRUg Miedication. An Address delivered before the Smithsonian Institute, Washington, D. C. Paper, 25 cents; cloth, 50 cents.

Water-Cure for the Million.-The processes of Water-Cure Explained, Popular Errors Exposed, Hygienic and Drug Medication Contrasted. Rules for Bathing, Dieting, Exercising, Recipes for Cooking, etc., etc. Directions for Home Treatment. Paper, 25 cts. ; cloth, 75 cts.

Hygeian Home Cook-Book; OR, HEALTHFUl aNd PaLATABlE FOOD WITHOUT CONDIMENTS. A Book of Recipes. Paper, 25 cts. ; cloth, 50 cts.

Accidents and Emergencies, a guide containing Directions for the Treatment in Bleeding, Cuts, Sprains, Rupiures, Dislocations, Burns and Scalds, Bites of Mad Dogs, Choking, Poisons, Fits, Sunstrokes, Drowning, etc. Ry Alfred Smee, with Notes and additions by R. T. Trall, M.D. New and revised edition. $25 \mathrm{cts}$.

Diseases of Throat and Lungs.Including Diphtheria and Proper Treatment. 25 cents.

The Bath.--Its History and Uses in Health and Disease. Paper 25c.; clo., 50c.

A Health Catechism.-Questions and Answers. With Illustrations. Ic cts.

Sent by Mail, post-paid. Fowler \& Wells, Publishers, 753 Broadway, ilezt York. 


\section{MISCELLANEOUS WORKS.}

\section{Hand-books for Home Improve- MENT (EDUCATIONAL); comprising, "How to IVrite," "How to Talk," "How to Behave," and "How to do Business." One 12mo vol., \$2.00.}

How to Write : a Pocket Manual of Composition and Letter-Writing. $75 \mathrm{cts}$.

How to Talk: a Pocket Manual of Conversation and Debate, with more than Five Ilundred Common Mistakes in Speaking Corrected. 75 cents.

How to Behave: a Pocket Manual of Republican Etiquette and Guide to Correct Personal Habits, with Rules for Debating Societies and Deliberative Assemblies. 75 cents.

How to Do Business: a Pocket Manual of Practical Affairs, and a Guide to Success in Life, with a Collection of Legal and Commercial Forms. $75 \mathrm{C}$.

How to Read.-What and Why; or, Hints in Choosing the Rest Bools, with Classified List of Best WVorks in Biography, Criticism, Fine Arts, History, Novels, Poetry, Scierce, Religion, loreign Languages, etc. By A. V. Petit. Clo., \$I.

How to Sing; or, the Voice and How to Use it. By W. H. Daniell. 50c; 75C.

How to Conduct a Public Meeting; or, The Chairman's Guide for Conducting Neetings, Public and Private. ${ }_{5} \mathrm{cts}$.

Hopes and Helps for the Young of BOTH SEXES. - Relating to the lormation of Character, Choice of Avocation, Health, Amusement, Music, Conversation, Social Affections, Courtship and Marriage. By WVeaver. \$1.25.

Aims and Aids for Girls and Young WonEN, on the various Duties of Life. Including Physical, lntellectual, and Moral Development, Dress, Beauty, Fashion, Employment, Education, the Home Relations, their Duties to Young Men, Marriage, Womanhood and Happiness. \$1.25.

Ways of Life, showing the Right Way and the IVrong IVay. Contrasting the High Way and the Low W'ay; the True IVay and the False IVay; the Upward WVay and the Downward Way; the Way of Honor and of Dishonor. $75 \mathrm{cts}$.

The Christian Household. - Embracing the Husband, Wife, Father, Mother, Child, Brother and Sister. \$I.00.
Weaver's Works for the Young, Comprising "Hopes and Helps for the Young of Both Sexes," "Aims and Aids for Girls and Young Women," "Ways of Life; or, the Rirht Way and the Wrong IVay." One vol. 12mo. \$2.50.

The Right Word in the Right Place. -A New Pocket Dictionary and Reference Book. Embracing extensive Collections of Synonyms, Technical Ternis, Abbreviations, Foreign Phrases, Chapters on Writing for the Press, Punctuation, ProofReading, and other Information. $75 \mathrm{cts}$.

How to Learn Short-Hand ; or, The Stenographic Instructor. An Improved System of Short-hand Writing arranged specially for the use of those desirous of acquiring the art without the aid of a teacher. By Arthur M. Baker. 25 cents.

Phonographic Note-Book. - For Students and Reporters. Double or Single ruled. I5 cents.

The Emphatic Diaglott, Containing the Original Greek Text of THE NEW TESTAMENT, with an Interlineary IVordfor-Word English Translation; a New Emplatic Version based on the Inierlineary Translation, on the Readings of the Vatican Manuscript (No. 1,200 in the Vatican Library): together with lllustrative and Explanatory loot Notes, and a copious Selection of References; to the whole of which is added a valuable Alpirabetical Index. By Benjamin IVilson. $8 S_{4} \mathrm{pp}$. $\$ 4.00$; extra fine binding $\$ 5.00$.

History of IVoman Suffrage.-Illustrated with Steel Engravings. Edited by Elizabeth Cady Stanton, Susan R. Anthony, Matilda Joslyn Gase. Complete in Three Octavo Volumes. Price per Volume, Cloth, \$5.00. Sheep, \$6.50.

Life at Home; or, The Family and its Members. Including Husbands and Wives, Parents, Cinildren, Brotlers, Sisters, Employers and Employed, The Aliar in the House, etc. By Rev. WVilliam Aikman, D.D. $12 \mathrm{mo}, \$ 1.50$; full gilt $\$ 2$.

A New Theory of the Origin of Species. By Benj. G. Ferris. क $\mathrm{T} \geqq$

Man in Genesis and in Geolory or, the Biblical Account of Man's Creation tested by Scientific Theories of :is Origin and Antiquity. By Josepli P. Thumpson, D.D., LL.D. \$1.00.

Sent by Mail, post-paid. Fowler \& IVELLS, Publishers, 753 Broadway, New York. 


\section{MISCELLANEOUS WORKS.}

The Conversion of St. Paul.-By Geo. Jarvis Geer, D.D. In three Parts. Ist. Its Relation to Unbelief. zd. Its False Uses and True. 3d. Its Relation to the Church. \$I.00.

The Temperance Reformation.-Its Histury from the first Temperance Society in the United States to the Adoption of the Maine Liquor Law. \$r.50.

Man and Woman, Considered in their Rclations to each other and to the World. By H. C. Pedder. Cloth, \$I.

Esop's Fables.--With Seventy Splendid Illustrations. One vol. I2mo, fancy cloth, gill edges, \$I. People's Edition, bound in boards, 25 cents.

Pope's Essay on Man, with Illustra tions and Notes by S. R. Wells. I2mo, tinted paper, fancy cloth, full gilt, price \$I. People's Edition, bound in boards, 25c.

Gems of Goldsmith: "The Traveler," "The Deserted Village," “The Hermit." With notes and Original Illustrations, and Biographical Sketch of the great author. One vol, fancy cloth, full gilt, \$r. People's Ed., bound in boards, $25 \mathrm{c}$.

The Rime of the Ancient Mariner. In Seven Parts. By Samuel T. Coleridge. With new Illustrations by Chapman. One vol., fancy cloth, full gilt, \$r. People's Ed., bound in boards, 25 cents.

Footprints of Life; or, Faith and $\mathrm{Na}$ TURE RECONCILED.-A Poem in Three Parts. The Rody; The Soul; The Deity. Philip Harvey, M.D. \$r.25.

How to Paint.-A Complete Compendium of the Art. Designed for the use of Tradesmen, Mechanics, Merchants and Farmers, and a Guide to the Protessional Painter, Containing a plain Commonsense statement of the Methods employed by Painters to produce satisfactory results in Plain and Fancy Painting of every Description, including Gilding, Gronzing, Staining, Graining, Marbling, Varnishing, Polishing, Kalsomining, Paper Harging, Striping, Lettering, Copying and Ornamenting, with l'ormulas for Mixing Paint in Oil or Water. Description of Various Pigments used: tools required, etc. By F, B. Gardner. \$r.oo.
The Carriage Painter's Illustrated Manual, containing a Treatise on the Art, Science, and Mystery of Coach, Carriage, and Car Painting. Including the Improvements in Fine Gilding, Bronzing, Staining, Varnishing, Polishing, Copying, Lettering, Scrolling, and Ornamenting. $\mathrm{B}_{j}$ F. B. Gardner. \$1.00.

How to Keep a Store, embodying the Experience of Thirty Years in Merchandizing. By Samuel H. Terry. \$I.50.

How to Raise Fruits. - A Hand-book. Being a Guide to the Cultivation and Mianagement of Fruit Trees, and of Grapes and Small Fruits. With Descriptions of the Best and Most Popular Varieties. Illustrated. By Thomas Gregs. \$I.

How to be Weather-Wise.-A new View of our Weather Systen. By I. P. Noyes. 25 cents.

How to Live.--Saving and Wasting; or, Domestic Economy lllustrated by the Life of two Families of Opposite Character, Habits, and Practices, full of Useful Lessons in Housekeeping, and Hints How to Live, How to Have, and How to be Happy, including the Story of "A Dime a Day," by Solon Robinson. \$I.25.

Oratory-Sacred and Secular, or the Extemporancous Speaker. Including a Chairnan's Guide for conducting Public Meetings according to the best Parliamentary forms. By Wm. Pittenger. \$I.25.

Homes for All ; or, the Gravel Wall. A Nerv, Cheap, and Superior Mode of Building, adapted to Rich and Poor. Showing the Superiority of the Gravel Concrete over Brick, Stone and Frame Houses; Manner of Making and Depositing it. By O. S. Fowler. \$1.25.

The Model Potato.-Proper cultivation and mode of cooking. 50 cents.

Traits of Representative Men. With portraits. By Geo. W. Bungay. \$1.50.

Capital Punishment; or, the Proper TREATMENT OF CRIMisals, ro cellts. "Father Matthew, the Temperance Apostle," Io cents. "Good Man's Leyacy," Io cents. Alphabet for Deaf and Dimb, Io cents.

Sent by Mail, post-paid. Fowler \& Wells, Puolishers, 753 Broadway, New York. 









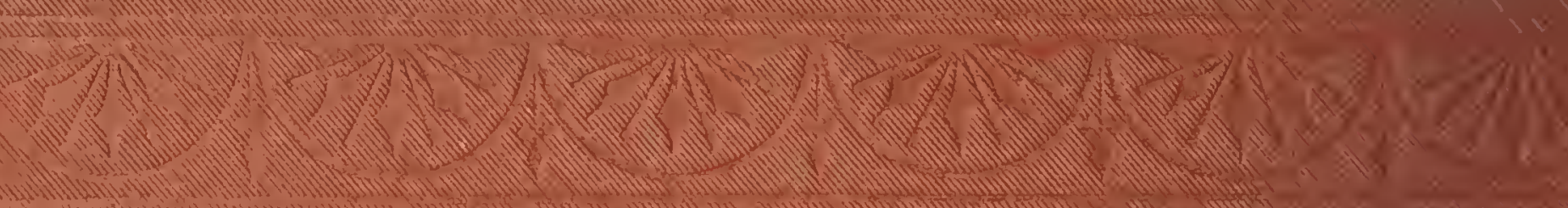
a 2 